\title{
Discovery and Heterologous Biosynthesis of the Burnettramic Acids: Rare PKS-NRPS-derived Bolaamphiphilic Pyrrolizidinediones from an Australian Fungus, Aspergillus burnettii
}

\author{
Hang Li, ${ }^{\dagger}$ Cameron L. M. Gilchrist, ${ }^{\dagger}$ Heather J. Lacey, ${ }^{\ddagger}$ Andrew Crombie, ${ }^{\ddagger}$ Daniel Vuong, ${ }^{\ddagger}$ John I. \\ Pitt, ${ }^{\#}$ Ernest Lacey, ${ }^{\ddagger}$ § Yit-Heng Chooi, ${ }^{*}, \dagger$ and Andrew M. Piggott ${ }^{*, \S}$ \\ †School of Molecular Sciences, The University of Western Australia, Perth, WA 6oog, Australia \\ ${ }^{\ddagger}$ Microbial Screening Technologies Pty. Ltd., Smithfield, NSW 2164, Australia. \\ \#Commonwealth Scientific and Industrial Research Organisation North Ryde, NSW 2113, Australia.

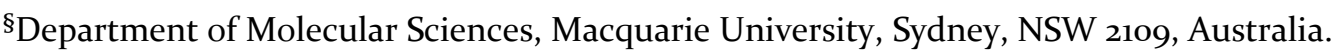

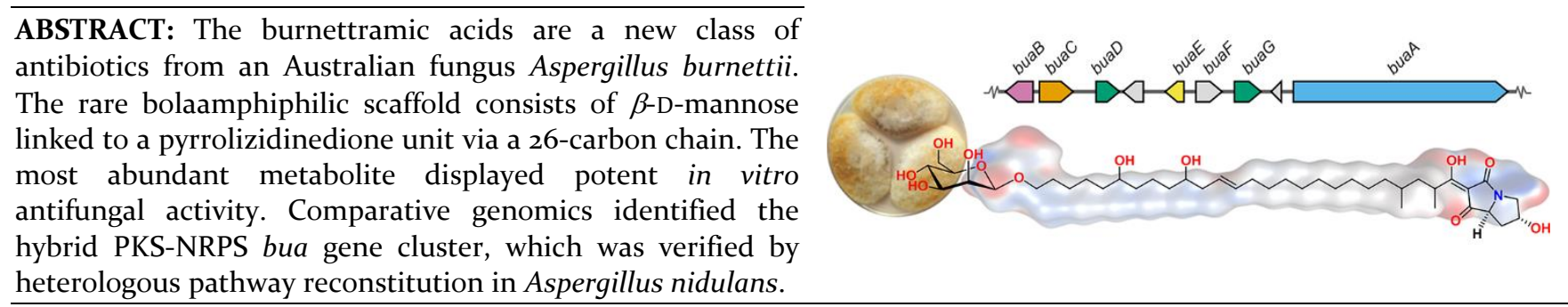

Fungi from the genus Aspergillus are prolific producers of bioactive metabolites, including clinical drugs such as cholesterol-lowering lovastatin ${ }^{1}$ and antifungal echinocandin, ${ }^{2,3}$ and pharmaceutical leads such as antiangiogenic fumagillin ${ }^{4}$ and anticancer phenylahistin. ${ }^{5}$ Genomic analyses of the biosynthetic gene clusters (BGCs) of aspergilli, ${ }^{6}$ including many surveyed recently, ${ }^{7}$ further demonstrate that Aspergillus species are particularly biosynthetically "talented". Therefore, the search for rare or novel Aspergillus species in a systematic manner is a fruitful strategy for discovering novel bioactive metabolites.

Continuing our chemotaxonomic exploration of Australian aspergilli, ${ }^{8-10}$ we identified a putative novel species from arable soil previously under peanut cultivation in the North Burnett region of southern Queensland, which we named Aspergillus burnettii FRR 5400. Preliminary phylogenetic analysis of $A$. burnettii suggests that it is within the section Flavi, which includes A. alliaceus, $A$. flavus, $A$. oryzae and the recently described $A$. hancockii (Figure $\mathrm{S}_{1}$ ).,11 The detailed morphological, genomic and chemotaxonomic characterization of $A$. burnettii will be reported elsewhere. Here, we report the discovery, biological investigation and heterologous biosynthesis of the burnettramic acids, an unusual class of bolaamphiphilic pyrrolizidinediones from $A$. burnettii.
To explore the accessible secondary metabolome of $A$. burnettii, the fungus was cultivated on a variety of solid and liquid growth media. Interestingly, the burnettramic acids were not readily detectable in crude extracts of any of these cultivations, but rather were isolated from an insoluble layer that formed at the ethyl acetate/aqueous partition interface following extraction of a large-scale culture of $A$. burnettii grown on pearl barley. Trituration of the insoluble material with methanol, followed by LCDAD-MS analysis of the soluble phase, revealed the presence of a pair of closely eluting peaks (major 1, minor 2), both with $m / z$ of $768[\mathrm{M}-\mathrm{H}]^{-}$. Similarly, LC-DAD-MS analysis of the ethyl acetate-soluble material revealed a less polar pair of closely eluting peaks (major 3, minor 4), both with $\mathrm{m} / \mathrm{z}$ of $606[\mathrm{M}-\mathrm{H}]^{-}$. All four compounds shared similar UV spectra. Using the UV spectrum of 1 [200 (87\%), $228(49 \%), 284(100 \%) \mathrm{nm}$ ], we searched against our in-house database $\left(\mathrm{COMET}^{12}\right)$ of $6,700 \mathrm{UV}$ spectra of microbial natural products, revealing a close match with epicoccamide, ${ }^{13}$ while equisetin, ${ }^{14}$ trichosetin $^{15}$ and epitrichosetin ${ }^{16}$ were the next three closest hits. This suggested the core chromophore of $\mathbf{1}$ was a tetramic acid, with the presence of additional isolated unsaturation to account for the enhanced absorption at $200 \mathrm{~nm}$. Compounds 1, 3 and 4 were present in sufficient quantities to be isolated by reversed-phase HPLC, while $\mathbf{2}$ was present in only trace amounts and was accessed semisynthetically, as described below. 


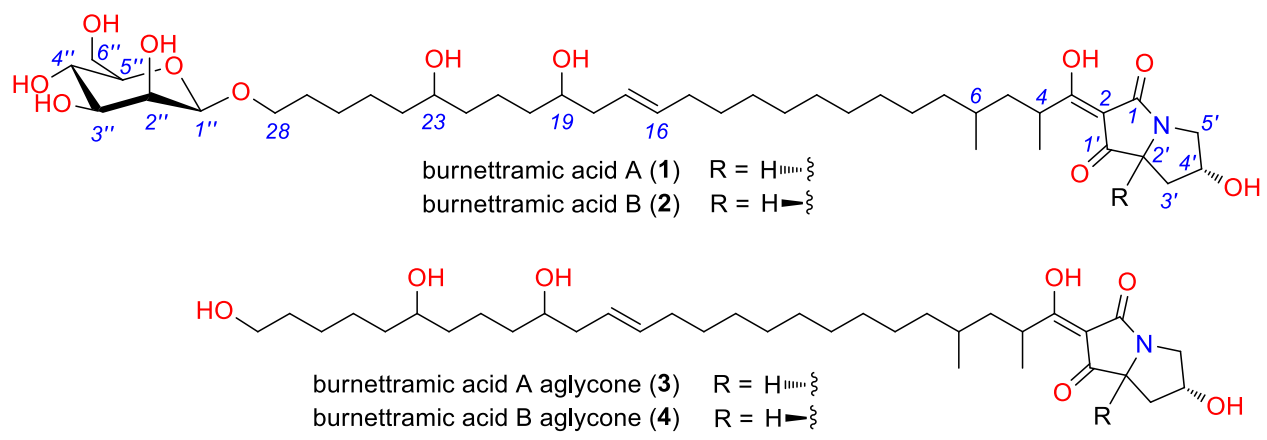

Figure 1. Structures of burnettramic acids 1-4.

HRESI(-)MS analysis of $\mathbf{1}$ revealed a deprotonated molecule at $\mathrm{m} / \mathrm{z} 768.4898$ corresponding to a molecular formula $\mathrm{C}_{41} \mathrm{H}_{71} \mathrm{NO}_{12}(\Delta \mathrm{mmu}-0.6)$. The ${ }^{1} \mathrm{H}$ and ${ }^{13} \mathrm{C} \mathrm{NMR}$ data for 1 in DMSO- $d_{6}$ (Table S6) revealed signals attributable to three distinct subunits; a monosaccharide, an extended alkyl chain and a tetramic acid moiety. Detailed analysis of the $1 \mathrm{D}$ and $2 \mathrm{D}$ NMR data for 1 (Figure S2) revealed the monosaccharide to be mannose, which was assigned a $\beta$-configuration based on the small vicinal coupling constant between $\mathrm{H}^{\prime \prime} \mathrm{1}^{\prime \prime}$ and $\mathrm{H}-2^{\prime \prime}(\mathrm{J}=0.7 \mathrm{~Hz})$. The sugar was isolated by acid-catalyzed hydrolysis of 1 and showed a positive specific rotation $\left([\alpha]_{D}=+16, \mathrm{H}_{2} \mathrm{O}\right)$, confirming the presence of $\beta$-D-mannose. Further analysis of the NMR data for 1 revealed the alkyl chain contained an isolated $E$-double bond $\left(\Delta^{16,17} ;{ }^{3} J_{16,17}=15.4 \mathrm{~Hz}\right)$, two secondary methyl groups (4-Me and 6-Me), two hydroxy groups $(19-\mathrm{OH}$ and $23-\mathrm{OH})$ and one oxymethylene group $\left(28-\mathrm{CH}_{2}\right)$. A diagnostic HMBC correlation from $\mathrm{H}_{2}-28$ to the anomeric carbon of the $\beta$-D-mannose moiety $\left(\mathrm{C}-\mathrm{1}^{\prime \prime}\right)$ confirmed the point of attachment of the sugar to be at the terminus of the alkyl chain. Significant broadening of the peaks for $\mathrm{C}-3$ and $\mathrm{C}_{-1}{ }^{\prime}$ of the tetramic acid moiety was observed in the ${ }^{13} \mathrm{C}$ NMR spectrum of $\mathbf{1}$, while peaks for $\mathrm{C}$ 1, C-2 and C-2' could not be detected. This was attributed to slow interconversion of tetramic acid tautomers on the NMR time scale. Increasing the temperature to $60^{\circ} \mathrm{C}$ did not significantly improve the line broadening or reveal the missing ${ }^{13} \mathrm{C}$ resonances. A key $\mathrm{HMBC}$ correlation from 4-Me to $C-3\left(\delta_{C} 190.8, \mathrm{br}\right)$ positioned the tetramic acid on the opposite terminus of the alkyl chain to the sugar. The remaining unassigned NMR resonances consisted of two methylene groups $\left(3^{\prime}-\mathrm{CH}_{2}\right.$ and $\left.5^{\prime}-\mathrm{CH}_{2}\right)$, two deshielded methines $\left(2^{\prime}-\mathrm{CH}\right.$ and $\left.4^{\prime}-\mathrm{CH}\right)$ and one hydroxy group ( $4^{\prime}-$ $\mathrm{OH})$. Detailed analysis of the NMR data confirmed these resonances belonged to a hydroxypyrrolidine residue, which was fused to the tetramic acid ring to form a pyrrolizidinedione. The relative configuration of the pyrrolizidinedione was assigned as trans based on ROESY correlations between $\mathrm{H}-2^{\prime}$ and $\mathrm{H}-3^{\prime} \mathrm{a}$ and between $\mathrm{H}-4{ }^{\prime}$ and $\mathrm{H}-\mathrm{z}^{\prime} \mathrm{b}$. Therefore, the structure of burnettramic acid A (1) was assigned as shown (Figure 1).

HRESI(-)MS analysis of 3 revealed a deprotonated molecule at $\mathrm{m} / \mathrm{z} 606.4370$ corresponding to a molecular formula $\mathrm{C}_{35} \mathrm{H}_{61} \mathrm{NO}_{7}(\Delta \mathrm{mmu}-0.5)$ that is $\mathrm{C}_{6} \mathrm{H}_{11} \mathrm{O}_{5}$ less than 1. The ${ }^{1} \mathrm{H}$ and ${ }^{13} \mathrm{C}$ NMR data for 3 (Table S8) were very similar to those for $\mathbf{1}$, with the only significant differences being the absence of all signals associated with the $\beta$-Dmannose residue and a small change in the ${ }^{1} \mathrm{H}$ and ${ }^{13} \mathrm{C}$ chemical shifts for $28-\mathrm{CH}_{2}$. This suggested that 3 is the aglycone of $\mathbf{1}$, which was confirmed by detailed analysis of the $2 \mathrm{D}$ NMR data. Similarly, HRESI(-)MS analysis of 4 revealed a deprotonated molecule at $\mathrm{m} / \mathrm{z}$ 606.4370 corresponding to a molecular formula $\mathrm{C}_{35} \mathrm{H}_{61} \mathrm{NO}_{7}(\Delta \mathrm{mmu}$ -0.5) that is isomeric with 3. The ${ }^{1} \mathrm{H}$ and ${ }^{13} \mathrm{C}$ NMR data for 4 (Table S9) were almost identical to those for 3, with only minor differences in the chemical shifts associated with the pyrrolidine residue. A diagnostic ROESY correlation between $\mathrm{H}-2^{\prime}$ and $\mathrm{H}-4^{\prime}$ confirmed that 4 is the cis-pyrrolizidine epimer of $\mathbf{3}$.

Table 1. In vitro bioassay results for burnettramic acids 1-4.

\begin{tabular}{|c|c|c|c|c|c|c|c|}
\hline \multirow{2}{*}{ Compound } & \multicolumn{7}{|c|}{$\mathrm{IC}_{5 \mathrm{o}}(\mu \mathrm{g} / \mathrm{mL})^{a}$} \\
\hline & $B s^{b}$ & $S a^{c}$ & $C a^{d}$ & $S c^{e}$ & $T f^{f}$ & $M m^{g}$ & $N f f^{h}$ \\
\hline $\mathbf{1}$ & $2.3 \pm 0.1$ & $5.9 \pm 5.4$ & $0.5 \pm 0.1$ & $0.2 \pm 0.2$ & $>50\left(56 \%^{j}\right)$ & $13.8 \pm 0.6$ & $>100\left(38 \%^{j}\right)$ \\
\hline 2 & $13.2 \pm 0.1$ & $i$ & $1.3 \pm 0.1$ & $1.8 \pm 0.3$ & $i$ & $>100\left(33 \%^{j}\right)$ & $>100\left(18 \%^{j}\right)$ \\
\hline 3 & $>100\left(17^{j}\right)$ & $>100\left(22 \%^{j}\right)$ & $>50\left(63 \%^{j}\right)$ & $i$ & $i$ & $15.2 \pm 1.3$ & $>100\left(34 \%^{j}\right)$ \\
\hline 4 & $>100\left(11 \%^{j}\right)$ & $i$ & $i$ & $i$ & $i$ & $8.5 \pm 0.5$ & $>100\left(26 \%{ }^{j}\right)$ \\
\hline Control & $0.2^{k}$ & $3.1^{k}$ & $0.1^{l}$ & $0.3^{l}$ & $1.2^{m}$ & $8.4^{n}$ & $>100^{n}\left(42^{\%} \%^{j}\right)$ \\
\hline
\end{tabular}

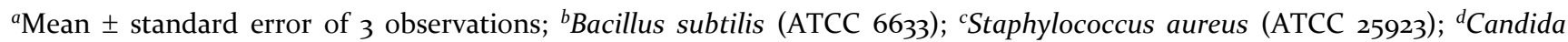

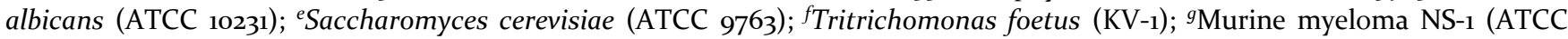
TIB-18); ${ }^{h}$ Neonatal foreskin fibroblast (NFF); ${ }^{i}$ No inhibition at $100 \mu \mathrm{g} / \mathrm{mL} ;{ }^{j}$ Incomplete dose response, $\%$ inhibition at $100 \mu \mathrm{g} / \mathrm{mL}$; kampicillin; lamphotericin B; ${ }^{m}$ metronidazole; ${ }^{n}$ mitomycin $\mathrm{C}$. 
A

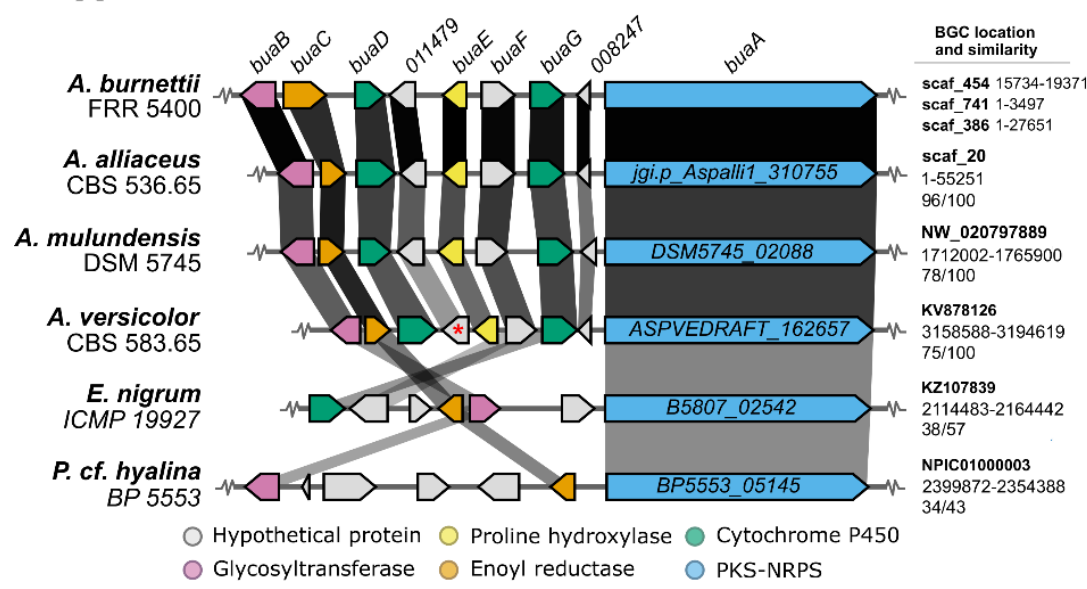

B

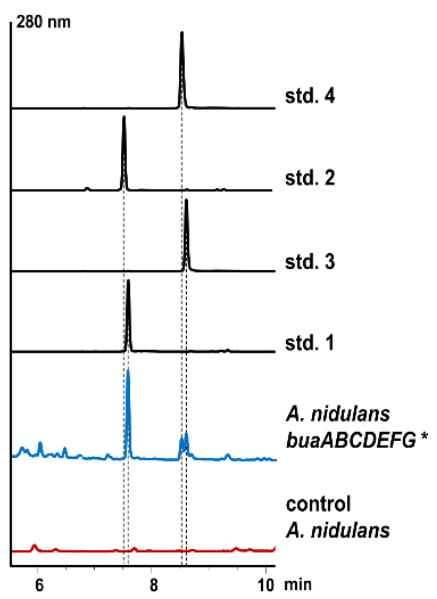

Figure 2. (A) Conservation of bua cluster with the contiguous homologous biosynthetic gene clusters identified in other fungi. Red $(*)$ indicates manually annotated gene; grayscale bars linking proteins indicate amino acid identity (o\% fully transparent, $100 \%$ black). Homologous gene clusters and protein identities are listed in Table S1o. (B) HPLC traces (280 nm) showing heterologous production of burnettramic acids in A. nidulans.

HRESI(-)MS analysis of the remaining metabolite 2 revealed a deprotonated molecule at $\mathrm{m} / \mathrm{z}$ 768.4898, corresponding to a molecular formula $\mathrm{C}_{41} \mathrm{H}_{71} \mathrm{NO}_{12}(\Delta \mathrm{mmu}$ -o.6) that is isomeric with 1. Unfortunately, the metabolite could not be isolated in sufficient quantities for structure elucidation. However, given the presence of the epimeric pair of burnettramic acid aglycones (3/4) in the extract, it was hypothesized that $\mathbf{2}$ could be the corresponding pyrrolidine epimer of $\mathbf{1}$. The epimerization of trans-4-hydroxy-L-proline to cis-4-hydroxy-D-proline has been shown previously to be catalyzed by aqueous acids.$^{17}$ Therefore, a sample of $\mathbf{1}$ (50 $\mathrm{mg}$ ) was treated with o.1 $\mathrm{M} \mathrm{HCl}$ in $15 \% \mathrm{H}_{2} \mathrm{O} / \mathrm{MeCN}$ at $60{ }^{\circ} \mathrm{C}$ for $2 \mathrm{~h}$ and the reaction mixture was analyzed by LCMS (Figure $\mathrm{S}_{3}$ ). This reaction resulted in a mixture of $\mathbf{1 - 4}$ in the ratio 3:1:4:1 respectively, thus yielding sufficient 2 for characterization. Detailed analysis of the $2 \mathrm{D}$ NMR data (Table $\mathrm{S}_{7}$ ), confirmed the structure of burnettramic acid B (2) as shown (Figure 1). The facile acid-catalyzed epimerization of $\mathbf{1}$ raises the prospect that minor epimers 2 and 4 may be artefacts of the isolation process. However, both minor epimers were observed in the initial crude extracts of the fungus, albeit in trace amounts, so it is likely that small amounts of these compounds will form naturally in acidic environments.

We next tested 1-4 for in vitro antibacterial, antifungal, antiparasitic and cytotoxic activities (Table 1). Burnettramic acid A (1) exhibited both antibacterial and antifungal activities, with especially potent activity against Candida albicans and Saccharomyces cerevisiae $\left(\mathrm{IC}_{50} 0.5\right.$ and $0.2 \mu \mathrm{g} / \mathrm{mL}$, respectively), comparable to amphotericin B. Compound $\mathbf{1}$ also showed modest cytotoxicity against murine myeloma (NS-1) cells $\left(\mathrm{IC}_{50}\right.$ $13.8 \mu \mathrm{g} / \mathrm{mL}$ ), but only minor activity against the nontumorigenic neonatal foreskin fibroblasts (NFF) at 100 $\mu \mathrm{g} / \mathrm{mL}$, indicative of a good therapeutic index. The epimer 2 exhibited reduced antimicrobial and cytotoxic activities, most noteworthy being the loss of activity against Staphylococcus aureus. Interestingly, aglycones 34 did not exhibit antimicrobial activities but retained activity against the mouse myeloma cell line, suggesting discrete modes of actions for the antibacterial, antifungal and cytotoxic activities.

The unique structures of 1-4, along with their interesting bioactivity profiles, prompted us to investigate the molecular genetic basis for their biosynthesis. The structural scaffold for 1-4 is relatively rare among fungal natural products. Burnettramic acids 1-2 are most closely related to the epicoccamides (Figure $\mathrm{S}_{7} \mathrm{~A}$ ), ${ }^{13,18}$ which consist of terminal tetramic acid and glycosidic moieties separated by a shorter 16-carbon alkyl chain. However, in 1-4, the tetramic acid moiety is fused with 4hydroxyproline to form a bicyclic pyrrolizidinedione, of which there are only two prior examples in fungi, $\mathrm{PF} 1018^{19}$ and talarotoxin ${ }^{20}$ (Figure S7A). Recently, Tang and coworkers reported the biosynthesis of UCS1025A, a decalin compound attached to a non-tetramate pyrrolizidinone at a lower oxidation state compared to pyrrolizidinedione. ${ }^{21}$ The pyrrolizidinone was shown to be derived from proline fused to a polyketide chain synthesized by a hybrid polyketide synthase nonribosomal peptide synthetase (PKS-NRPS) (Figure S7B). Thus, we hypothesized that $\mathbf{1}$ could be synthesized in a similar manner by a PKS-NRPS.

The genome of $A$. burnettii was sequenced by Illumina HiSeq 2500, and the biosynthetic gene clusters (BGCs) were predicted using antiSMASH 4.1.0.3. ${ }^{22}$ As 1 also contains a $\beta$-D-mannose residue and the proline moiety is hydroxylated, we reasoned that the biosynthesis of $\mathbf{1}$ would likely involve a PKS-NRPS, a glycosyltransferase and a proline hydroxylase. While we did not observe any BGC that encodes all of the above, we did identify a short scaffold (386) encoding the PKS-NRPS BuaA situated closely to the gene encoding BuaE, which shares $49 \%$ identity with the proline hydroxylase HtyE involved in echinocandin B biosynthesis in Emericella rugulosa NRRL 11440 (Table $\mathrm{S}_{3}$ ). ${ }^{3}$ Comparative genomics has been shown to be a powerful tool for identifying missing components of truncated gene clusters. ${ }^{23}$ Using such an approach, we 


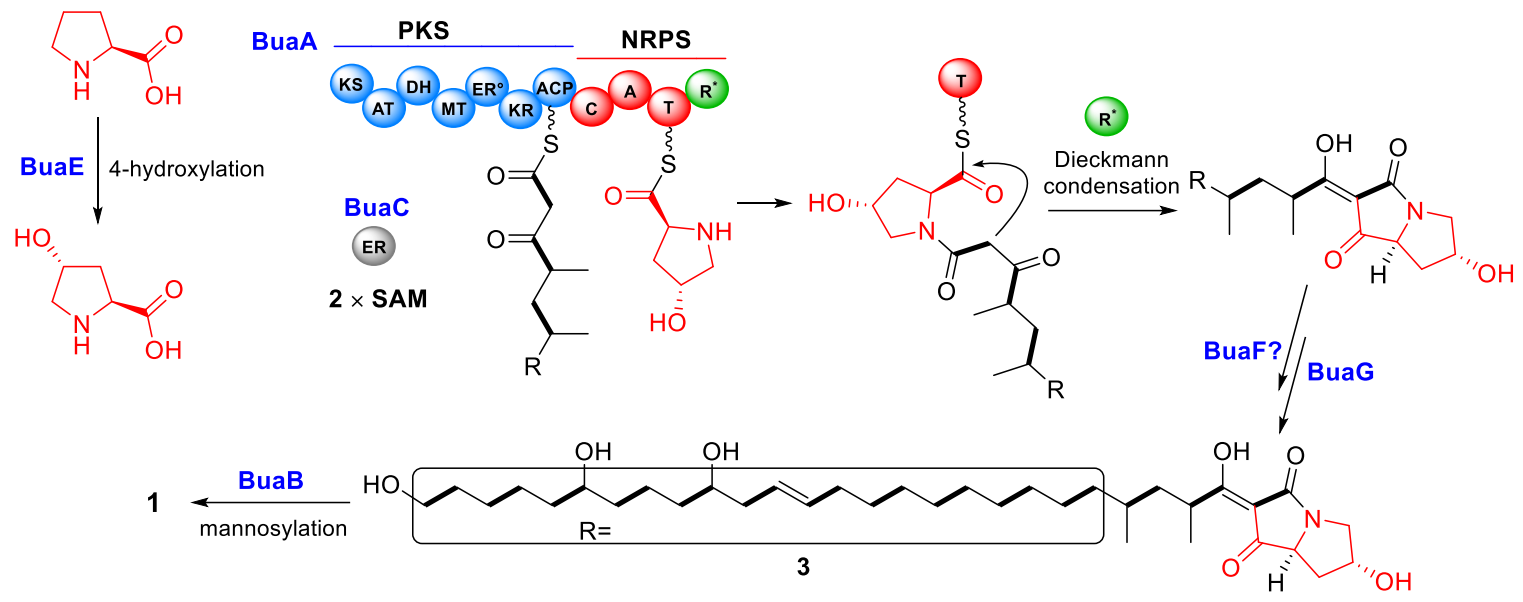

Figure 3. Proposed biosynthetic pathway for burnettramic acids 1 and 3. KS, ketosynthase; AT, malonyl-CoA transferase; DH, dehydratase; MT, methyltransferase; ER, enoyl reductase; KR, ketoreductase; ACP, acyl carrier protein; C, condensation; A, adenylation; T, thiolation; $\mathrm{R}^{*}$, Dieckmann condensation domain; SAM, S-adenosylmethionine.

identified a highly conserved PKS-NRPS in A. alliaceus CBS 536.65 (Aspalli1_310755), which shows 99.3\% identity to BuaA. Genes both up and downstream of BuaA are heavily conserved in both protein sequence and synteny (Figure 2A). The $A$. alliaceus BGC, however, encodes additional genes, such as a putative enoyl reductase (Aspalliı_319470) and a glycosyltransferase (Aspalli1_77391). A local tBLASTn search against the $A$. burnettii genome using these proteins revealed the remaining bua genes on two additional scaffolds (454 and 741) (Figure 2A), which were subsequently verified by PCR amplification and sequencing to be adjacent genomic loci (Figure $\mathrm{S}_{4}$ ). Given that we had access to an A. alliaceus strain (NRRL315), we also checked the metabolite profile of this fungus and indeed could detect the production of $\mathbf{1}$ (Figure S8).

To verify the involvement of the bua gene cluster in burnettramic acid biosynthesis, we applied a whole pathway reconstitution approach in a characterized host A. nidulans $\mathrm{LO}_{7890}{ }^{24}$ using a hybrid yeast-fungal artificial chromosome (pYFAC) expression system. ${ }^{25}$ The pYFAC system allows yeast transformation-mediated homologous recombination cloning and episomal expression in $A$. nidulans. ${ }^{26,27}$ We first introduced the PKS-NRPS backbone gene buaA into pYFAC-pyrG by yeast homologous recombination. Next, the enoyl reductase gene buaC alone, or buaC and the proline hydroxylase gene buaE together, were introduced into pYFAC-ribo. Expression of buaAC or buaACE in $A$. nidulans did not produce any new metabolites compared to the control (Figure S9). We then added the $\mathrm{P}_{450}$ gene into pYFAC-ribo. The remaining genes buaB, buaD and buaF, encoding a glycosyltransferase, a $\mathrm{P}_{450}$ and a hypothetical protein, respectively, were cloned into pYFAC-pyrO. The A. nidulans strain expressing buaABCDEFG accumulated three small peaks corresponding to 1,3 and 4 (Figures $2 \mathrm{~B}$ and $\mathrm{S} 9$ ). This confirmed the role of the bua cluster in burnettramic acid biosynthesis.

We next proposed a biosynthetic pathway for the burnettramic acids based on our pathway reconstitution results and the established PKS-NRPS biosynthetic paradigm (Figure 3). ${ }^{28}$ The absence of non-hydroxylated proline analogs of 1-4 in the culture extracts of $A$. burnettii suggests that BuaE first catalyzes the hydroxylation of proline to generate 4-hydroxyproline, similar to HtyE in the biosynthesis of echinocandin. ${ }^{3}$ The PKS-NRPS BuaA and trans-enoyl reductase BuaC construct the highly-reduced polyketide chain, and the condensation (C) domain of BuaA then catalyzes the amide bond formation with the activated 4hydroxyproline. This is followed by the $\mathrm{R}^{*}$ domain releasing the nascent polyketide-peptide directly via a Dieckmann condensation to afford a tetramic acid fused to the hydroxyproline, generating the bicyclic pyrrolidinedione moiety. Indeed, our analysis of the BuaA $C$-terminal domain confirmed that it corresponds to the previously characterized Dieckmann $\mathrm{R}^{*}$ domains, which contain a phenylalanine in place of tyrosine in the typical catalytic triad of the short chain dehydrogenase/reductase SDR superfamily (Figure S6). ${ }^{29,30}$ This differs from UCS1025A biosynthesis by UcsA, in which reductive release followed by a Knoevenagel condensation affords a non-tetramate pyrrolidinone (Figure $\mathrm{S}_{7} \mathrm{~B}$ ). ${ }^{21}$ The $\mathrm{P}_{45}$ os BuaD/G are likely responsible for the multiple hydroxylations on the polyketide chain and its terminus, although in the heterologous context, BuaD does not appear to be required (Figure S9). Therefore, while BuaG may be a multifunctional $\mathrm{P}_{450}$, we cannot rule out that the two secondary alcohols on the polyketide chain could have an acetate origin. Finally, the glycosyltransferase $\mathrm{BuaB}$ transfers $\beta$-D-mannose to the aglycone 3 to form 1 (Figure 3). Glycosylated natural products are quite rare in fungi compared to actinomycetes. An NCBI "Conserved Domain Search" showed that BuaB belongs to glycosyltransferase family 1 , which use activated nucleotide diphospho-sugar donors. Further studies, including in vitro characterization of individual tailoring enzymes in the bua cluster, will be required to understand their specific functions.

BuaA is quite an unusual PKS-NRPS as the polyketide chain present in 1-4 $\left(\mathrm{C}_{28}\right.$, a tetradecaketide) is one of the 
longest observed from an iterative Type I PKS. For instance, although the polyketide chains comprising the T-toxins from Cochliobolus heterostrophus are up to $\mathrm{C}_{41}$ long, these have been shown to involve two PKSs in their biosynthesis. ${ }^{31}$ Additionally, BuaA is only the second PKSNRPS that has been shown to activate the amino acid proline (the other being UcsA in UCS1025A biosynthesis). ${ }^{21}$ The 10 signature residues for the adenylation domains of the two reported prolineincorporating PKS-NRPSs ${ }^{32,33}$ showed that position 172 is conserved and that both positions 270 and 278 are aliphatic amino acids (Table $\mathrm{S}_{5}$ ). However, their significance for proline selectivity can only be confirmed with additional proline-incorporating PKS-NRPS sequences becoming available in the future.

The bolaamphiphilicity of $\mathbf{1}$ and $\mathbf{2}$, and the amphiphilicity of $\mathbf{3}$ and $\mathbf{4}$, likely contribute to their bioactivities. Repurposing aminoglycoside antibiotics like kanamycin and tobramycin as amphiphilic antifungal compounds by attaching lipophilic alkyl chains is an active area of research. ${ }^{34-36}$ Intriguingly, our bioassays showed that the glycoside moiety of $\mathbf{1}$ and $\mathbf{2}$ is essential for the antifungal activity, but not for the mammalian cell cytotoxicity. It is possible that $\mathbf{1 - 4}$, like the semisynthetic amphiphilic aminoglycosides, have similar membranetargeting properties. To test if we could use our newfound knowledge of burnettramic acid biosynthesis to mine for BGCs encoding new bolaamphiphilic polyketidepeptides, we searched the NCBI database for species encoding homologs of both the PKS-NRPS BuaA and the glycosyltransferase BuaB. This led to the discovery of four additional homologous BGCs in A. mulundensis, $A$. versicolor, Epicoccum nigrum and Phialophora cf. hyaline (Figure 2A). The core genes that are conserved across all species are buaABC, with the buaG-encoding $\mathrm{P}_{450}$ monooxygenase conserved in $E$. nigrum and all the Aspergillus spp. It is possible that the E. nigrum BGC encodes the epicoccamides isolated from E. purpurascens of the same genus. ${ }^{13}$ The results demonstrate the potential utility of the bua genes as beacons to guide genome mining for novel bolaamphiphilic compounds. It is anticipated that more of these BGCs will be discovered in the future with the steadily increasing availability of fungal genomes. Further investigation into the structureactivity relationships and modes of action of this intriguing class of metabolites could lead to the development of much-needed new antifungal drugs.

\section{ASSOCIATED CONTENT}

\section{Supporting Information}

The Supporting Information is available free of charge on the ACS Publications website.

Experimental details, spectroscopic data, supplementary figures and tables.

\section{AUTHOR INFORMATION}

\section{Corresponding Authors}

* Email: yitheng.chooi@uwa.edu.au

*Email: andrew.piggott@mq.edu.au

\section{Notes}

The authors declare no competing financial interests.

\section{ACKNOWLEDGMENT}

We thank Dr M. McKay (Macquarie University) for the acquisition of HRMS data. HL and CLMG are supported by an Australian Government International Postgraduate Research Scholarship and a Research Training Program PhD Scholarship, respectively. This research was funded, in part, by the Australian Research Council (FT160100233, FT130100142) and by the Cooperative Research Centres Program (CRCPFIVEoool19).

\section{REFERENCES}

(1) Alberts, A. W.; Chen, J.; Kuron, G.; Hunt, V.; Huff, J.; Hoffman, C.; Rothrock, J.; Lopez, M.; Joshua, H.; Harris, E.; Patchett, A.; Monaghan, R.; Currie, S.; Stapley, E.; AlbersSchonberg, G.; Hensens, O.; Hirshfield, J.; Hoogsteen, K.; Liesch, J.; Springer, J. Proc. Natl. Acad. Sci. U. S. A. 1980, 77, 3957.

(2) Benz, F.; Knüsel, F.; Nüesch, J.; Treichler, H.; Voser, W.; Nyfeler, R.; Keller-Schierlein, W. Helv. Chim. Acta 1974, 57, 2459.

(3) Cacho, R. A.; Jiang, W.; Chooi, Y.-H.; Walsh, C. T.; Tang, Y. J. Am. Chem. Soc. 2012, 134, 16781.

(4) Lin, H.-C.; Chooi, Y.-H.; Dhingra, S.; Xu, W.; Calvo, A. M.; Tang, Y. J. Am. Chem. Soc. 2o13, 135, 4616.

(5) Yamazaki, Y.; Tanaka, K.; Nicholson, B.; Deyanat-Yazdi, G.; Potts, B.; Yoshida, T.; Oda, A.; Kitagawa, T.; Orikasa, S.; Kiso, Y.; Yasui, H.; Akamatsu, M.; Chinen, T.; Usui, T.; Shinozaki, Y.; Yakushiji, F.; Miller, B. R.; Neuteboom, S.; Palladino, M.; Kanoh, K.; Lloyd, G. K.; Hayashi, Y. J. Med. Chem. 2012, 55, 1056.

(6) Sanchez, J. F.; Somoza, A. D.; Keller, N. P.; Wang, C. C. C. Nat. Prod. Rep. 2012, 29, 351.

(7) Kjærbølling, I.; Vesth, T. C.; Frisvad, J. C.; Nybo, J. L.; Theobald, S.; Kuo, A.; Bowyer, P.; Matsuda, Y.; Mondo, S.; Lyhne, E. K.; Kogle, M. E.; Clum, A.; Lipzen, A.; Salamov, A.; Ngan, C. Y.; Daum, C.; Chiniquy, J.; Barry, K.; LaButti, K.; Haridas, S.; Simmons, B. A.; Magnuson, J. K.; Mortensen, U. H.; Larsen, T. O.; Grigoriev, I. V.; Baker, S. E.; Andersen, M. R. P Proc. Natl. Acad. Sci. U. S. A. 2018, 115, E753.

(8) Pitt, J. I.; Lange, L.; Lacey, A. E.; Vuong, D.; Midgley, D. J.; Greenfield, P.; Bradbury, M. I.; Lacey, E.; Busk, P. K.; Pilgaard, B.; Chooi, Y.-H.; Piggott, A. M. PLoS One 2017, 12, eo170254.

(9) Lacey, H. J.; Vuong, D.; Pitt, J. I.; Lacey, E.; Piggott, A. M. Aust. J. Chem. 2016, 69, 152.

(10) Chaudhary, N. K.; Pitt, J. I.; Lacey, E.; Crombie, A.; Vuong, D.; Piggott, A. M.; Karuso, P. J. Nat. Prod. 2018, 81, 1517.

(11) Frisvad, J. C.; Hubka, V.; Ezekiel, C. N.; Hong, S. B.; Nováková, A.; Chen, A. J.; Arzanlou, M.; Larsen, T. O.; Sklenáŕ, F.; Mahakarnchanakul, W.; Samson, R. A.; Houbraken, J. Stud. Mycol. 2019, 93, 1.

(12) Lacey, E.; Tennant, S. Microbiol. Aust. 2003, 24, 34.

(13) Wright, A. D.; Osterhage, C.; König, G. M. Org. Biomol. Chem. 2003, 1, 507.

(14) Singh, S. B.; Zink, D. L.; Goetz, M. A.; Dombrowski, A. W.; Polishook, J. D.; Hazuda, D. J. Tetrahedron Lett. 1998, 39, 2243.

(15) Marfori, E. C.; Kajiyama, S.; Fukusaki, E.; Kobayashi, A. Z. Naturforsch. C Bio. Sci. 2002, 57, 465.

(16) Inokoshi, J.; Shigeta, N.; Fukuda, T.; Uchida, R.; Nonaka, K.; Masuma, R.; Tomoda, H. J. Antibiot. 2013, 66, 549.

(17) Dziewiatkowski, D. D.; Hascall, V. C.; Riolo, R. L. Anal. Biochem. 1972, 49, 550.

(18) Wangun, H. V. K.; Dahse, H.-M.; Hertweck, C. J. Nat. Prod. 2007, 70, 1800 . 
(19) Gomi, S.; Imamura, K.; Yaguchi, T.; Kodama, Y.; Minowa, N.; Koyama, M. J. Antibiot. 1994, 47, 571.

(20) Ishii, K.; Itoh, T.; Kobayashi, K.; Horie, Y.; Ueno, Y. Appl. Environ. Microbiol. 1995, 61, 941.

(21) Li, L.; Tang, M.-C.; Tang, S.; Gao, S.; Soliman, S.; Hang, L.; Xu, W.; Ye, T.; Watanabe, K.; Tang, Y. J. Am. Chem. Soc. 2018, $140,2067$.

(22) Weber, T.; Blin, K.; Duddela, S.; Krug, D.; Kim, H. U.; Bruccoleri, R.; Lee, S. Y.; Fischbach, M. A.; Müller, R.; Wohlleben, W.; Breitling, R.; Takano, E.; Medema, M. H. Nucleic Acids Res. 2015, 43, W237.

(23) Cacho, R. A.; Tang, Y.; Chooi, Y.-H. Front. Microbiol. 2015, $5,640$.

(24) Chiang, Y.-M.; Ahuja, M.; Oakley, C. E.; Entwistle, R.; Asokan, A.; Zutz, C.; Wang, C. C. C.; Oakley, B. R. Angew. Chem. Int. Ed. 2016, 55, 1662.

(25) Tsunematsu, Y.; Ishikawa, N.; Wakana, D.; Goda, Y.; Noguchi, H.; Moriya, H.; Hotta, K.; Watanabe, K. Nat. Chem. Biol. 2013, 9, 818.

(26) Li, H.; Hu, J.; Wei, H.; Solomon, P. S.; Vuong, D.; Lacey, E.; Stubbs, K. A.; Piggott, A. M.; Chooi, Y.-H. Org. Lett. 2018, 20 , 6148.

(27) Hu, J.; Sarrami, F.; Li, H.; Zhang, G.; Stubbs, K.; Lacey, E.; Stewart, S.; Karton, A.; Piggott, A. M.; Chooi, Y.-H. Chem. Sci. 2019, DOI: 10.1039/C8SC0287oB.

(28) Boettger, D.; Hertweck, C. ChemBioChem 2013, 14, 28.

(29) Ladenstein, R.; Winberg, J.-O.; Benach, J. Cell. Mol. Life Sci. 2008, 65, 3918.

(30) Liu, X.; Walsh, C. T. Biochemistry 20o9, 48, 8746.

(31) Baker, S. E.; Kroken, S.; Inderbitzin, P.; Asvarak, T.; Li, B.Y.; Shi, L.; Yoder, O. C.; Turgeon, B. G. Mol. Plant. Microbe Interact. 2006, 19, 139.

(32) Stachelhaus, T.; Mootz, H. D.; Marahiel, M. A. Chem. Biol. 1999, 6, 493.

(33) Boettger, D.; Bergmann, H.; Kuehn, B.; Shelest, E.; Hertweck, C. ChemBioChem 2012, 13, 2363.

(34) Chang, C. W. T.; Takemoto, J. Y. MedChemComm 2014, 5, 1048.

(35) Fosso, M.; AlFindee, M. N.; Zhang, Q.; Nziko, V. d. P. N.; Kawasaki, Y.; Shrestha, S. K.; Bearss, J.; Gregory, R.; Takemoto, J. Y.; Chang, C.-W. T. J. Org. Chem. 2015, 8o, 4398.

(36) Fosso, M. Y.; Zhu, H.; Green, K. D.; Garneau-Tsodikova, S.; Fredrick, K. ChemBioChem 2015, 16, 1565 


\section{SUPPORTING INFORMATION}

Discovery and heterologous biosynthesis of the burnettramic acids: Rare PKS-NRPS-derived bolaamphiphilic pyrrolizidinediones from an Australian Fungus, Aspergillus burnettii

Hang Li, ${ }^{a}$ Cameron L. M. Gilchrist, ${ }^{a}$ Heather J. Lacey, ${ }^{\mathrm{b}}$ Andrew Crombie, ${ }^{\mathrm{b}}$ Daniel Vuong, ${ }^{\mathrm{b}}$ John I. Pitt, ${ }^{c}$ Ernest Lacey, ${ }^{\text {bd }}$ Yit-Heng Chooi ${ }^{a, *}$ and Andrew M. Piggott ${ }^{d, *}$

${ }^{a}$ School of Molecular Sciences, University of Western Australia, Perth, WA 6009, Australia

${ }^{b}$ Microbial Screening Technologies, Smithfield, Sydney, NSW 2164, Australia.

${ }^{c}$ Commonwealth Scientific and Industrial Research Organisation, NSW 2113, Australia

${ }^{d}$ Department of Molecular Sciences, Macquarie University, Sydney, NSW 2109, Australia.

* Corresponding authors:

Andrew Piggott: Ph: +61-2-9850-8251; Email: andrew.piggott@mq.edu.au

Yit-Heng Chooi: Ph: +61-8-6488-3041; Email: yitheng.chooi@uwa.edu.au 


\section{Table of Contents}

SUPPLEMENTARY PROCEDURES

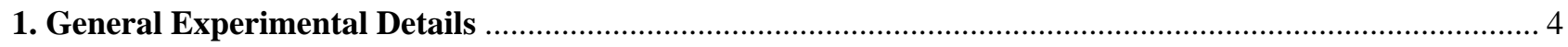

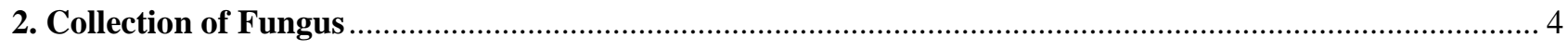

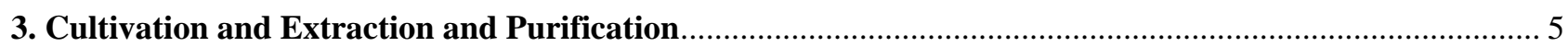

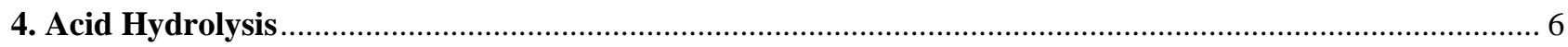

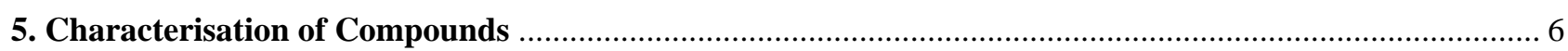

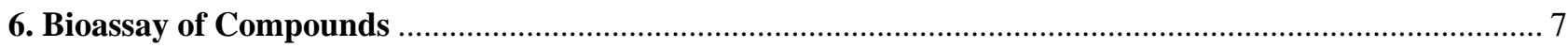

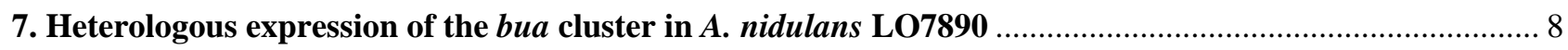

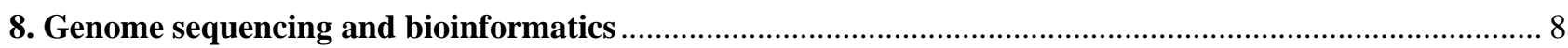

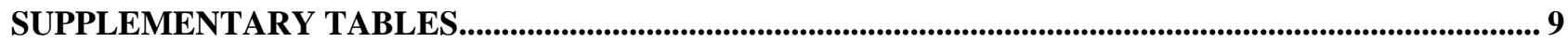

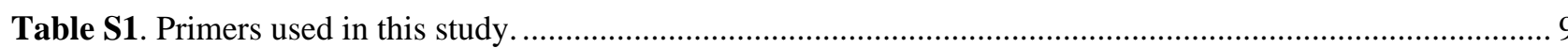

Table S2. Genes within the bua BGC and conservation with A. alliaceus CBS 536.65. Identity and similarity values are taken from pairwise amino acid alignments constructed with MUSCLE v3.8.31 ............................ 10

Table S3. Identity (\%) matrix of the MUSCLE pairwise protein alignment of proline hydroxylases.................... 11

Table S4. Similarity (\%) matrix of pairwise protein alignment of proline hydroxylases. Generated by MUSCLE v

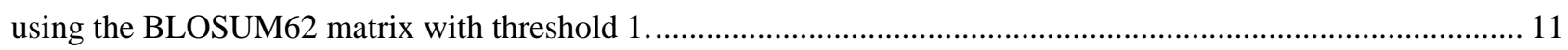

Table S5. Signature residues for amino acid selection by adenylation (A) domains .......................................... 12

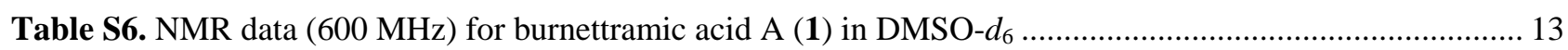

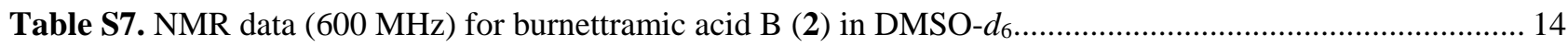

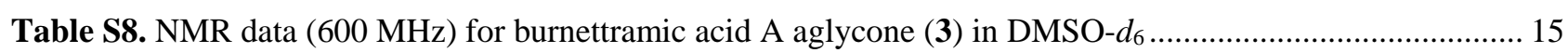

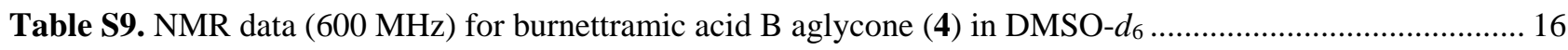

Table S10. Orthologous gene clusters identified in other fungal species. (NCBI accession number. of bua cluster

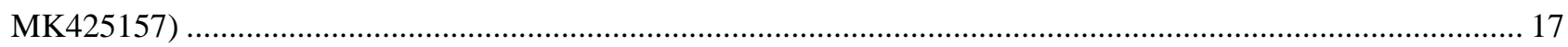

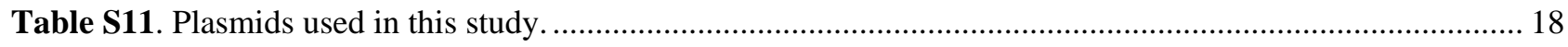

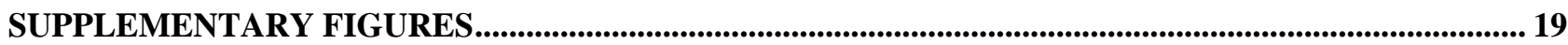

Figure S1. Phylogenetic analyses of Internal Transcribed Spacer (ITS) regions of Aspergillus species in sections Flavi and Nidulantes constructed using a) RAxML-NG v0.6.0 and b) MrBayes v3.2.6. A. burnettii clades with section Flavi, with its closest neighbour being A. alliaceus. (A. burnettii ITS sequence NCBI accession number. MK429758 )

Figure S2. 2D NMR correlations for (A) burnettramic acid A (1) and (B) burnettramic acid B (2) 20

Figure S3. HPLC trace $(280 \mathrm{~nm})$ of reaction mixture following treatment of burnettramic acid A (1) with $0.1 \mathrm{M}$ $\mathrm{HCl}$ for $2 \mathrm{~h}$ at $60{ }^{\circ} \mathrm{C}$. The new peak at 7.17 min corresponds to burnettramic acid B (2).....

Figure S4. Primer positions used to verify the connection between scaffolds N386/N454 and N454/N741, respectively and PCR products of 896 bp linking scaffolds N454/N741 and of 789 bp linking scaffolds N741/N386

Figure S5. Multiple sequence alignment of proline hydroxylases constructed using MUSCLE. BuaE from the bua cluster in the present study; AniF from the echinocandin B BGC in A. nidulans NRRL 8112; HtyE in the echinocandin B BGC in Emericella rugulosa NRRL 11440; and GloF from the pneumocandin BGC in Glarea lozoyensis ATCC 74030. 
Figure S6. Sequence alignment of the R domain from fungal PKS-NRPSs utilizing both the DKC mode of release (TenS, CpaS, and ApdA) and a predicted reductive release (ACE1, Fus1, CcsA, CheS, UcsA and MycA)......... 23

Figure S7. (A) The structures of epicoccamides (top) and pyrrolizidinone alkaloids from fungi (pyrrolizidinone core highlighted in red) (B) the proposed PKS-NRPS-derived biosynthetic pathway of UCS-1025A.

Figure S8. Comparison of the extracted ion chromatogram (EIC) of the metabolite profiles of Aspergillus alliaceus and Aspergillus burnetti indicating the presence of burnettramic acid A (1). The production of $\mathbf{1}$ in $A$. alliaceus is much lower than A. burnetti on Czapek-Dox agar extracted after 14 days of growth. 26

Figure S9. Chromatograms of A. nidulans expressing bua genes compared to standards. A) HPLC traces at 280

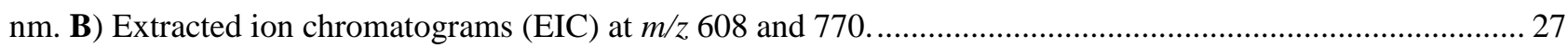

Figure S10. Flow chart of the isolation of burnettramic acids from A. burnettii ................................................... 28

Figure S11. ${ }^{1} \mathrm{H}$ NMR spectrum $\left(600 \mathrm{MHz}\right.$, DMSO- $\left.d_{6}\right)$ of burnettramic acid A (1) ............................................ 29

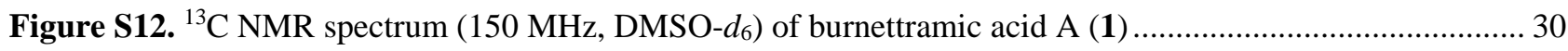

Figure S13. ${ }^{1} \mathrm{H}^{13} \mathrm{C}$ HSQC NMR spectrum $\left(600 \mathrm{MHz}\right.$, DMSO- $\left.d_{6}\right)$ of burnettramic acid A (1) ............................. 31

Figure S14. ${ }^{1} \mathrm{H}^{13}{ }^{13} \mathrm{C}$ HMBC NMR spectrum $\left(600 \mathrm{MHz}\right.$, DMSO- $\left.d_{6}\right)$ of burnettramic acid A (1)......................... 32

Figure S15. ${ }^{1} \mathrm{H}-{ }^{1} \mathrm{H}$ COSY NMR spectrum $\left(600 \mathrm{MHz}\right.$, DMSO- $\left.d_{6}\right)$ of burnettramic acid A (1) ........................... 33

Figure S16. ${ }^{1} \mathrm{H}-{ }^{1} \mathrm{H}$ ROESY NMR spectrum $\left(600 \mathrm{MHz}, \mathrm{DMSO}-d_{6}\right)$ of burnettramic acid A (1)......................... 34

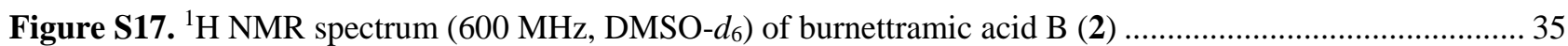

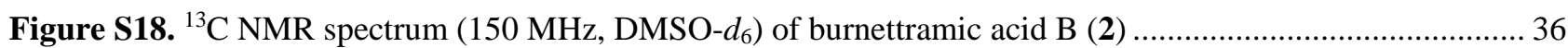

Figure S19. ${ }^{1} \mathrm{H}-{ }^{13} \mathrm{C}$ HSQC NMR spectrum (600 MHz, DMSO- $d_{6}$ ) of burnettramic acid B (2) ........................... 37

Figure S20. ${ }^{1} \mathrm{H}^{1}{ }^{13} \mathrm{C}$ HMBC NMR spectrum (600 MHz, DMSO- $d_{6}$ ) of burnettramic acid B (2) ........................... 38

Figure S21. ${ }^{1} \mathrm{H}-{ }^{1} \mathrm{H}$ COSY NMR spectrum $\left(600 \mathrm{MHz}\right.$, DMSO- $\left.d_{6}\right)$ of burnettramic acid B (2) ............................. 39

Figure S22. ${ }^{1} \mathrm{H}-{ }^{1} \mathrm{H}$ ROESY NMR spectrum (600 MHz, DMSO- $d_{6}$ ) of burnettramic acid B (2)........................ 40

Figure S23. ${ }^{1} \mathrm{H}$ NMR spectrum $\left(600 \mathrm{MHz}, \mathrm{DMSO}-d_{6}\right)$ of burnettramic acid A aglycone (3) .............................. 41

Figure S24. ${ }^{13} \mathrm{C}$ NMR spectrum $\left(150 \mathrm{MHz}\right.$, DMSO- $\left.d_{6}\right)$ of burnettramic acid A aglycone (3)........................... 42

Figure S25. ${ }^{1} \mathrm{H}^{13} \mathrm{C}$ HSQC NMR spectrum $\left(600 \mathrm{MHz}\right.$, DMSO- $\left.d_{6}\right)$ of burnettramic acid A aglycone (3)............. 43

Figure S26. ${ }^{1} \mathrm{H}-{ }^{13} \mathrm{C}$ HMBC NMR spectrum (600 MHz, DMSO- $d_{6}$ ) of burnettramic acid A aglycone (3) ............ 44

Figure S27. ${ }^{1} \mathrm{H}-{ }^{1} \mathrm{H}$ COSY NMR spectrum $\left(600 \mathrm{MHz}\right.$, DMSO- $\left.d_{6}\right)$ of burnettramic acid A aglycone (3).............. 45

Figure S28. ${ }^{1} \mathrm{H}-{ }^{1} \mathrm{H}$ ROESY NMR spectrum (600 MHz, DMSO- $d_{6}$ ) of burnettramic acid A aglycone (3) ........... 46

Figure S29. ${ }^{1} \mathrm{H}$ NMR spectrum $\left(600 \mathrm{MHz}, \mathrm{DMSO}-d_{6}\right.$ ) of burnettramic acid B aglycone (4) ............................... 47

Figure S30. ${ }^{13} \mathrm{C}$ NMR spectrum (150 MHz, DMSO- $d_{6}$ ) of burnettramic acid B aglycone (4) ........................... 48

Figure S31. ${ }^{1} \mathrm{H}^{-13} \mathrm{C}$ HSQC NMR spectrum $\left(600 \mathrm{MHz}\right.$, DMSO- $\left.d_{6}\right)$ of burnettramic acid B aglycone (4) .............. 49

Figure S32. ${ }^{1} \mathrm{H}-{ }^{13} \mathrm{C}$ HMBC NMR spectrum (600 MHz, DMSO- $d_{6}$ ) of burnettramic acid B aglycone (4)............ 50

Figure S33. ${ }^{1} \mathrm{H}-{ }^{1} \mathrm{H}$ COSY NMR spectrum $\left(600 \mathrm{MHz}\right.$, DMSO- $\left.d_{6}\right)$ of burnettramic acid B aglycone (4).............. 51

Figure S34. ${ }^{1} \mathrm{H}-{ }^{1} \mathrm{H}$ ROESY NMR spectrum ( $600 \mathrm{MHz}$, DMSO- $d_{6}$ ) of burnettramic acid B aglycone (4) ............. 52

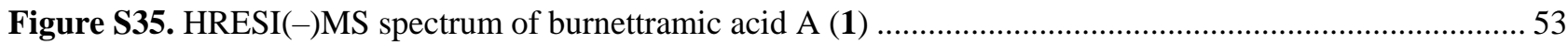

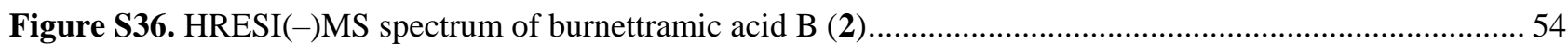

Figure S37. HRESI(-)MS spectrum of burnettramic acid A aglycone (3) .................................................... 55

Figure S38. HRESI(-)MS spectrum of burnettramic acid B aglycone (4) .................................................... 56

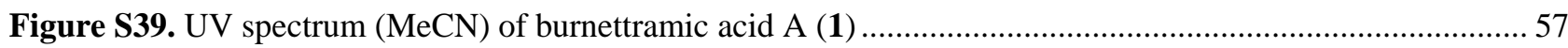

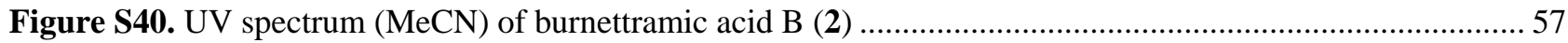

Figure S41. UV spectrum (MeCN) of burnettramic acid A aglycone (3) ........................................................ 58

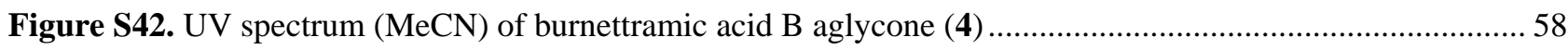

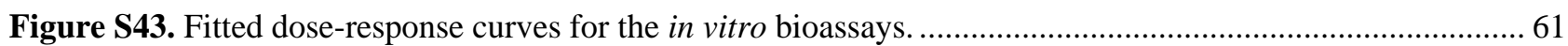

Supplementary references.................................................................................................................................................. 62 


\section{SUPPLEMENTARY PROCEDURES}

\section{General Experimental Details}

${ }^{1} \mathrm{H}$ NMR and ${ }^{13} \mathrm{C}$ NMR spectra were recorded in $5 \mathrm{~mm}$ Pyrex tubes (Wilmad, USA) on a Bruker Avance II DRX-600K $600 \mathrm{MHz}$ spectrometer. All NMR spectra were obtained at $25^{\circ} \mathrm{C}$, processed using Bruker Topspin 3.5 software and referenced to residual solvent signals (DMSO- $d_{6} \delta_{\mathrm{H}} 2.49$ / $\delta_{\mathrm{C}} 39.5 \mathrm{ppm}$ ). High resolution electrospray ionization mass spectra (HRESIMS) were obtained on a Q Exactive Plus hybrid quadrupole-Orbitrap mass spectrometer (Thermo Fisher Scientific, Bremen, Germany) by direct infusion. Electrospray ionization mass spectra (ESIMS) were acquired on an Agilent 1260 UHPLC coupled to an Agilent 6130 single quadrupole mass detector. Chiroptical measurements $\left([\alpha]_{\mathrm{D}}\right)$ were obtained on a JASCO P-1000 polarimeter in a $100 \times 10 \mathrm{~mm}$ cell. UV-vis spectra were acquired in MeCN on a Varian Cary 300 spectrophotometer in a $10 \times 10 \mathrm{~mm}$ quartz cell.

Analytical HPLC was performed on a gradient Agilent 1260 Infinity quaternary HPLC system. The column was an Agilent Zorbax SB-C18 $(2.1 \times 50 \mathrm{~mm}, 1.8 \mu \mathrm{m})$ eluted with a $0.6 \mathrm{~mL} / \mathrm{min}$ gradient of $10-100 \%$ acetonitrile/water (0.01\% TFA) over $8.33 \mathrm{~min}$. Preparative HPLC was performed on a gradient Shimadzu HPLC system comprising two LC-8A preparative liquid pumps with static mixer, SPD-M10AVP diode array detector and SCL-10AVP system controller with standard Rheodyne injection port. The columns used in the purification of the metabolites were selected from either a Vydac $\mathrm{C}_{18}$ column $(50 \times 100 \mathrm{~mm}, 5 \mu \mathrm{m}$; Grace Discovery), a Zorbax SB-C18 column $(50 \times$ $150 \mathrm{~mm}, 5 \mu \mathrm{m}$; Agilent $)$ or an Alltima $\mathrm{C}_{18}(22 \times 250 \mathrm{~mm}, 5 \mu \mathrm{m}$, Grace Discovery $)$ isocratically with acetonitrile/water mixtures containing $0.1 \%$ TFA modifier.

For the A. nidulans strains, the analyses of the metabolite profiles were performed on an Agilent 1260 liquid chromatography (LC) system coupled to a diode array detector (DAD) and an Agilent 6130 Quadrupole mass spectrometer (MS) with an ESI source. Chromatographic separation was performed at $40{ }^{\circ} \mathrm{C}$ using a Kinetex $\mathrm{C} 18$ column $(2.6 \mu \mathrm{m}, 2.1 \mathrm{~mm} \times 100 \mathrm{~mm}$; Phenomenex). The $A$. nidulans cells from liquid culture were extracted with acetone. For liquid cultures, the metabolites were extracted from the liquid culture with an organic solvent mixture containing ethyl acetate/methanol/acetic acid at 89:10:1 ratio. The crude extracts were dried down in vacuo and redissolved in methanol for LC-MS analysis. Chromatographic separation was achieved with a linear gradient of 5-95\% MeCN-H $\mathrm{H}_{2} \mathrm{O}(0.1 \%(v / v)$ formic acid) in $10 \mathrm{~min}$ followed by $95 \% \mathrm{MeCN}$ for 3 min then $5 \% \mathrm{MeCN}-\mathrm{H}_{2} \mathrm{O}$ for $3 \mathrm{~min}$, with a flow rate of $0.75 \mathrm{~mL} / \mathrm{min}$. The MS data were collected in the $m / z$ range $100-1000$.

\section{Collection of Fungus}

A. burnettii MST-FP2249 was isolated from a sample of cultivated soil from a property at Coalstoun Lakes in the South Burnett region of Queensland in 2004. On isolation the fungus displayed an interesting phenotype and chemotaxonomic profile indicative of the new species belonging to the A. alliaceus clade in subgenus Circumdati section Flavi. Cultures were freeze dried and accessioned into the FRR collection (FRR 5400), the culture collection at CSIRO Agriculture and Food, North Ryde, NSW, Australia. 


\section{Cultivation and Extraction and Purification}

Agar squares taken from 10-day-old Petri plates of A. burnettii were used to inoculate $40 \times 250 \mathrm{~mL}$ Erlenmeyer flasks each containing $48 \mathrm{~g}$ of sterile pearl barley $\left(+35 \mathrm{~mL}\right.$ water; autoclaved $120{ }^{\circ} \mathrm{C}$ for $40 \mathrm{~min}$ ). The flasks were incubated at $24{ }^{\circ} \mathrm{C}$ for 21 days, after which the grains were pooled from individual flasks and extracted with acetone $(2 \times 3 \mathrm{~L})$. The combined acetone extracts were concentrated in vacuo to give an aqueous residue $(1.2 \mathrm{~L})$. The residue was then partitioned against ethyl acetate $(2 \times 1.5 \mathrm{~L})$ and the combined organic layer was dried in vacuo to give a crude extract $(18.11 \mathrm{~g})$. An insoluble phase $(5.79 \mathrm{~g})$ was also isolated from the partition.

The crude extract was redissolved in $90 \% \mathrm{MeOH} / \mathrm{H}_{2} \mathrm{O}(500 \mathrm{~mL})$ and partitioned against hexane (2 $\times 500 \mathrm{~mL}$ ) to remove lipids and provide an enriched extract $(9.11 \mathrm{~g})$. The enriched extract was dissolved in $\mathrm{MeOH}(35 \mathrm{~mL})$ and fractionated by size exclusion chromatography (Sephadex LH-20, $5.5 \mathrm{~cm} \times 24 \mathrm{~cm}$ column) to give $30 \times 20 \mathrm{~mL}$ vials. Analysis by analytical HPLC identified an unusual family of UV spectra in the early eluting fractions (F8-11). These fractions were pooled and reduced to dryness in vасиo $(1.78 \mathrm{~g})$ then further fractioned by isocratic preparative HPLC (Vydac $\mathrm{C}_{18}$, isocratic $70 \% \mathrm{MeCN} / \mathrm{H}_{2} \mathrm{O}+0.1 \% \mathrm{TFA}, 60 \mathrm{~mL} / \mathrm{min}$ ) to give $24 \times 20 \mathrm{~mL}$ with the late eluting fraction (F22-24) pooled and evaporated to dryness (161 mg). Highly enriched fractions were purified by isocratic preparative HPLC (Alltima $\mathrm{C}_{18}$, isocratic $77.5 \% \mathrm{MeCN} / \mathrm{H}_{2} \mathrm{O}+0.1 \% \mathrm{TFA}, 20$ $\mathrm{mL} / \mathrm{min}$ ) to yield burnettramic acid B aglycone (4) ( $t_{\mathrm{R}} 17.9 \mathrm{~min} ; 22.3 \mathrm{mg}$ ) and burnettramic acid A aglycones (3) ( $\left.t_{\mathrm{R}} 20.7 \mathrm{~min} ; 20.8 \mathrm{mg}\right)$.

The insoluble phase from the ethyl acetate partition was triturated with $\mathrm{MeOH}(3 \times 50 \mathrm{~mL})$ and the soluble portion $(2.00 \mathrm{~g}$ ) was fractionated by size exclusion chromatography (Sephadex LH-20, 5.5 $\mathrm{cm} \times 45 \mathrm{~cm})$ and $44 \times 20 \mathrm{~mL}$ fractions were collected. Analysis by analytical HPLC identified an unusual family of UV spectra in the early eluting fractions (F8-14). These fractions were pooled and reduced to dryness in vacuo $(548 \mathrm{mg}$ ) then purified by isocratic preparative HPLC (Zorbax SB-C18, isocratic stepwise $\left.60 \%-100 \% \mathrm{MeCN} / \mathrm{H}_{2} \mathrm{O}+0.1 \% \mathrm{TFA}, 60 \mathrm{~mL} / \mathrm{min}\right)$ to yield burnettramic acid A (1) $\left(t_{\mathrm{R}} 18.4 \mathrm{~min} ; 57.2 \mathrm{mg}\right.$ ) with only traces of burnettramic B (2) detectable $(<1 \mathrm{mg})$. (See flow chart Figure S10). 


\section{Acid Hydrolysis}

A solution of burnettramic acid A $(70 \mathrm{mg}, 9.1 \mathrm{mmol})$ in $0.1 \mathrm{M}$ hydrochloric acid $(7 \mathrm{~mL} ; 15 \%$ $\left.\mathrm{H}_{2} \mathrm{O} / \mathrm{MeCN}\right)$ was heated to $60{ }^{\circ} \mathrm{C}$ for $2 \mathrm{~h}$. The reaction mixture was diluted with water $(100 \mathrm{~mL})$ and applied to a $10 \mathrm{~g} \mathrm{C}_{18} \mathrm{SPE}$ column. The column was flushed with $\mathrm{H}_{2} \mathrm{O}(200 \mathrm{~mL})$ and then eluted with $\mathrm{MeOH}(100 \mathrm{~mL})$. The $\mathrm{MeOH}$ eluate was reduced to dryness in vacuo $(50 \mathrm{mg})$ then purified by isocratic preparative HPLC (Zorbax $\mathrm{C}_{18}$, isocratic $60 \% \mathrm{MeCN} / \mathrm{H}_{2} \mathrm{O}+0.1 \% \mathrm{TFA}, 20 \mathrm{~mL} / \mathrm{min}$ ) to yield unreacted burnettramic acid A (1) $\left(t_{\mathrm{R}} 16.5 \mathrm{~min} ; 9.0 \mathrm{mg}\right)$ and burnettramic acid B (2) $\left(t_{\mathrm{R}} 14.2\right.$ min; $2.0 \mathrm{mg}$ ). A final elution of the column with $100 \% \mathrm{MeCN}+0.1 \%$ TFA gave burnettramic acid B aglycone (4) ( $t \mathrm{R} 23.1 \mathrm{~min} ; 3.1 \mathrm{mg}$ ) and burnettramic acid A aglycone (3) ( $t \mathrm{R} 23.7 \mathrm{~min} ; 11.1 \mathrm{mg})$. The $\mathrm{H}_{2} \mathrm{O}$ flush from the SPE column was lyophilized and the residue was triturated with $\mathrm{MeOH}$. The $\mathrm{MeOH}$-soluble material was reduced to dryness under a stream of nitrogen to give D-mannose.

\section{Characterisation of Compounds}

Burnettramic acid A (1): off-white solid; $[\alpha]_{\mathrm{D}}^{23}-41\left(c\right.$ 0.04, MeOH). UV (MeCN) $\lambda_{\max }(\log \varepsilon)$ 248 (3.68), 281 (3.69) nm. NMR (600 MHz, DMSO-d6) see Table S6. HRESI(-)MS m/z 768.4898 $[\mathrm{M}-\mathrm{H}]^{-}$(calcd. for $\mathrm{C}_{41} \mathrm{H}_{70} \mathrm{NO}_{12}{ }^{-}$768.4904).

Burnettramic acid B (2): off-white solid; $[\alpha]_{\mathrm{D}}^{23}-30(c 0.04, \mathrm{MeOH})$. UV (MeCN) $\lambda_{\max }(\log \varepsilon) 228$ (3.59), 249 (3.64), 280 (3.77) nm. NMR (600 MHz, DMSO- $d_{6}$ ) see Table S7. HRESI(-)MS $m / z$ $768.4898[\mathrm{M}-\mathrm{H}]^{-}$(calcd. for $\mathrm{C}_{41} \mathrm{H}_{70} \mathrm{NO}_{12}{ }^{-}$768.4904).

Burnettramic acid A aglycone (3): off-white solid; $[\alpha]_{\mathrm{D}}^{23}-7(c 0.02, \mathrm{MeOH})$. UV (MeCN) $\lambda \max$ ( $\log \varepsilon) 224$ (3.53); 280 (3.75) nm. NMR (600 MHz, DMSO- $\left.d_{6}\right)$ see Table S8. HRESI(-)MS $m / z$ $606.4370[\mathrm{M}-\mathrm{H}]^{-}$(calcd. for $\mathrm{C}_{35} \mathrm{H}_{60} \mathrm{NO}_{7}{ }^{-}$606.4375).

Burnettramic acid B aglycone (4): off-white solid; $[\alpha]_{\mathrm{D}}^{23}-18(c 0.01, \mathrm{MeOH}) . \mathrm{UV}(\mathrm{MeCN}) \lambda_{\max }$ $(\log \varepsilon) 248$ (2.93); 279 (3.06) nm. NMR (600 MHz, DMSO-d6) see Table S9. HRESI(-)MS $\mathrm{m} / z$ $606.4373[\mathrm{M}-\mathrm{H}]^{-}$(calcd. for $\mathrm{C}_{35} \mathrm{H}_{60} \mathrm{NO}_{7}{ }^{-}$606.4375). 


\section{Bioassay of Compounds}

\section{Bioassays $^{[1]}$}

Purified metabolites were dissolved in DMSO to provide stock solutions $(10,000 \mu \mathrm{g} / \mathrm{mL}$ or 5,000 $\mu \mathrm{g} / \mathrm{mL}$ depending on the amount of material available). An aliquot of each stock solution was transferred to the first lane of Rows B to $G$ in a 96-well microtitre plate and two-fold serially diluted with DMSO across the 12 lanes of the plate to provide a 2,048-fold concentration gradient. Bioassay medium was added to an aliquot of each test solution to provide a 100 -fold dilution into the final bioassay, thus yielding a test range of 100 to $0.05 \mu \mathrm{g} / \mathrm{mL}$ in $1 \%$ DMSO. Row A contained no test compound (as a reference for no inhibition) and Row $\mathrm{H}$ was uninoculated (as a reference for complete inhibition).

CyTOX: NS-1 (ATCC TIB-18) mouse myeloma cells and Neonatal Foreskin Fibroblast (NFF) cells were inoculated in 96-well microtitre plates $(190 \mu \mathrm{L})$ at 50,000 cells $/ \mathrm{mL}$ in DMEM (Dulbecco's Modified Eagle Medium $+10 \%$ fetal bovine serum (FBS) $+1 \%$ penicillin/streptomycin $(10,000 \mathrm{U} / \mathrm{mL} / 10,000 \mu \mathrm{g} / \mathrm{mL}$, Life Technologies Cat. No. 15140122$)$ and incubated in $37^{\circ} \mathrm{C}(5 \%$ $\left.\mathrm{CO}_{2}\right)$ incubator. At $48 \mathrm{~h}$, resazurin $(250 \mu \mathrm{g} / \mathrm{mL} ; 10 \mu \mathrm{L})$ was added to each well and the plates were incubated for a further $48 \mathrm{~h}$. Finally, the absorbance of each well at $605 \mathrm{~nm}$ was measured using a Spectromax plate reader (Molecular Devices).

ProTOX: Bacillus subtilis (ATCC 6633) and Staphylococcus aureus (ATCC 25923) were used as indicative species for Gram positive and negative antibacterial activity, respectively. A bacterial suspension ( $50 \mathrm{~mL}$ in $250 \mathrm{~mL}$ flask) was prepared in nutrient media by cultivation for $24 \mathrm{~h}$ at 250 $\mathrm{rpm}, 28{ }^{\circ} \mathrm{C}$. The suspension was diluted to an absorbance of 0.01 absorbance units per $\mathrm{mL}$, and 10 $\mu \mathrm{L}$ aliquots were added to the wells of a 96-well microtitre plate, which contained the test compounds dispersed in nutrient broth (Amyl) with resazurin $(12.5 \mu \mathrm{g} / \mathrm{mL}$ ). The plates were incubated at $28^{\circ} \mathrm{C}$ for $48 \mathrm{~h}$ during which time the positive control wells change colour from a blue to light pink colour. MIC end points were determined visually. The absorbance was measured using Spectromax plate reader (Molecular Devices) at $605 \mathrm{~nm}$ and the IC50 values determined graphically.

EuTOX: Candida albicans (ATCC 10231) and Saccharomyces cerevisiae (ATCC 9763) were usedas indicative species for antifungal activity. A yeast suspension $(50 \mathrm{~mL}$ in $250 \mathrm{~mL}$ flask $)$ was prepared in $1 \%$ malt extract broth by cultivation for $24 \mathrm{~h}$ at $250 \mathrm{rpm}, 24{ }^{\circ} \mathrm{C}$. The suspension was diluted to an absorbance of 0.005 and 0.03 absorbance units per $\mathrm{mL}$ for $C$. albicans and $\mathrm{S}$. cerevisiae, respectively. Aliquots $(20 \mu \mathrm{L}$ and $30 \mu \mathrm{L})$ of $C$. albicans and S. cerevisiae, respectively were applied to the wells of a 96-well microtitre plate, which contained the test compounds dispersed in malt extract agar containing bromocresol green $(50 \mu \mathrm{g} / \mathrm{mL})$. The plates were incubated at $24{ }^{\circ} \mathrm{C}$ for $48 \mathrm{~h}$ during which time the positive control wells change colour from a blue to yellow colour. MIC end points were determined visually. The absorbance was measured using Spectromax plate reader (Molecular Devices) at $620 \mathrm{~nm}$ and the IC50 determined graphically.

TriTOX: Tritrichomonas foetus (strain $\mathrm{KV}-1$ ) was used as an indicative species for antiprotozoal activity. T. foetus was inoculated in 96 -well microtitre plates $(200 \mu \mathrm{L})$ at $4 \times 10^{4}$ cells $/ \mathrm{mL}$ in $T$. foetus medium $(0.2 \%$ tryptone, Oxoid; $0.1 \%$ yeast extract, Difco; $0.25 \%$ glucose; $0.1 \%$ L-cysteine; $0.1 \% \mathrm{~K}_{2} \mathrm{HPO}_{4} ; 0.1 \% \mathrm{KH}_{2} \mathrm{PO}_{4} ; 0.1 \%$ ascorbic acid; $0.01 \% \mathrm{FeSO}_{4} .7 \mathrm{H}_{2} \mathrm{O} ; 1 \%$ penicillin/streptomycin $(10,000 \mathrm{U} / \mathrm{mL} / 10,000 \mu \mathrm{g} / \mathrm{mL}$, Life Technologies Cat. No. 15140122), 10\% new born calf serum (NBCS), Life Technologies). The plates were incubated in anaerobic jars (Oxoid AG25) containing Anaerogen satchel (Oxoid AN25) in $37{ }^{\circ} \mathrm{C}\left(5 \% \mathrm{CO}_{2}\right)$ incubator. At $72 \mathrm{~h}, T$. foetus proliferation was counted and \% Inhibition graphed to determine the $\mathrm{IC}_{50}$ values. 


\section{Heterologous expression of the bua cluster in A. nidulans LO7890}

All bua genes were cloned into the pYFAC episomal vector by yeast transformation-assisted recombination. Full length of buaA was amplified by PCR with three sets of primers from $A$. burnettii gDNA (Table S1). Then Saccharomyces cerevisiae strain BJ5464-NpgA competent cells were transformed by the three overlapping DNA fragments and PacI-digested pYFAC-pyrG and generated pYFAC-CL10 by yeast homologous recombination. BuaC, buaE, and buaG were amplified with the designed primers and ligated into the PacI, NotI and AsisI site of pYFAC-ribo, respectively, to get pYFAC-CL13 plasmid. BuaB, BuaD and buaF were amplified with the designed primers (Table S1) and ligated into the PacI and AscI site of pYFAC-pyrO, respectively, to get pYFAC-CL14 plasmid (Table S11). Plasmids were confirmed by restriction enzyme digestion and DNA sequencing and plasmids maps were shown below. The resulting heterologous expression plasmids were introduced into A. nidulans LO7890 by polyethylene glycol protoplast transformation as described previously. ${ }^{[2]}$

\section{Genome sequencing and bioinformatics}

The A. burnettii genome was sequenced with Illumina HiSeq 2000. Sequencing reads were trimmed for quality using Trimmomatic v0.38 and then assembled using SPAdes v3.10.1. ${ }^{[3]}$ Gene prediction and functional annotation was performed using the Funannotate v1.3.3 pipeline (https://github.com/nextgenusfs/funannotate). All pairwise amino acid alignments were constructed using MUSCLE v3.8.31. ${ }^{[4]}$ Protein similarity was calculated based on MUSCLE alignment using the BLOSUM62 matrix with threshold 1. Gene cluster similarity figures were generated using custom Python scripts (available online: https://bitbucket.org/clmgil/cluster-crosslinker). Internal Transcribed Spacer region nucleotide sequences were retrieved from the NCBI GenBank database. A multiple sequence alignment was constructed using MAFFT v7.407 and manually trimmed for length using Geneious 10.2.6. ${ }^{[5]}$ Phylogenetic trees were constructed using RAxML-NG v0.6.0 and MrBayes v3.2.6 and visualised using the ETE3 toolkit. ${ }^{[6]}$

The sequence data of the ITS sequence (accession number MK429758) and the bua gene cluster (accession number MK425157) have been deposited in the GenBank. 


\section{SUPPLEMENTARY TABLES}

Table S1. Primers used in this study.

\begin{tabular}{|c|c|}
\hline Primer & Sequence \\
\hline PalcA-buaA-F & $\begin{array}{l}\text { GTTAATTAGAACTCTTCCAATCCTATCACCTCGCCTTAATATGTC } \\
\text { CTTCAGCTACAACAG }\end{array}$ \\
\hline Frag1-buaA-R & TCTAATGGCCCCTTCAACAT \\
\hline Frag2-buaA-F & TACCTGAAGCAGCTCCACGA \\
\hline Frag2-buaA-R & ACGCTGTTTGCACATGACAT \\
\hline Frag3-buaA-F & AGAAGTACGTGTTTAATATT \\
\hline $\begin{array}{l}\text { pKW-pyrG- } \\
\text { buaA-R }\end{array}$ & $\begin{array}{l}\text { CTTCAACACAGTGGAGGACATACCCGTAATTTTCTGGGCTTAAT } \\
\text { CCTCCGCAGTTCCAAT }\end{array}$ \\
\hline PalcA-buaB-F & $\begin{array}{l}\text { GTTAATTAGAACTCTTCCAATCCTATCACCTCGCCTTAATATGCC } \\
\text { GGGCCAAAAACCAGT }\end{array}$ \\
\hline T1-buaB-R & $\begin{array}{l}\text { CGCGCTCCACGGGGACTCGCTTCAATTTGTTCCGCTTAATCGCCG } \\
\text { TGATCATGTCCAATA }\end{array}$ \\
\hline PalcA-buaC-F & $\begin{array}{l}\text { GTTAATTAGAACTCTTCCAATCCTATCACCTCGCCTTAATATGGG } \\
\text { GATCCAACATATGCT }\end{array}$ \\
\hline T1-buaC-R & $\begin{array}{l}\text { GGCTCGCGCTCCACGGGGACTCGCTTCAATTTGTTCCGCTTAATC } \\
\text { GCTGATCTCTCCCTT }\end{array}$ \\
\hline PalcSM-buaD-F & $\begin{array}{l}\text { TGAGATACCAAAGCATTGAGCCCAGAAACAGCAGAAGCATGAA } \\
\text { AGATGTCCCCAATAAGG }\end{array}$ \\
\hline T1-buaD-R & $\begin{array}{l}\text { TTAGTCTAAAGGTCTACAATCAATTCAGGCCGTATTCAGGGCCT } \\
\text { ACCAGCCCTCCAGCAC }\end{array}$ \\
\hline PalcSM-buaE-F & $\begin{array}{l}\text { TTTGAGATACCAAAGCATTGAGCCCAGAAACAGCAGAAGCATG } \\
\text { GAGGTTGAACGACTCGA }\end{array}$ \\
\hline T1-buaE-R & $\begin{array}{l}\text { TTAGTCTAAAGGTCTACAATCAATTCAGGCCGTATTCAGGGCGT } \\
\text { ATGTCTGCAAGAGACG }\end{array}$ \\
\hline PalcSM-buaG-F & $\begin{array}{l}\text { CCCTTTTCCTTATTAAACCATATATCTCCAGCAGAGCGATATGTT } \\
\text { TCTTTTGATCCTATA }\end{array}$ \\
\hline T2-buaG-R & $\begin{array}{l}\text { AAGCCAACTTCGATCTCAACTAAATTATCTCCTCCCGCGATTCCC } \\
\text { TCTACATGCCGCAAG }\end{array}$ \\
\hline PladA-buaF-F & $\begin{array}{l}\text { ACTCTCCTCTCCCAAGATACCCATATTTCCCGCTCACCGGATGGT } \\
\text { GGTAGTTCTAGAGAG }\end{array}$ \\
\hline T2-buaF-R & $\begin{array}{l}\text { TTAGGGAGCGGCGGATGCCTACTTACTTCTGGGAACGAGGTCAT } \\
\text { CССТTTGCAGCCTCAG }\end{array}$ \\
\hline N454-N741-F & TGCACGCACAAATACACAGC \\
\hline N741-N454-R & TCGCCCATCCGTTCTGTAAC \\
\hline N741-N386-F & GAGCGTGTGAGGGTGAATCA \\
\hline N386-N741-R & CGGGACCATCACTTTGCTCT \\
\hline
\end{tabular}


Table S2. Genes within the bua BGC and conservation with A. alliaceus CBS 536.65. Identity and similarity values are taken from pairwise amino acid alignments constructed with MUSCLE v3.8.31.

\begin{tabular}{|c|c|c|c|c|}
\hline A. burnettii FRR 5400 & A. alliaceus CBS 536.65 & Predicted function & $\begin{array}{c}\text { Identity } \\
(\%)\end{array}$ & $\begin{array}{c}\text { Similarity } \\
(\%)\end{array}$ \\
\hline \multicolumn{5}{|l|}{ Scaffold 454} \\
\hline buaB & jgi.p_Aspalli1_77391 & Glycosyltransferase & 98.98 & 99.39 \\
\hline buaC & jgi.p_Aspalli1_319470 & Enoyl reductase & 69.76 & 69.96 \\
\hline \multicolumn{5}{|l|}{ Scaffold 741} \\
\hline buaD & jgi.p_Aspalli1_319471 & Cytochrome P450 & 82.56 & 83.3 \\
\hline- & jgi.p_Aspalli1_310750 & Ankyrin-repeat containing & 98.38 & 98.92 \\
\hline \multicolumn{5}{|l|}{ Scaffold 386} \\
\hline buaE & jgi.p_Aspalli1_274973 & Oxidoreductase & 100 & 100 \\
\hline buaF & jgi.p_Aspalli1_274975 & Hypothetical protein & 97.62 & 97.86 \\
\hline buaG & jgi.p_Aspalli1_319472 & Cytochrome P450 & 98.81 & 99.01 \\
\hline- & jgi.p_Aspalli1_310754 & Hypothetical protein & 98.88 & 100 \\
\hline buaA & jgi.p_Aspalli1_310755 & PKS-NRPS & 99.17 & 99.32 \\
\hline
\end{tabular}


Table S3. Identity (\%) matrix of the MUSCLE pairwise protein alignment of proline hydroxylases.

\begin{tabular}{|l|c|c|c|}
\cline { 2 - 4 } \multicolumn{1}{c|}{} & BuaE & AniF & HtyE \\
\hline BuaE & & 49.85 & 48.94 \\
\hline AniF & 49.85 & & 94.22 \\
\hline HtyE & 48.94 & 94.22 & \\
\hline GloF & 20.87 & 22.35 & 22.64 \\
\hline
\end{tabular}

Table S4. Similarity (\%) matrix of pairwise protein alignment of proline hydroxylases. Generated by MUSCLE v using the BLOSUM62 matrix with threshold 1.

\begin{tabular}{|l|c|c|c|}
\cline { 2 - 4 } \multicolumn{1}{c|}{} & BuaE & AniF & HtyE \\
\hline BuaE & & 64.44 & 63.53 \\
\hline AniF & 64.44 & & 97.87 \\
\hline HtyE & 63.53 & 97.87 & \\
\hline GloF & 36.52 & 38.68 & 38.4 \\
\hline
\end{tabular}


Table S5. Signature residues for amino acid selection by adenylation (A) domains

\begin{tabular}{|c|c|c|c|c|c|c|c|c|c|c|c|}
\hline \multirow{2}{*}{ Sequence } & \multirow{2}{*}{ Selectivity } & \multicolumn{10}{|c|}{ Signature position } \\
\hline & & 171 & 172 & 175 & 214 & 237 & 238 & 270 & 278 & 279 & 393 \\
\hline Fus 1 & Hse & D & $\mathrm{M}$ & $\mathrm{T}$ & $\mathrm{F}$ & V & $\mathbf{W}$ & $\mathrm{G}$ & $\mathrm{I}$ & I & $\mathbf{K}$ \\
\hline FusA & Hse & D & $\mathrm{M}$ & $\mathrm{T}$ & $\mathrm{F}$ & $\mathrm{V}$ & $\mathbf{W}$ & $\mathrm{G}$ & $\mathrm{I}$ & $\mathrm{N}$ & $\mathbf{K}$ \\
\hline NGS1 & Hse & D & $\mathrm{M}$ & $\mathrm{T}$ & $\mathrm{F}$ & $S$ & $\mathbf{W}$ & $\mathrm{G}$ & $\mathrm{I}$ & $\mathrm{N}$ & $\mathbf{K}$ \\
\hline EqiS & Ser & D & $\mathrm{F}$ & $\mathrm{E}$ & $S$ & $\mathrm{H}$ & $\mathbf{W}$ & $\mathrm{N}$ & $\mathrm{I}$ & A & $\mathbf{K}$ \\
\hline Pks3 & Ser & $\mathbf{D}$ & $\mathrm{L}$ & $\mathrm{L}$ & $\mathrm{M}$ & $\mathrm{T}$ & $\mathbf{W}$ & $\mathrm{W}$ & I & V & $\mathbf{K}$ \\
\hline ATEG_00325 & Leu & D & A & $S$ & $\mathrm{~L}$ & Q & $\mathbf{W}$ & A & I & M & $\mathbf{K}$ \\
\hline MycA & Leu & $\mathbf{D}$ & $\mathrm{L}$ & $\mathrm{W}$ & $\mathrm{G}$ & $\mathrm{T}$ & $\mathbf{W}$ & $\mathrm{C}$ & $\mathrm{V}$ & $\mathrm{G}$ & $\mathbf{K}$ \\
\hline ApdA & Tyr & D & $\mathrm{M}$ & V & I & $\mathrm{Y}$ & $\mathbf{W}$ & $\mathrm{C}$ & A & A & $\mathbf{K}$ \\
\hline TenS & Tyr & D & $\mathrm{M}$ & V & I & $\mathrm{T}$ & $\mathbf{W}$ & $\mathrm{C}$ & A & A & $\mathbf{K}$ \\
\hline DmbS & Tyr & D & $\mathrm{M}$ & V & I & $\mathrm{T}$ & $\mathbf{W}$ & $\mathrm{C}$ & A & A & $\mathbf{K}$ \\
\hline ACE1 & Tyr & D & $\mathrm{M}$ & A & $\mathrm{Q}$ & $S$ & $\mathbf{W}$ & $\mathrm{G}$ & $\mathrm{I}$ & $\mathrm{N}$ & $\mathbf{K}$ \\
\hline $\begin{array}{l}\text { CpaS } \\
\text { (A.flavus) }\end{array}$ & Trp & D & $\mathrm{M}$ & A & $\mathrm{L}$ & $\mathrm{T}$ & $\mathbf{W}$ & $\mathrm{S}$ & A & $\mathrm{C}$ & $\mathbf{K}$ \\
\hline $\begin{array}{l}\text { CpaS } \\
(\text { A. oryzae })\end{array}$ & Trp & D & $\mathrm{M}$ & A & $\mathrm{L}$ & A & W & $S$ & A & $\mathrm{C}$ & $\mathbf{K}$ \\
\hline PsoA & Phe & D & A & $\mathrm{Y}$ & $\mathrm{T}$ & $S$ & $\mathbf{W}$ & A & I & $\mathrm{C}$ & $\mathbf{K}$ \\
\hline $\mathrm{Ccs} \mathrm{A}$ & Phe & D & $\mathrm{M}$ & $S$ & $\mathrm{E}$ & $\mathrm{S}$ & $\mathbf{W}$ & $\mathrm{C}$ & $\mathrm{F}$ & $\mathrm{C}$ & $\mathbf{K}$ \\
\hline UcsA & $\begin{array}{l}3- \\
\text { methylproline }\end{array}$ & D & $\mathbf{V}$ & W & $\mathrm{F}$ & $S$ & W & I & I & $\mathrm{P}$ & $\mathbf{K}$ \\
\hline BuaA & $\begin{array}{l}\text { 4- } \\
\text { hydroxyproline }\end{array}$ & D & $\mathbf{V}$ & $\mathrm{Q}$ & $\mathrm{H}$ & K & $\mathbf{W}$ & $\mathbf{V}$ & $\mathbf{V}$ & I & $\mathrm{K}$ \\
\hline
\end{tabular}

Note: The 10 signature residues were based on the bacteria A domain as established previously. Sequence numbering is according to A domain of BuaA as predicted by antiSMASH $4.0^{[7]}$ (corresponds to amino acid 2935 - 3345 of the full length BuaA) and were based on homology modelling with bacterial A domain as performed previously by Stachelhaus et al. ${ }^{[8]}$ The signature residue table above is an expansion the table in this previous study. ${ }^{[9]}$ 


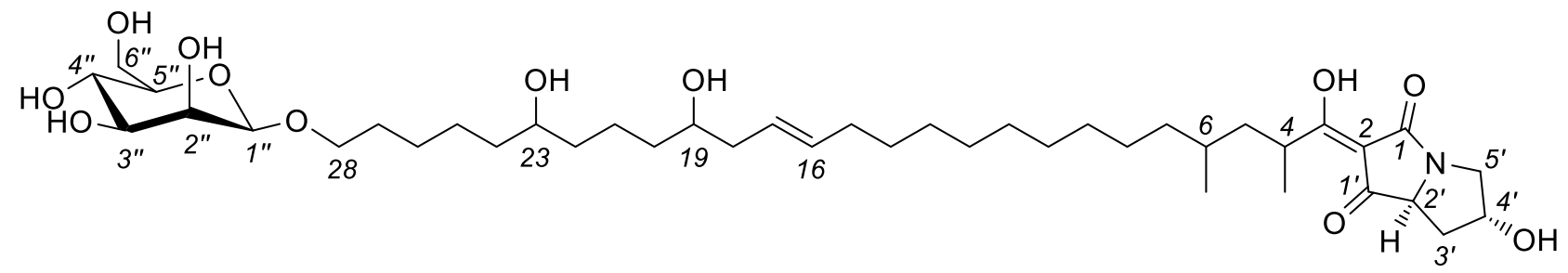

Table S6. NMR data (600 MHz) for burnettramic acid A (1) in DMSO- $d_{6}$

\begin{tabular}{|c|c|c|c|c|c|}
\hline Pos. & $\delta_{\mathrm{H}}$, mult $(J$ in $\mathrm{Hz})$ & $\delta_{\mathrm{C}}$ & HMBC & COSY & ROESY \\
\hline 1 & & Not observed & & & \\
\hline 2 & & Not observed & & & \\
\hline 3 & & 190.8 (br) & & & \\
\hline 4 & 3.62 , br m & 32.8 & 4-Me, 5,6 & $4-\mathrm{Me}, 5 \mathrm{a} / \mathrm{b}$ & \\
\hline 4-Me & $1.04, \mathrm{~d}(6.8)$ & 16.9 & $3,4,5$ & 4 & \\
\hline $5 a$ & $1.43, \mathrm{~m}$ & 40.2 & 4-Me, 6, 6-Me, 7 & 4 & \\
\hline $5 b$ & $1.35, \mathrm{~m}$ & & 4-Me, 6, 6-Me, 7 & 4 & \\
\hline 6 & $1.36, \mathrm{~m}$ & 30.0 & $5,6-\mathrm{Me}, 7,8$ & 6-Me & \\
\hline 6-Me & $0.81, \mathrm{~d}(6.4)$ & 19.4 & $5,6,7$ & 6 & \\
\hline $7 \mathrm{a}$ & $1.26, \mathrm{~m}$ & 36.11 & $6,6-\mathrm{Me}, 8,9$ & & \\
\hline $7 b$ & $1.03, \mathrm{~m}$ & & $6,6-\mathrm{Me}, 8,9$ & & \\
\hline $8 a$ & $1.25, \mathrm{~m}$ & 26.2 & & & \\
\hline $8 b$ & $1.16, \mathrm{~m}$ & & & & \\
\hline 9 & $1.14-1.31, \mathrm{~m}$ & $28.8-29.2$ & & & \\
\hline 10 & $1.14-1.31, \mathrm{~m}$ & $28.8-29.2$ & & & \\
\hline 11 & $1.21, \mathrm{~m}$ & 28.5 & & & \\
\hline 12 & $1.14-1.31, \mathrm{~m}$ & $28.8-29.2$ & & & \\
\hline 13 & $1.14-1.31, \mathrm{~m}$ & $28.8-29.2$ & & & \\
\hline 14 & $1.14-1.31, \mathrm{~m}$ & $28.8-29.2$ & & & \\
\hline 15 & $1.93, \mathrm{dt}(6.7,6.0)$ & 32.0 & $13 / 14,16,17$ & 14,16 & \\
\hline 16 & $5.35, \mathrm{dt}(15.4,6.0)$ & 131.5 & $14,15,17,18$ & 15 & \\
\hline 17 & $5.39, \mathrm{dt}(15.4,6.3)$ & 127.2 & $15,16,18,19$ & 18 & \\
\hline 18 & $2.01, \mathrm{dd}(6.3,6.0)$ & 40.6 & $16,17,19,20$ & 17,19 & \\
\hline 19 & $3.37, \mathrm{~m}$ & 69.9 & $17,18,20,21$ & $18,20 \mathrm{a} / \mathrm{b}$ & \\
\hline $20 \mathrm{a}$ & $1.33, \mathrm{~m}$ & 36.6 & & 19 & \\
\hline $20 \mathrm{~b}$ & $1.20, \mathrm{~m}$ & & & 19 & \\
\hline $21 \mathrm{a}$ & $1.46, \mathrm{~m}$ & 21.5 & $19,20,22,23$ & $20 \mathrm{~b}, 21 \mathrm{~b}$ & \\
\hline $21 b$ & $1.20, \mathrm{~m}$ & & $19,20,22,23$ & $21 \mathrm{a}$ & \\
\hline $22 \mathrm{a}$ & $1.29, \mathrm{~m}$ & 37.4 & & 23 & \\
\hline $22 b$ & $1.21, \mathrm{~m}$ & & & 23 & \\
\hline 23 & $3.33, \mathrm{~m}$ & 69.6 & $21,22,24,25$ & $22 \mathrm{a} / \mathrm{b}, 24 \mathrm{a} / \mathrm{b}$ & \\
\hline $24 \mathrm{a}$ & $1.30, \mathrm{~m}$ & 37.2 & & 23 & \\
\hline $24 b$ & $1.24, \mathrm{~m}$ & & & 23 & \\
\hline $25 \mathrm{a}$ & $1.34, \mathrm{~m}$ & 25.3 & & $24 b, 25 b$ & \\
\hline $25 b$ & $1.23, \mathrm{~m}$ & & & $24 \mathrm{a}$ & \\
\hline 26 & $1.27, \mathrm{~m}$ & 25.6 & 28 & 27 & \\
\hline 27 & $1.49, \mathrm{p}(6.9)$ & 29.3 & $25,26,28$ & $26,28 \mathrm{a} / \mathrm{b}$ & \\
\hline $28 \mathrm{a}$ & $3.74, \mathrm{dt}(9.6,6.9)$ & 68.4 & $26,27,1^{\prime \prime}$ & $27,28 b$ & $1^{\prime \prime}$ \\
\hline $28 b$ & 3.39 , dt $(9.6,6.9)$ & & $26,27,1^{\prime \prime}$ & $27,28 \mathrm{a}$ & $1^{\prime \prime}$ \\
\hline $1^{\prime}$ & & 194.8 (br) & & & \\
\hline $2^{\prime}$ & 4.22 , br s & Not observed & & $3^{\prime} \mathrm{a} / \mathrm{b}$ & $3^{\prime} \mathrm{a}$ \\
\hline $3^{\prime} \mathrm{a}$ & $1.92, \mathrm{~m}$ & 36.17 & $4^{\prime}, 5^{\prime}$ & $2^{\prime}, 3^{\prime} \mathrm{b}, 4^{\prime}$ & $2^{\prime}$ \\
\hline $3^{\prime} \mathrm{b}$ & 1.59 , br t (12.9) & & & $2^{\prime}, 3^{\prime} \mathrm{a}, 4^{\prime}$ & $4^{\prime}$ \\
\hline $4^{\prime}$ & 4.47, br t (4.9) & 72.1 & $5^{\prime}$ & $3^{\prime} \mathrm{a} / \mathrm{b}, 4^{\prime}-\mathrm{OH}, 5^{\prime} \mathrm{a} / \mathrm{b}$ & $3^{\prime} \mathrm{b}, 5^{\prime} \mathrm{a}$ \\
\hline $4^{\prime}-\mathrm{OH}$ & 5.24, br s & & & $4^{\prime}$ & \\
\hline $5^{\prime} \mathrm{a}$ & 3.76, br m & 52.5 & $4^{\prime}$ & $4^{\prime}, 5^{\prime} b$ & $4^{\prime}$ \\
\hline $5^{\prime} \mathrm{b}$ & 2.96, br d (12.0) & & $4^{\prime}$ & $4^{\prime}, 5^{\prime} \mathrm{a}$ & \\
\hline $1^{\prime \prime}$ & $4.32, \mathrm{~d}(0.7)$ & 100.2 & $28,2^{\prime \prime}, 3^{\prime \prime}, 5^{\prime \prime}$ & $2^{\prime \prime}$ & $28 \mathrm{a} / \mathrm{b}, 2^{\prime \prime}, 3^{\prime \prime}, 5^{\prime \prime}$ \\
\hline $2^{\prime \prime}$ & 3.60, dd $(3.1,0.7)$ & 70.6 & $1^{\prime \prime}, 3^{\prime \prime}, 4^{\prime \prime}$ & $1^{\prime \prime}, 3^{\prime \prime}$ & $1^{\prime \prime}$ \\
\hline $3^{\prime \prime}$ & 3.23 , dd $(9.3,3.1)$ & 73.7 & $2^{\prime \prime}, 4^{\prime \prime}, 5^{\prime \prime}$ & $2^{\prime \prime}$ & $1^{\prime \prime}, 5^{\prime \prime}$ \\
\hline $4^{\prime \prime}$ & 3.27 , dd $(9.3,9.0)$ & 67.2 & $2^{\prime \prime}, 3^{\prime \prime}, 5^{\prime \prime}, 6^{\prime \prime}$ & $5^{\prime \prime}$ & $6 " a / b$ \\
\hline $5^{\prime \prime}$ & 2.99, ddd $(9.0,6.4,2.3)$ & 77.5 & $1^{\prime \prime}, 3^{\prime \prime}, 4^{\prime \prime}, 6^{\prime \prime}$ & $4^{\prime \prime}, 6^{\prime \prime} \mathrm{a} / \mathrm{b}$ & $1^{\prime \prime}, 3^{\prime \prime}$ \\
\hline $6^{\prime \prime} \mathrm{a}$ & 3.67, dd $(11.7,2.3)$ & 61.4 & $4^{\prime \prime}, 5^{\prime \prime}$ & $4^{\prime \prime}, 6^{\prime \prime} \mathrm{b}$ & $4 "$ \\
\hline $6^{\prime \prime} \mathrm{b}$ & 3.43 , dd $(11.7,6.4)$ & & $4^{\prime \prime}, 5^{\prime \prime}$ & $4^{\prime \prime}, 6$ "a & $4^{\prime \prime}$ \\
\hline
\end{tabular}




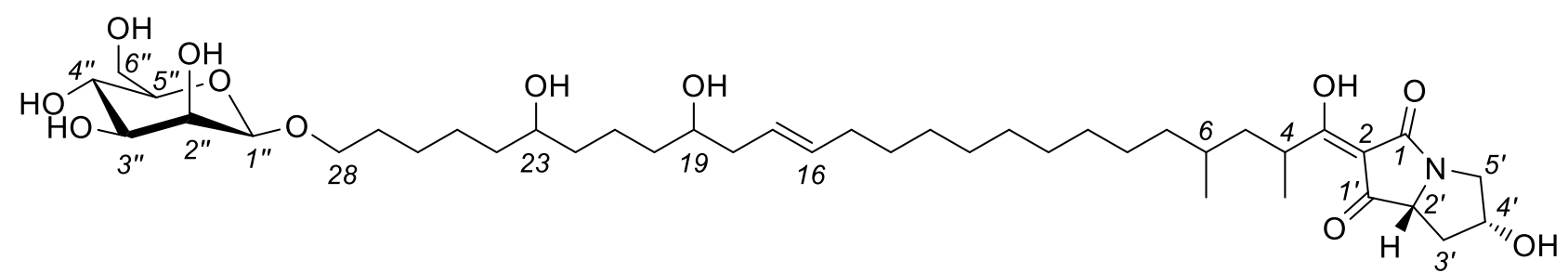

Table S7. NMR data (600 MHz) for burnettramic acid B (2) in DMSO- $d_{6}$

\begin{tabular}{|c|c|c|c|c|c|}
\hline Pos. & $\delta_{\mathrm{H}}$, mult $(J$ in $\mathrm{Hz})$ & $\delta_{\mathrm{C}}$ & HMBC & COSY & ROESY \\
\hline 1 & & Not observed & & & \\
\hline 2 & & Not observed & & & \\
\hline 3 & & 192.5 & & & \\
\hline 4 & 3.64 , br m & 33.8 & 4-Me, 5,6 & $4-\mathrm{Me}, 5 \mathrm{a} / \mathrm{b}$ & \\
\hline 4-Me & $1.04, \mathrm{~d}(6.8)$ & 16.9 & $3,4,5$ & 4 & \\
\hline $5 a$ & $1.43, \mathrm{~m}$ & 40.2 & 4-Me, 6, 6-Me, 7 & 4 & \\
\hline $5 b$ & $1.35, \mathrm{~m}$ & & 4-Me, 6, 6-Me, 7 & 4 & \\
\hline 6 & $1.36, \mathrm{~m}$ & 30.0 & $5,6-\mathrm{Me}, 7,8$ & 6-Me & \\
\hline 6-Me & $0.81, \mathrm{~d}(6.4)$ & 19.4 & $5,6,7$ & 6 & \\
\hline $7 a$ & $1.26, \mathrm{~m}$ & 36.11 & $6,6-\mathrm{Me}, 8,9$ & & \\
\hline $7 b$ & $1.03, \mathrm{~m}$ & & $6,6-\mathrm{Me}, 8,9$ & & \\
\hline $8 a$ & $1.25, \mathrm{~m}$ & 26.2 & & & \\
\hline $8 b$ & $1.16, \mathrm{~m}$ & & & & \\
\hline 9 & $1.14-1.31, \mathrm{~m}$ & $28.8-29.2$ & & & \\
\hline 10 & $1.14-1.31, \mathrm{~m}$ & $28.8-29.2$ & & & \\
\hline 11 & $1.21, \mathrm{~m}$ & 28.5 & & & \\
\hline 12 & $1.14-1.31, \mathrm{~m}$ & $28.8-29.2$ & & & \\
\hline 13 & $1.14-1.31, \mathrm{~m}$ & $28.8-29.2$ & & & \\
\hline 14 & $1.14-1.31, \mathrm{~m}$ & $28.8-29.2$ & & & \\
\hline 15 & $1.93, \mathrm{dt}(6.7,6.0)$ & 32.0 & $13 / 14,16,17$ & 16 & \\
\hline 16 & $5.35, \mathrm{dt}(15.4,6.0)$ & 131.5 & $14,15,17,18$ & 15 & \\
\hline 17 & $5.39, \mathrm{dt}(15.4,6.3)$ & 127.2 & $15,16,18,19$ & 18 & \\
\hline 18 & $2.01, \mathrm{dd}(6.3,6.0)$ & 40.6 & $16,17,19,20$ & 17,19 & \\
\hline 19 & $3.37, \mathrm{~m}$ & 69.9 & $17,18,20,22$ & $18,20 \mathrm{a} / \mathrm{b}$ & \\
\hline $20 \mathrm{a}$ & $1.33, \mathrm{~m}$ & 36.6 & & 19 & \\
\hline $20 \mathrm{~b}$ & $1.20, \mathrm{~m}$ & & & 19 & \\
\hline $21 \mathrm{a}$ & $1.46, \mathrm{~m}$ & 21.5 & $19,20,22,23$ & $20 \mathrm{~b}, 21 \mathrm{~b}$ & \\
\hline $21 b$ & $1.20, \mathrm{~m}$ & & $19,20,22,23$ & $21 \mathrm{a}$ & \\
\hline $22 \mathrm{a}$ & $1.29, \mathrm{~m}$ & 37.4 & & 23 & \\
\hline $22 b$ & $1.21, \mathrm{~m}$ & & & 23 & \\
\hline 23 & $3.33, \mathrm{~m}$ & 69.6 & $21,22,24,25$ & $22 \mathrm{a} / \mathrm{b}, 24 \mathrm{a} / \mathrm{b}$ & \\
\hline $24 \mathrm{a}$ & $1.30, \mathrm{~m}$ & 37.2 & & 23 & \\
\hline $24 b$ & $1.24, \mathrm{~m}$ & & & 23 & \\
\hline $25 \mathrm{a}$ & $1.34, \mathrm{~m}$ & 25.3 & & $24 b, 25 b$ & \\
\hline $25 b$ & $1.23, \mathrm{~m}$ & & & $24 \mathrm{a}$ & \\
\hline 26 & $1.27, \mathrm{~m}$ & 25.6 & 28 & 27 & \\
\hline 27 & $1.49, \mathrm{p}(6.9)$ & 29.3 & $25,26,28$ & $26,28 \mathrm{a} / \mathrm{b}$ & \\
\hline $28 \mathrm{a}$ & $3.74, \mathrm{dt}(9.6,6.9)$ & 68.4 & $26,27,1^{\prime \prime}$ & $27,28 b$ & $1^{\prime \prime}$ \\
\hline $28 b$ & 3.39 , dt $(9.6,6.9)$ & & $26,27,1^{\prime \prime}$ & $27,28 \mathrm{a}$ & $1^{\prime \prime}$ \\
\hline $1^{\prime}$ & & Not observed & & & \\
\hline $2^{\prime}$ & $4.05, \mathrm{dd}(10.0,5.7)$ & Not observed & & 3'a/b & $3^{\prime} \mathrm{a}, 4^{\prime}$ \\
\hline 3 'a & 2.18, ddd $(15.0,10.0,5.0)$ & 35.5 & $4^{\prime}, 5^{\prime}$ & $2^{\prime}, 3^{\prime} \mathrm{b}, 4^{\prime}$ & $2^{\prime}, 4^{\prime}$ \\
\hline $3^{\prime} \mathrm{b}$ & $1.58, \mathrm{dm}(15.0)$ & & & $2^{\prime}, 3^{\prime} \mathrm{a}, 4^{\prime}$ & \\
\hline $4^{\prime}$ & 4.30, br s & 71.1 & $5^{\prime}$ & $3^{\prime} \mathrm{a} / \mathrm{b}, 4^{\prime}-\mathrm{OH}, 5^{\prime} \mathrm{a} / \mathrm{b}$ & $2^{\prime}, 3^{\prime} \mathrm{a}, 5^{\prime} \mathrm{a} / \mathrm{b}$ \\
\hline $4^{\prime}-\mathrm{OH}$ & 4.93 , br s & & & $4^{\prime}$ & \\
\hline $5^{\prime} \mathrm{a}$ & 3.59, br d (11.7) & 53.4 & $4^{\prime}$ & $4^{\prime}, 5^{\prime} \mathrm{b}$ & $4^{\prime}$ \\
\hline $5^{\prime} \mathrm{b}$ & 3.08, br d (11.7) & & $4^{\prime}$ & $4^{\prime}, 5^{\prime} \mathrm{a}$ & $4^{\prime}$ \\
\hline $1^{\prime \prime}$ & $4.32, \mathrm{~d}(0.7)$ & 100.2 & $28,2^{\prime \prime}, 3^{\prime \prime}, 5^{\prime \prime}$ & $2^{\prime \prime}$ & $28 \mathrm{a} / \mathrm{b}, 2^{\prime \prime}, 3^{\prime \prime}, 5^{\prime \prime}$ \\
\hline $2^{\prime \prime}$ & $3.60, \mathrm{dd}(3.1,0.7)$ & 70.6 & $1^{\prime \prime}, 3^{\prime \prime}, 4^{\prime \prime}$ & $1^{\prime \prime}, 3^{\prime \prime}$ & $1 "$ \\
\hline $3^{\prime \prime}$ & 3.23 , dd $(9.3,3.1)$ & 73.7 & $2^{\prime \prime}, 4^{\prime \prime}, 5^{\prime \prime}$ & $2^{\prime \prime}$ & $1^{\prime \prime}, 5^{\prime \prime}$ \\
\hline $4^{\prime \prime}$ & 3.27 , dd $(9.3,9.0)$ & 67.2 & $2^{\prime \prime}, 3^{\prime \prime}, 5^{\prime \prime}, 6^{\prime \prime}$ & $5^{\prime \prime}$ & $6^{\prime \prime} \mathrm{a} / \mathrm{b}$ \\
\hline $5^{\prime \prime}$ & 2.99, ddd $(9.0,6.4,2.3)$ & 77.5 & $1^{\prime \prime}, 3^{\prime \prime}, 4^{\prime \prime}, 6^{\prime \prime}$ & $4^{\prime \prime}, 6^{\prime \prime} \mathrm{a} / \mathrm{b}$ & $1^{\prime \prime}, 3^{\prime \prime}$ \\
\hline $6^{\prime \prime} \mathrm{a}$ & 3.67, dd $(11.7,2.3)$ & 61.4 & $4^{\prime \prime}, 5^{\prime \prime}$ & $4^{\prime \prime}, 6^{\prime \prime} \mathrm{b}$ & $4^{\prime \prime}$ \\
\hline $6^{\prime \prime} \mathrm{b}$ & 3.43 , dd $(11.7,6.4)$ & & $4^{\prime \prime}, 5^{\prime \prime}$ & $4^{\prime \prime}, 6 " \mathrm{a}$ & $4^{\prime \prime}$ \\
\hline
\end{tabular}




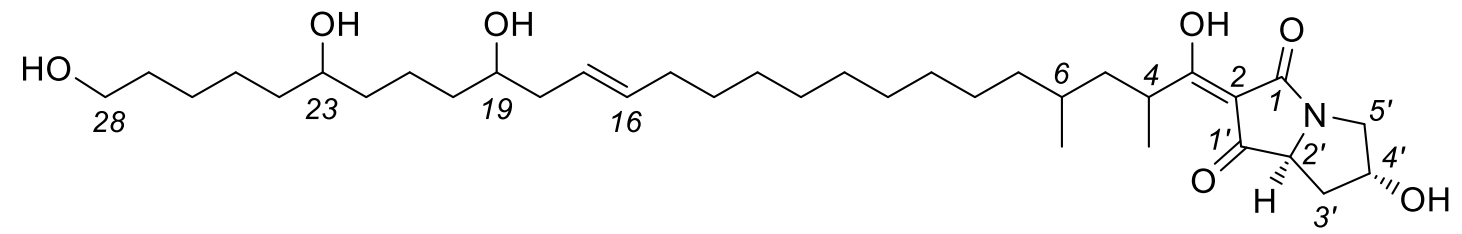

Table S8. NMR data (600 MHz) for burnettramic acid A aglycone (3) in DMSO- $d_{6}$

\begin{tabular}{|c|c|c|c|c|c|}
\hline Pos. & $\delta_{\mathrm{H}}$, mult $(J$ in $\mathrm{Hz})$ & $\delta_{\mathrm{C}}$ & HMBC & COSY & KEY ROESY \\
\hline 1 & & Not observed & & & \\
\hline 2 & & Not observed & & & \\
\hline 3 & & 192.8 (br) & & & \\
\hline 4 & 3.62 , br m & 32.8 & 4-Me, 5,6 & $4-\mathrm{Me}, 5 \mathrm{a} / \mathrm{b}$ & \\
\hline 4-Me & $1.04, \mathrm{~d}(6.8)$ & 16.9 & $3,4,5$ & 4 & \\
\hline $5 a$ & $1.43, \mathrm{~m}$ & 40.2 & 4-Me, 6, 6-Me, 7 & 4 & \\
\hline $5 b$ & $1.35, \mathrm{~m}$ & & 4-Me, 6, 6-Me, 7 & 4 & \\
\hline 6 & $1.36, \mathrm{~m}$ & 30.0 & $5,6-\mathrm{Me}, 7,8$ & 6-Me & \\
\hline 6-Me & $0.81, \mathrm{~d}(6.4)$ & 19.4 & $5,6,7$ & 6 & \\
\hline $7 \mathrm{a}$ & $1.26, \mathrm{~m}$ & 36.11 & $6,6-\mathrm{Me}, 8,9$ & & \\
\hline $7 b$ & $1.03, \mathrm{~m}$ & & $6,6-\mathrm{Me}, 8,9$ & & \\
\hline $8 a$ & $1.25, \mathrm{~m}$ & 26.2 & & & \\
\hline $8 b$ & $1.16, \mathrm{~m}$ & & & & \\
\hline 9 & $1.14-1.31, \mathrm{~m}$ & $28.8-29.2$ & & & \\
\hline 10 & $1.14-1.31, \mathrm{~m}$ & $28.8-29.2$ & & & \\
\hline 11 & $1.21, \mathrm{~m}$ & 28.5 & & & \\
\hline 12 & $1.14-1.31, \mathrm{~m}$ & $28.8-29.2$ & & & \\
\hline 13 & 1.14-1.31, m & $28.8-29.2$ & & & \\
\hline 14 & $1.14-1.31, \mathrm{~m}$ & $28.8-29.2$ & & & \\
\hline 15 & $1.93, \mathrm{dt}(6.7,6.0)$ & 32.0 & $13 / 14,16,17$ & 14,16 & \\
\hline 16 & $5.35, \mathrm{dt}(15.4,6.0)$ & 131.5 & $14,15,17,18$ & 15 & \\
\hline 17 & $5.39, \mathrm{dt}(15.4,6.3)$ & 127.2 & $15,16,18,19$ & 18 & \\
\hline 18 & 2.01, dd $(6.3,6.0)$ & 40.6 & $16,17,19,20$ & 17,19 & \\
\hline 19 & $3.37, \mathrm{~m}$ & 69.9 & $17,18,20,21$ & $18,20 \mathrm{a} / \mathrm{b}$ & \\
\hline $20 \mathrm{a}$ & $1.33, \mathrm{~m}$ & 36.6 & & 19 & \\
\hline $20 \mathrm{~b}$ & $1.20, \mathrm{~m}$ & & & 19 & \\
\hline $21 \mathrm{a}$ & $1.46, \mathrm{~m}$ & 21.5 & $19,20,22,23$ & $20 \mathrm{~b}, 21 \mathrm{~b}$ & \\
\hline $21 \mathrm{~b}$ & $1.20, \mathrm{~m}$ & & $19,20,22,23$ & $21 \mathrm{a}$ & \\
\hline $22 \mathrm{a}$ & $1.29, \mathrm{~m}$ & 37.4 & & 23 & \\
\hline $22 b$ & $1.21, \mathrm{~m}$ & & & 23 & \\
\hline 23 & $3.33, \mathrm{~m}$ & 69.6 & $21,22,24,25$ & $22 \mathrm{a} / \mathrm{b}, 24 \mathrm{a} / \mathrm{b}$ & \\
\hline $24 \mathrm{a}$ & $1.30, \mathrm{~m}$ & 37.2 & & 23 & \\
\hline $24 b$ & $1.24, \mathrm{~m}$ & & & 23 & \\
\hline $25 \mathrm{a}$ & $1.34, \mathrm{~m}$ & 25.3 & & $24 b, 25 b$ & \\
\hline $25 b$ & $1.23, \mathrm{~m}$ & & & $24 \mathrm{a}$ & \\
\hline 26 & $1.27, \mathrm{~m}$ & 25.6 & 28 & 27 & \\
\hline 27 & $1.49, \mathrm{~m}$ & 32.6 & $25,26,28$ & 26,28 & \\
\hline 28 & $3.35, \mathrm{t}(6.6)$ & 60.7 & 26,27 & 27 & \\
\hline $1^{\prime}$ & & 194.9 (br) & & & \\
\hline $2^{\prime}$ & 4.22 , br s & Not observed & & $3^{\prime} \mathrm{a} / \mathrm{b}$ & 3'a \\
\hline $3^{\prime} \mathrm{a}$ & $1.92, \mathrm{~m}$ & 36.17 & $4^{\prime}, 5^{\prime}$ & $2^{\prime}, 3^{\prime} \mathrm{b}, 4^{\prime}$ & $2^{\prime}$ \\
\hline $3^{\prime} \mathrm{b}$ & 1.59 , br t (12.9) & & & $2^{\prime}, 3^{\prime} \mathrm{a}, 4^{\prime}$ & $4^{\prime}$ \\
\hline $4^{\prime}$ & 4.47 , br t (4.9) & 72.1 & $5^{\prime}$ & $3^{\prime} \mathrm{a} / \mathrm{b}, 4^{\prime}-\mathrm{OH}, 5^{\prime} \mathrm{a} / \mathrm{b}$ & $3^{\prime} b, 5^{\prime} a$ \\
\hline $4^{\prime}-\mathrm{OH}$ & 5.24 , br s & & & $4^{\prime}$ & \\
\hline 5'a & 3.76 , br m & 52.5 & $4^{\prime}$ & $4^{\prime}, 5^{\prime} \mathrm{b}$ & $4^{\prime}$ \\
\hline $5^{\prime} \mathrm{b}$ & 2.96, br d $(12.0)$ & & $4^{\prime}$ & $4^{\prime}, 5^{\prime} \mathrm{a}$ & \\
\hline
\end{tabular}




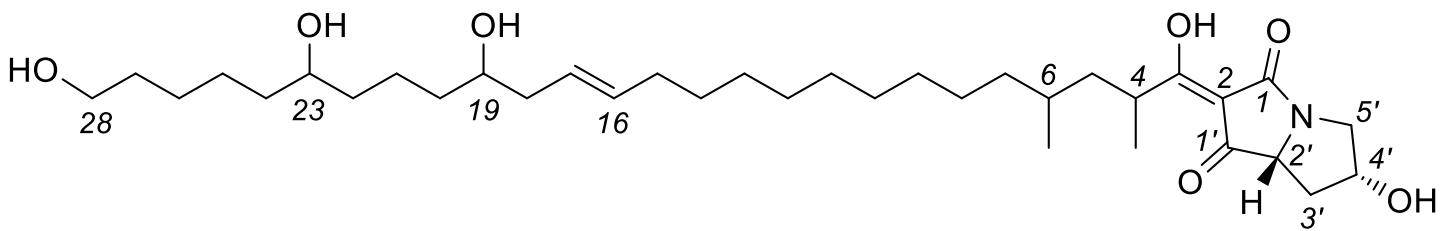

Table S9. NMR data (600 MHz) for burnettramic acid B aglycone (4) in DMSO- $d_{6}$

\begin{tabular}{|c|c|c|c|c|c|}
\hline Pos. & $\delta_{\mathrm{H}}$, mult $(\mathrm{J}$ in $\mathrm{Hz})$ & $\delta_{\mathrm{c}}$ & HMBC & COSY & KEY ROESY \\
\hline 1 & & Not observed & & & \\
\hline 2 & & Not observed & & & \\
\hline 3 & & Not observed & & & \\
\hline 4 & 3.66 , br m & Not observed & 4-Me, 5,6 & $4-\mathrm{Me}, 5 \mathrm{a} / \mathrm{b}$ & \\
\hline $4-\mathrm{Me}$ & $1.05, \mathrm{~d}(6.5)$ & 16.9 & 5 & 4 & \\
\hline $5 a$ & $1.39, \mathrm{~m}$ & 40.4 & 4-Me, 6, 6-Me, 7 & 4 & \\
\hline $5 b$ & $1.33, \mathrm{~m}$ & & $4-\mathrm{Me}, 6,6-\mathrm{Me}, 7$ & 4 & \\
\hline 6 & $1.33, \mathrm{~m}$ & 30.2 & $5,6-\mathrm{Me}, 7,8$ & 6-Me & \\
\hline 6-Me & $0.81, \mathrm{~d}(6.4)$ & 19.4 & $5,6,7$ & 6 & \\
\hline $7 \mathrm{a}$ & $1.26, \mathrm{~m}$ & 36.11 & $6,6-\mathrm{Me}, 8,9$ & & \\
\hline $7 \mathrm{~b}$ & $1.03, \mathrm{~m}$ & & $6,6-\mathrm{Me}, 8,9$ & & \\
\hline $8 \mathrm{a}$ & $1.25, \mathrm{~m}$ & 26.2 & & & \\
\hline $8 b$ & $1.16, \mathrm{~m}$ & & & & \\
\hline 9 & $1.14-1.31, \mathrm{~m}$ & $28.8-29.2$ & & & \\
\hline 10 & $1.14-1.31, \mathrm{~m}$ & $28.8-29.2$ & & & \\
\hline 11 & $1.21, \mathrm{~m}$ & 28.5 & & & \\
\hline 12 & $1.14-1.31, \mathrm{~m}$ & $28.8-29.2$ & & & \\
\hline 13 & $1.14-1.31, \mathrm{~m}$ & $28.8-29.2$ & & & \\
\hline 14 & $1.14-1.31, \mathrm{~m}$ & $28.8-29.2$ & & & \\
\hline 15 & $1.93, \mathrm{dt}(6.7,6.0)$ & 32.0 & $13 / 14,16,17$ & 16 & \\
\hline 16 & $5.35, \mathrm{dt}(15.4,6.0)$ & 131.5 & $14,15,17,18$ & 15 & \\
\hline 17 & $5.39, \mathrm{dt}(15.4,6.3)$ & 127.2 & $15,16,18,19$ & 18 & \\
\hline 18 & $2.01, \mathrm{dd}(6.3,6.0)$ & 40.6 & $16,17,19,20$ & 17,19 & \\
\hline 19 & $3.37, \mathrm{~m}$ & 69.9 & $17,18,20,22$ & $18,20 \mathrm{a} / \mathrm{b}$ & \\
\hline $20 \mathrm{a}$ & $1.33, \mathrm{~m}$ & 36.6 & & 19 & \\
\hline $20 \mathrm{~b}$ & $1.20, \mathrm{~m}$ & & & 19 & \\
\hline $21 \mathrm{a}$ & $1.46, \mathrm{~m}$ & 21.5 & $19,20,22,23$ & $20 \mathrm{~b}, 21 \mathrm{~b}$ & \\
\hline $21 \mathrm{~b}$ & $1.20, \mathrm{~m}$ & & $19,20,22,23$ & $21 \mathrm{a}$ & \\
\hline $22 \mathrm{a}$ & $1.29, \mathrm{~m}$ & 37.4 & & 23 & \\
\hline $22 b$ & $1.21, \mathrm{~m}$ & & & 23 & \\
\hline 23 & $3.33, \mathrm{~m}$ & 69.6 & $21,22,24,25$ & $22 \mathrm{a} / \mathrm{b}, 24 \mathrm{a} / \mathrm{b}$ & \\
\hline $24 a$ & $1.30, \mathrm{~m}$ & 37.2 & & 23 & \\
\hline $24 \mathrm{~b}$ & $1.24, \mathrm{~m}$ & & & 23 & \\
\hline $25 \mathrm{a}$ & $1.34, \mathrm{~m}$ & 25.3 & & $24 b, 25 b$ & \\
\hline $25 \mathrm{~b}$ & $1.23, \mathrm{~m}$ & & & $24 \mathrm{a}$ & \\
\hline 26 & $1.27, \mathrm{~m}$ & 25.6 & 28 & 27 & \\
\hline 27 & $1.49, \mathrm{~m}$ & 32.6 & $25,26,28$ & 26,28 & \\
\hline 28 & $3.35, \mathrm{t}(6.6)$ & 60.7 & 26,27 & 27 & \\
\hline $1^{\prime}$ & & Not observed & & & \\
\hline $2^{\prime}$ & $4.05, \mathrm{dd}(10.0,5.7)$ & Not observed & & $3^{\prime} \mathrm{a} / \mathrm{b}$ & $3^{\prime} \mathrm{a}, 4^{\prime}$ \\
\hline $3^{\prime} \mathrm{a}$ & 2.18, ddd $(15.0,10.0,5.0)$ & 35.5 & $4^{\prime}, 5^{\prime}$ & $2^{\prime}, 3^{\prime} \mathrm{b}, 4^{\prime}$ & $2^{\prime}, 4^{\prime}$ \\
\hline $3 ' b$ & $1.58, \mathrm{dm}(15.0)$ & & & $2^{\prime}, 3^{\prime} \mathrm{a}, 4^{\prime}$ & \\
\hline $4^{\prime}$ & $4.30, \mathrm{br} \mathrm{s}$ & 71.1 & $5^{\prime}$ & $3^{\prime} \mathrm{a} / \mathrm{b}, 4^{\prime}-\mathrm{OH}, 5^{\prime} \mathrm{a} / \mathrm{b}$ & $2^{\prime}, 3^{\prime} \mathrm{a}, 5^{\prime} \mathrm{a} / \mathrm{b}$ \\
\hline $4^{\prime}-\mathrm{OH}$ & 4.93, br s & & & $4^{\prime}$ & \\
\hline $5^{\prime} \mathrm{a}$ & 3.59, br d (11.7) & 53.4 & $4^{\prime}$ & $4^{\prime}, 5^{\prime} \mathrm{b}$ & $4^{\prime}$ \\
\hline $5^{\prime} \mathrm{b}$ & 3.08, br d (11.7) & & $4^{\prime}$ & $4^{\prime}, 5^{\prime} \mathrm{a}$ & $4^{\prime}$ \\
\hline
\end{tabular}


Table S10. Orthologous gene clusters identified in other fungal species. (NCBI accession number. of bua cluster MK425157)

\begin{tabular}{|c|c|c|c|c|c|c|c|c|c|}
\hline $\begin{array}{l}\text { A. burnettii } \\
\text { FRR } 5400\end{array}$ & & & & & & & & $\begin{array}{l}\text { BGC Similarity } \\
(\%)\end{array}$ & $\begin{array}{l}\text { BGC } \\
\text { Conservation } \\
(\%)\end{array}$ \\
\hline bua cluster designation & buaB & buaC & buaD & buaE & buaF & buaG & buaA & $\begin{array}{l}\text { (sum(protein } \\
\text { length * identity) / } \\
\text { maximum score) } \\
* 100 \\
\text { where maximum } \\
\text { score = sum }(100 * \\
\text { protein length) }\end{array}$ & $\begin{array}{l}\text { (number of } \\
\text { homologs / 7) } \\
100\end{array}$ \\
\hline Protein length (AA) & 490 & 427 & 455 & 319 & 412 & 503 & 3987 & $\begin{array}{l}\text { Maximum score }= \\
657000\end{array}$ & \\
\hline \multicolumn{10}{|l|}{$\begin{array}{l}\text { A. alliaceus } \\
\text { CBS } 536.65\end{array}$} \\
\hline Gene & $\begin{array}{l}\text { jgi.p_Aspalli1 } \\
\_77391\end{array}$ & $\begin{array}{l}\text { jgi.p_Aspalli1 } \\
\text { _319470 }\end{array}$ & $\begin{array}{l}\text { jgi.p_Aspalli1 } \\
\text { _319471 }\end{array}$ & $\begin{array}{l}\text { jgi.p_Aspalli1 } \\
\text { _274973 }\end{array}$ & $\begin{array}{l}\text { jgi.p_Aspalli1 } \\
274975\end{array}$ & $\begin{array}{l}\text { jgi.p_Aspalli1 } \\
\text { _319472 }\end{array}$ & $\begin{array}{l}\text { jgi.p_Aspalli1 } \\
\_310755\end{array}$ & & \\
\hline Identity (\%) & 98.98 & 69.76 & 82.56 & 100 & 97.62 & 98.81 & 99.17 & 96 & 100 \\
\hline Similarity (\%) & 99.39 & 69.96 & 83.3 & 100 & 97.86 & 99.01 & 99.32 & & \\
\hline \multicolumn{10}{|l|}{$\begin{array}{l}\text { A. mulundensis } \\
\text { DSM } 5745\end{array}$} \\
\hline Identity (\%) & 74.65 & 62.92 & 87.37 & 70.27 & 80.33 & 72.41 & 79.36 & 78 & 100 \\
\hline Similarity (\%) & 81.69 & 65.29 & 91.43 & 75.08 & 85.55 & 80.84 & 86.34 & & \\
\hline \multicolumn{10}{|l|}{$\begin{array}{l}\text { A. versicolor } \\
\text { CBS } 583.65\end{array}$} \\
\hline Gene & $\begin{array}{l}\text { ASPVEDRAFT } \\
\text { _97195 }\end{array}$ & $\begin{array}{l}\text { ASPVEDRAFT } \\
\_126247\end{array}$ & $\begin{array}{l}\text { ASPVEDRAFT } \\
\_50570\end{array}$ & $\begin{array}{l}\text { ASPVEDRAFT } \\
\_80633\end{array}$ & $\begin{array}{l}\text { ASPVEDRAFT } \\
\_25846\end{array}$ & $\begin{array}{l}\text { ASPVEDRAFT } \\
\_80635\end{array}$ & $\begin{array}{l}\text { ASPVEDRAFT } \\
\_162657\end{array}$ & & \\
\hline Identity (\%) & 62.73 & 60.16 & 67.7 & 70.86 & 71 & 72.87 & 79.84 & 75 & 100 \\
\hline Similarity (\%) & 70.88 & 64.10 & 73.18 & 76.38 & 78.31 & 81.98 & 86.85 & & \\
\hline \multicolumn{10}{|l|}{$\begin{array}{l}\text { E. nigrum } \\
\text { ICMP } 19927\end{array}$} \\
\hline Gene & B5807_02540 & B5807_02539 & & & & B5807_02536 & B5807_02542 & & \\
\hline Identity (\%) & 39.88 & 38.89 & & & & 42.00 & 48.90 & 38 & 57.14 \\
\hline Similarity (\%) & 54.31 & 50.19 & & & & 57.80 & 63.45 & & \\
\hline \multicolumn{10}{|l|}{$\begin{array}{l}\text { P. cf. Hyalina } \\
\text { BP } 5553\end{array}$} \\
\hline Similarity (\%) & 51.94 & 52.47 & & & & & 63.99 & & \\
\hline
\end{tabular}


Table S11. Plasmids used in this study.

\begin{tabular}{|l|l|l|}
\hline Plasmid Name & Plasmid backbone & Description of plasmid \\
\hline pYFAC-CL10 & pYFAC-pyrG & $\begin{array}{l}\text { Aspergillus nidulans expression vector containing gene } \\
\text { buaA under the alcA promoter. }\end{array}$ \\
\hline pYFAC-CL11 & pYFAC-ribo & $\begin{array}{l}\text { Aspergillus nidulans expression vector containing } \\
\text { genes buaC under the alcA promoter. }\end{array}$ \\
\hline pYFAC-CL12 & pYFAC-ribo & $\begin{array}{l}\text { Aspergillus nidulans expression vector containing } \\
\text { genes buaC under the alcA promoter and alpE under } \\
\text { the alcS } \text { promoter. }\end{array}$ \\
\hline pYFAC-CL13 & pYFAC-ribo & $\begin{array}{l}\text { Aspergillus nidulans expression vector containing } \\
\text { genes buaC under the alcA promoter, alpE under the } \\
\text { alcS promoter and alpG under the aldA promoter. }\end{array}$ \\
\hline pYFAC-CL14 & pYFAC-pyrO & $\begin{array}{l}\text { Aspergillus nidulans expression vector containing } \\
\text { genes buaB under the alcA promoter, alpD under the } \\
\text { alcS } S \text { promoter and alpF under the aldA promoter. }\end{array}$ \\
\hline
\end{tabular}




\section{SUPPLEMENTARY FIGURES}

a)

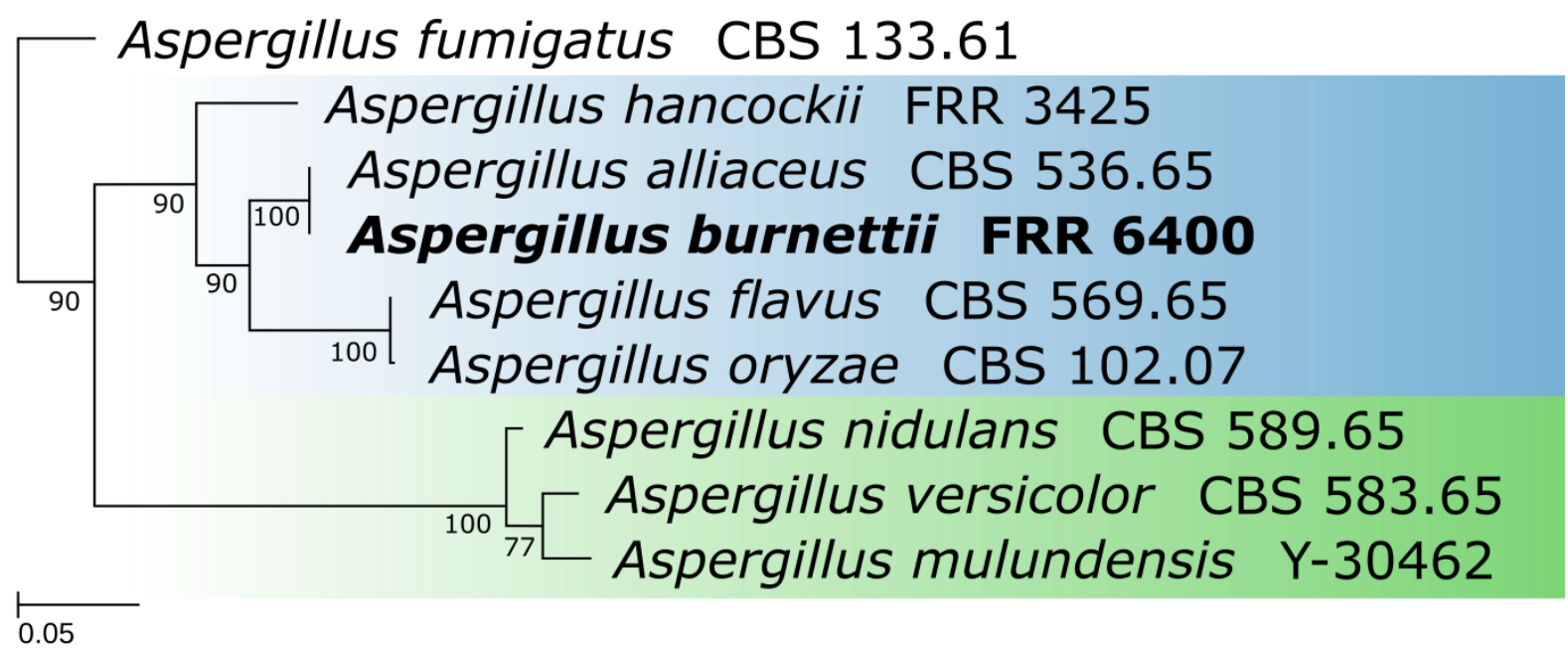

b)

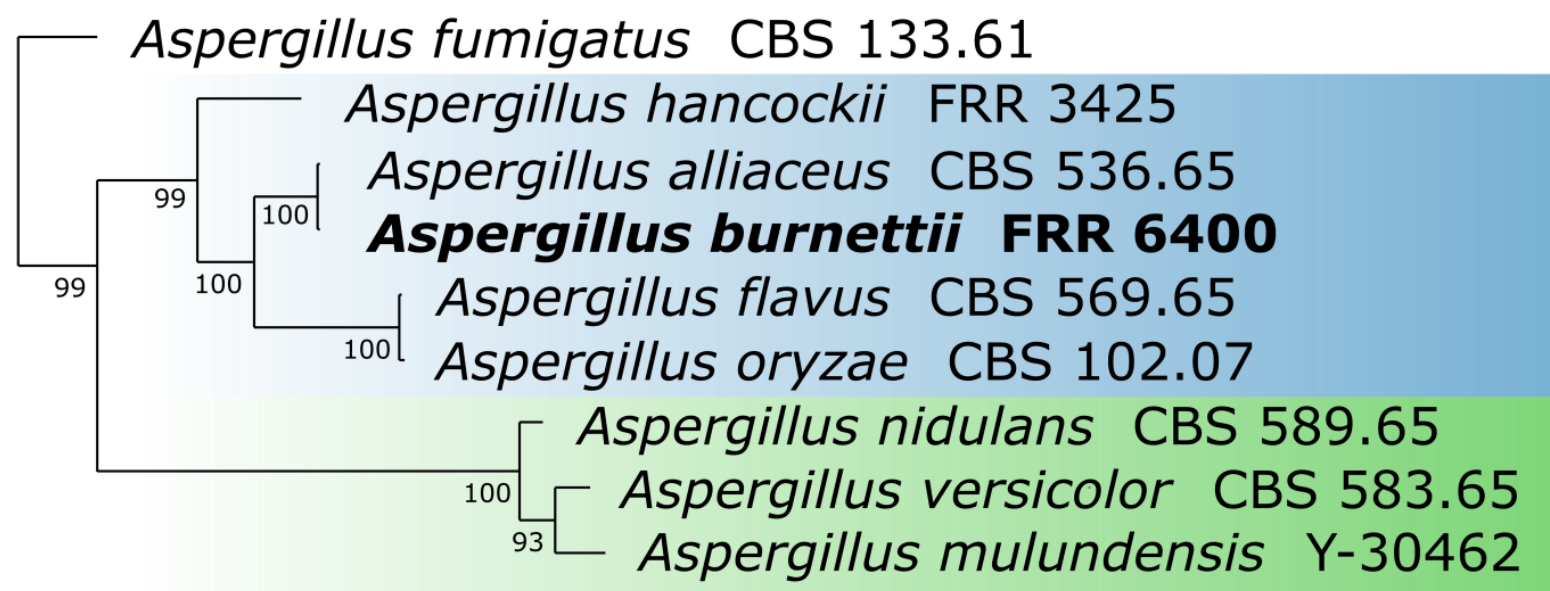

○ section Flavi $\bigcirc$ section Nidulantes

Figure S1. Phylogenetic analyses of Internal Transcribed Spacer (ITS) regions of Aspergillus species in sections Flavi and Nidulantes constructed using a) RAxML-NG v0.6.0 and b) MrBayes v3.2.6. A. burnettii clades with section Flavi, with its closest neighbour being A. alliaceus. (A. burnettii ITS sequence NCBI accession number. MK429758) 
(A)

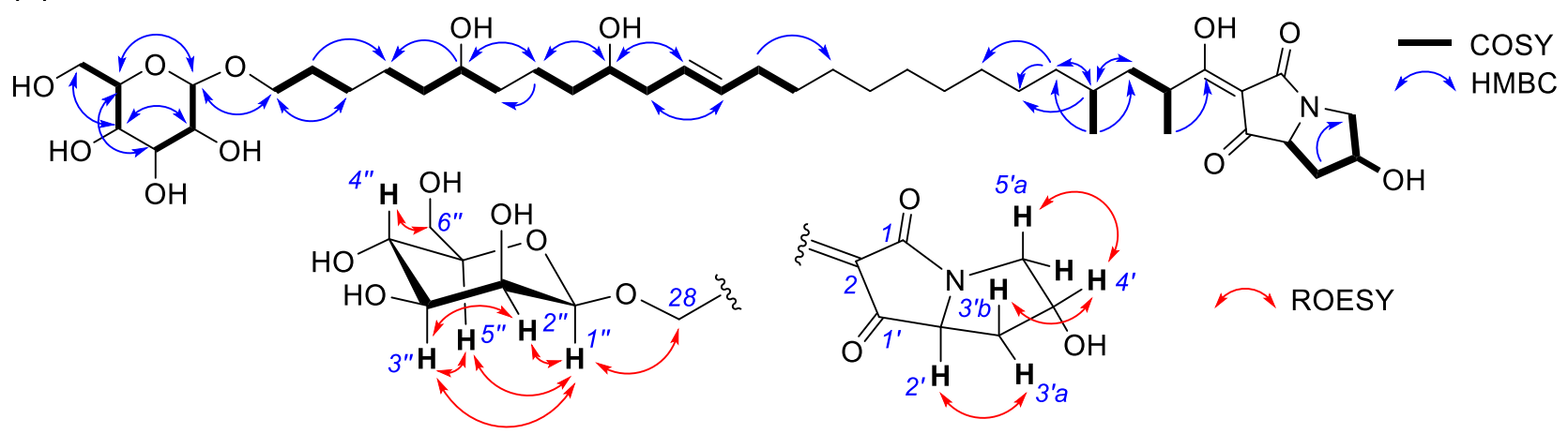

(B)

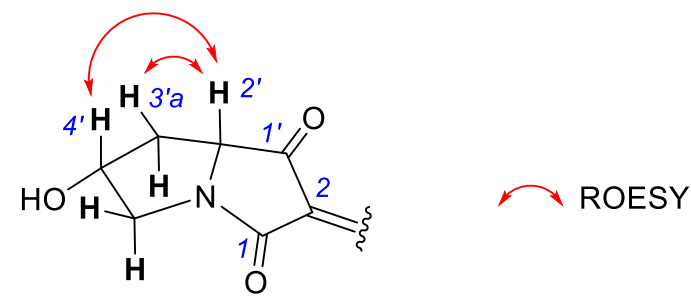

Figure S2. 2D NMR correlations for (A) burnettramic acid A (1) and (B) burnettramic acid B (2)

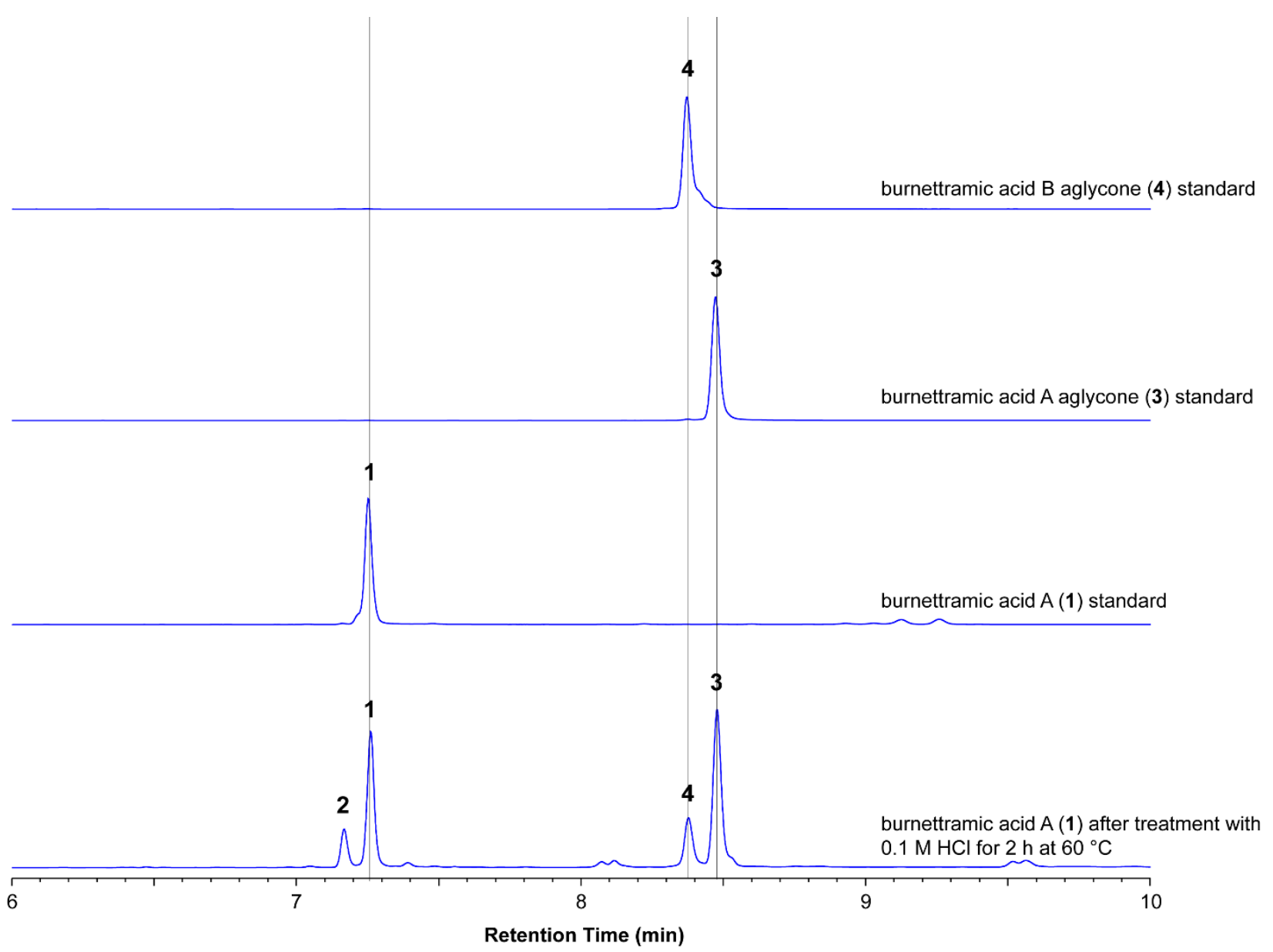

Figure S3. HPLC trace $(280 \mathrm{~nm})$ of reaction mixture following treatment of burnettramic acid A (1) with $0.1 \mathrm{M} \mathrm{HCl}$ for $2 \mathrm{~h}$ at $60{ }^{\circ} \mathrm{C}$. The new peak at 7.17 min corresponds to burnettramic acid B (2). 


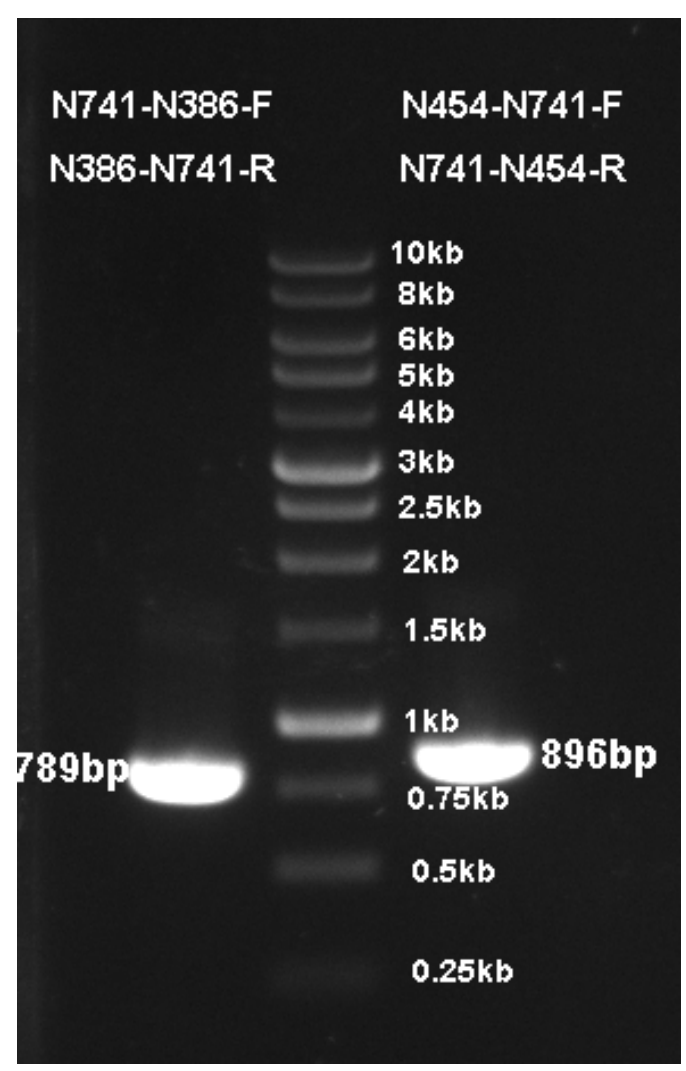

Figure S4. Primer positions used to verify the connection between scaffolds N386/N454 and N454/N741, respectively and PCR products of 896 bp linking scaffolds N454/N741 and of $789 \mathrm{bp}$ linking scaffolds N741/N386. 


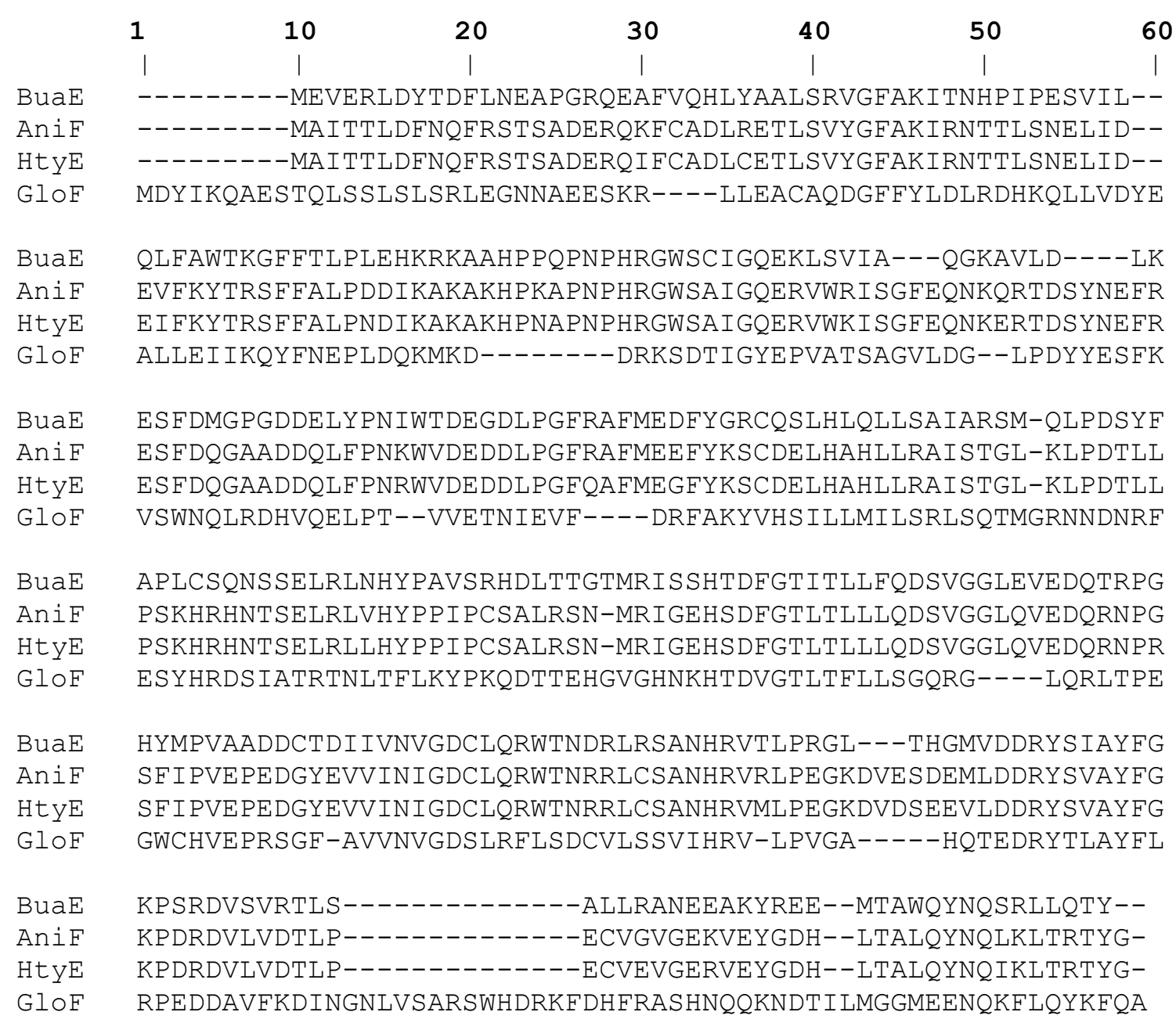

Figure S5. Multiple sequence alignment of proline hydroxylases constructed using MUSCLE. BuaE from the bua cluster in the present study; AniF from the echinocandin B BGC in A. nidulans NRRL 8112; HtyE in the echinocandin B BGC in Emericella rugulosa NRRL 11440; and GloF from the pneumocandin BGC in Glarea lozoyensis ATCC 74030. 


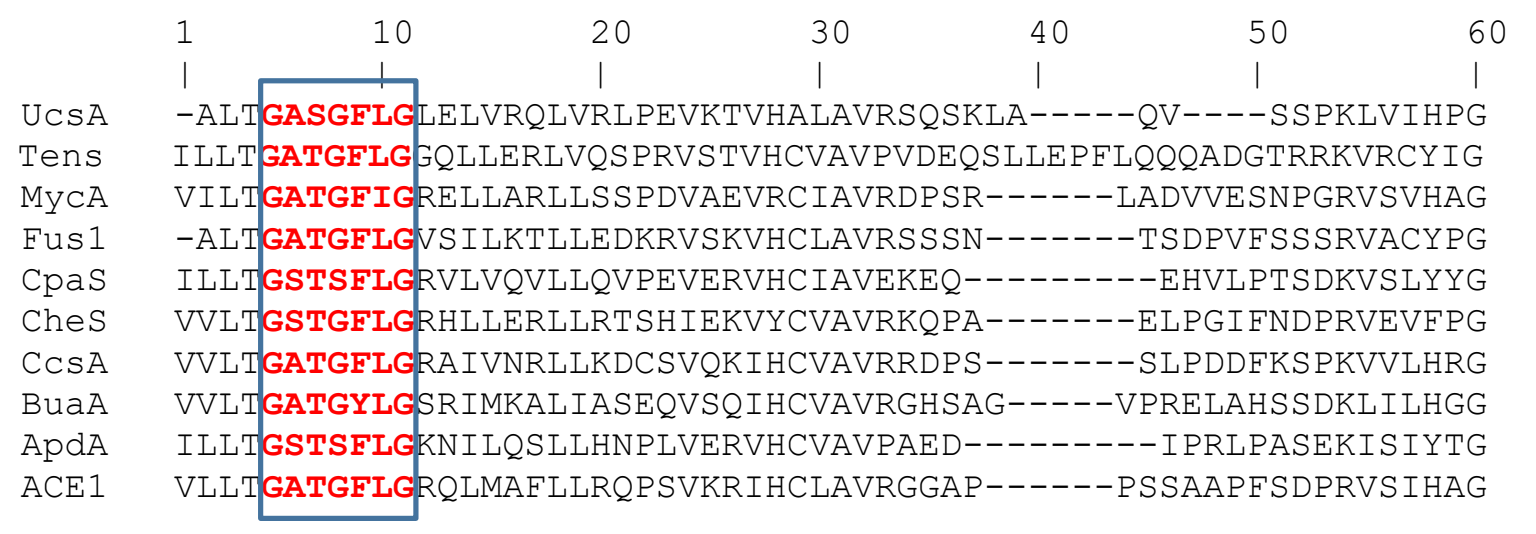

UCSA DLSKPQLGLTDTAATEVFKTSHAVIHNGADVSFLKAYGSVRRTNLESTKDIVKLALQHGN Tens NLAAPALGLTAADQTALSQTADVIVHAGSMGHCLNTYATLSAPNFASTRHLCALALSRSP MYCA DLTSVEETVGEEDEQRLFADAHAVIHCGADVSFLKTYATLRRANVGSTKALARLA--LRH Fus1 DLSLPRLGLSQEQFDQLAKTVERI I HNGADVSFLKTYQSLKRSNVSSSRELARMA--ITR CPaS SLLDPNLGLSTAEWASLQDRIDVVI HNGSNGHCLNTYNSLKGPNLGSTHRLAEFA--LQS CheS DLSLAGLGLSDADTERVFSTADAVLHNGADVSFMKTYISLRPTNVAATQQLAALAQRQGR CCSA DLTLPQLGLTDRAATEIFAEADAVIHNGADVSFMKTYQSLKQANLEATKELVRLS--APH BUaA HLEDPLLGMSEEEFTFVARETDLVIHSGANRSFWDHYERLRGPNVLSTKTLVDLA--LQN ApdA SLLTPSLGLTKTEIAVLQSSLDVIIHAGSTGHCLNNYSSLRASNVDSTKFLAAIA--LLC ACE1 DLNAPHLGLGEAVAELLFAQADVI I HNGADVSFLKTYATLRATNVGSTRELARLA--APR

UCSA VRHLHYISTAGIATM---------L--GHDLYEESLGAFPP---TSSPEG----YVLSK Tens PIPLAFASSNRVALL---------T-GSTAPPPGSAAAFPP---PPGAQ----GFTASK MYCA GLDFHYVSTAATGRLLLVADPSSSPTARGDVFGEESVAAYPP---PPGWLDH---YVASK Fus1 RIPVHFVSTGGVVQLT---------GQDGLDEVSVADSVP---PTDGSLG---YVASK CPaS QIPLHYISSGRVILQS----------GQTALGPTSVSFHPP---PLDGSDG---LTATK CheS RIPFHFVSSAAVTQLT----------PLDEVGEVSVAAYPPAVSSPSSSSSAGGYVAAK CCSA RLSFHYISSASVTRLA----------GQESFDQSSVSAFPP---SAED-----GYVASK BuaA QAPLHFISSGGVHLLC----------SGEDYAAESLASYLP---PTDGSN---GFIASK ApdA RIPIHFISSNRVTLLS----------GSTSLPPASVSSSLP---NTDGSE---GFTASK ACE1 RIPFHFVSSASITQLT----------GLDEFGEASMAAWAP---PADPRGMSGGYAAAK

UCSA WASELYLERASAVTG-----------L-P---VTIHRPTAIVGENAPHLDVMSNILHYSR Tens WASEAFLEKLTASMSDVSKTKTKTTTTVMPWRVS IHRPCALISDRAPNS DALNA ILRYST MYCA WASEAFLERAAARLG----------L-----RVWVHRPTSVTGPGAGETDVMSTVMRFAK Fus1 WASEVILEKYASQYN-------L-------PVWIHRPSNITGPNAPKADLMQNIFHYSV CPAS WASEVFLERLAEHTDI------S--------ISIHRPCTPIGDQAPAQDALNSLLRYSV CheS WVSERHLEQVAQAHGL-------P-------VTIHRPSS ILGNDASDVDLMGNLFRYVE CCSA WASERYLEKVSDQCGL------P--------IWIHRPSS IVGEGAPDTDMMASLLGYSR BUaA WASEVYLEKAAQKTSL------P--------VYVHRLT------------------ApdA WASERLLESVANLASGL-----P-------VTIHRPCAVFGEEAPNEDALNALLKYSK ACE1 WASEVLLEKAARAWGL------P--------VVIHRPSS ITGEGTNSLDLMGNMFKYIE

UCSA QMATVPSM-SA-LEGTFQFVPVEDVAGGI-

Tens SMRCVPSLPEHRAEGYLDFGQVDKVVEEMV

MYCA KLRAVPV--SSRWRGSLDFVPVETVADGIV

Fus1 KTASLPDLAS--WSGCFDFVPVDVVAAGIA

CPAS NLGATPRLTR--MEGYLDFQKVEIIAQEIA

CheS RLQAVPESRD--WKGYFDLISVHTVAAAIV

CCSA TLRAIPQTDG--WTGWLDFVSADRVAMQIA

BUAA -----------------------

ApdA LTRCVPRFEN--FEGYLDFEDVHRVAATIA

ACE1 QLEAVPESDS--WKGNFDFVSVENVAADIV

Figure S6. Sequence alignment of the R domain from fungal PKS-NRPSs utilizing both the DKC mode of release (TenS, CpaS, and ApdA) and a predicted reductive release (ACE1, Fus1, CcsA, CheS, UcsA and MycA). 
Note: Sequences were obtained from NCBI and submitted to antiSMASH4 to identify domain boundaries. ${ }^{[10]}$ The resultant C-terminal domains were aligned using Geneious. The blue dashed box indicates the conserved NADH/NADPH binding domain; the blue solid squares indicate the SDR Ser-Tyr-Lys catalytic triad; the yellow square indicates the Tyr $\rightarrow$ Phe / Leu mutation which abolishes the reductase activities. $\mathrm{R}$ represents the abbreviation of reductase. Protein name abbreviations: TenS (tenellin synthase), CpaS (cyclopiazonic acid synthase, A. flavus NRRL3357), ApdA (aspyridone synthase), Fus1 (fusarin synthase), CcsA (cytochalasin synthase, ACLA_078660, CheS (chaetoglobosin synthase, CHGG_01239), MycA (myceliothermophin A synthase, $M$. thermophile ATCC 42462), UcsA (UCS1025A synthase, Myceliophthora thermophila ATCC 42464). 
A
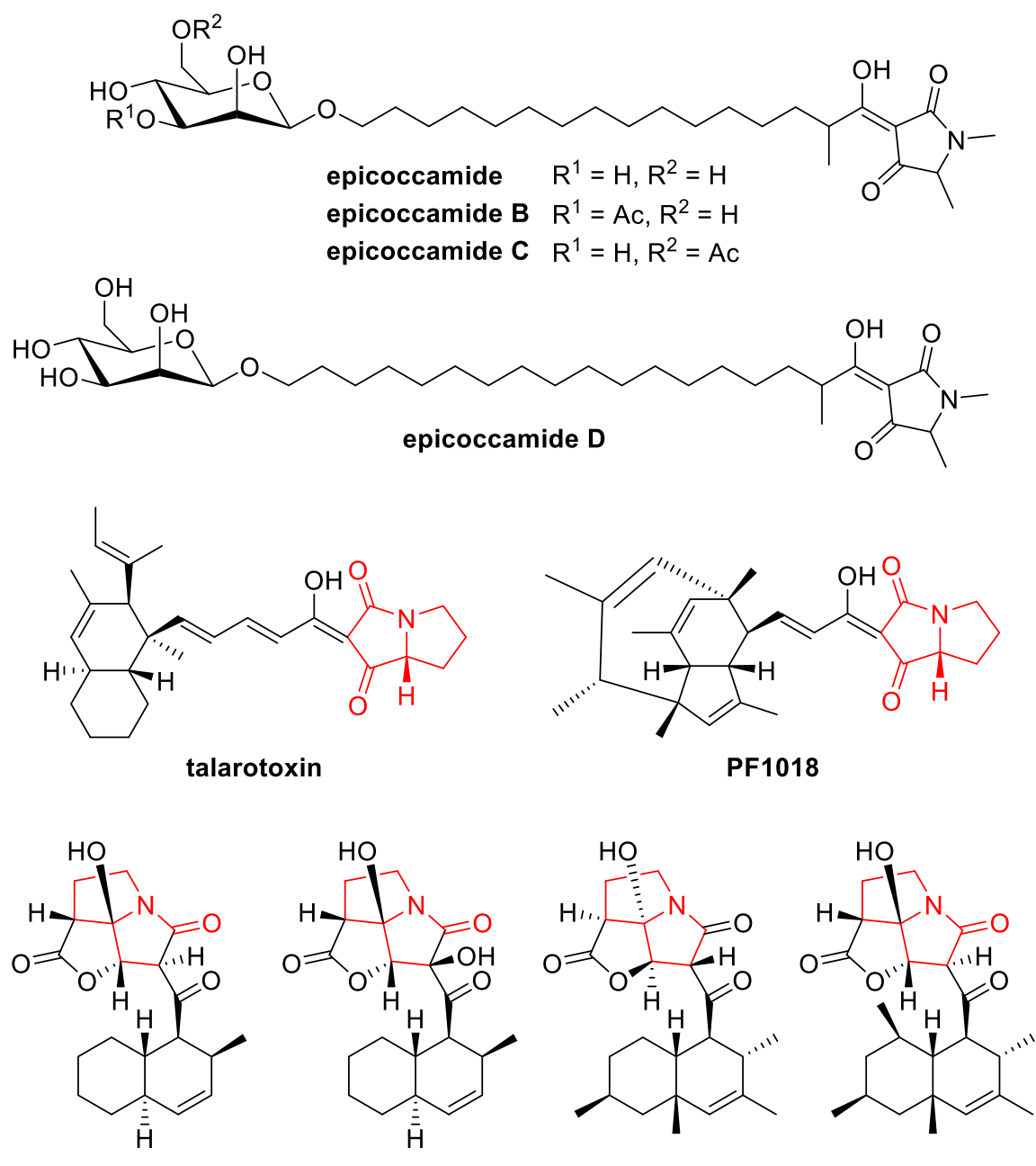

B

UCS1025A

UCS1025B

CJ-16264

pyrrolizilactone

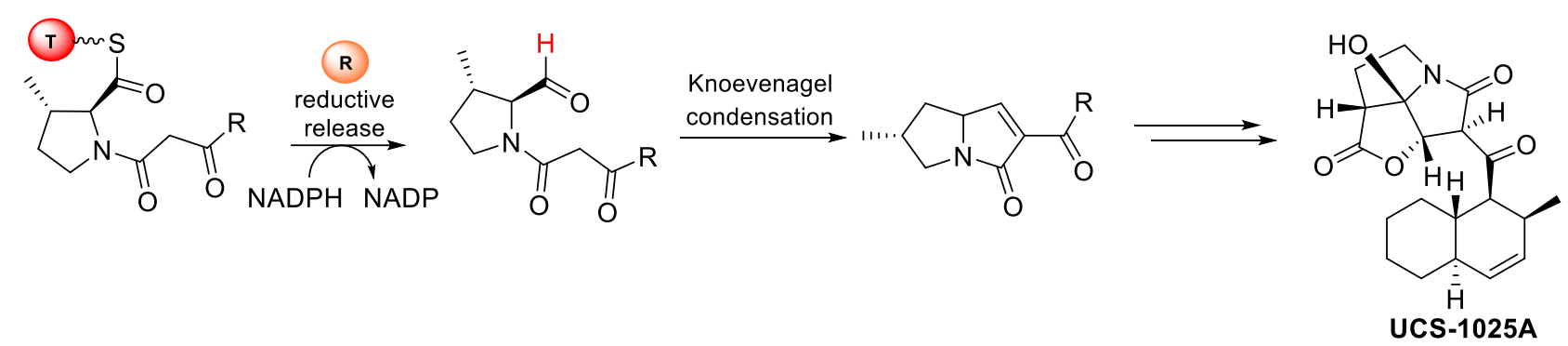

Figure S7. (A) The structures of epicoccamides (top) and pyrrolizidinone alkaloids from fungi (pyrrolizidinone core highlighted in red) (B) the proposed PKS-NRPS-derived biosynthetic pathway of UCS-1025A. ${ }^{[11]}$ 


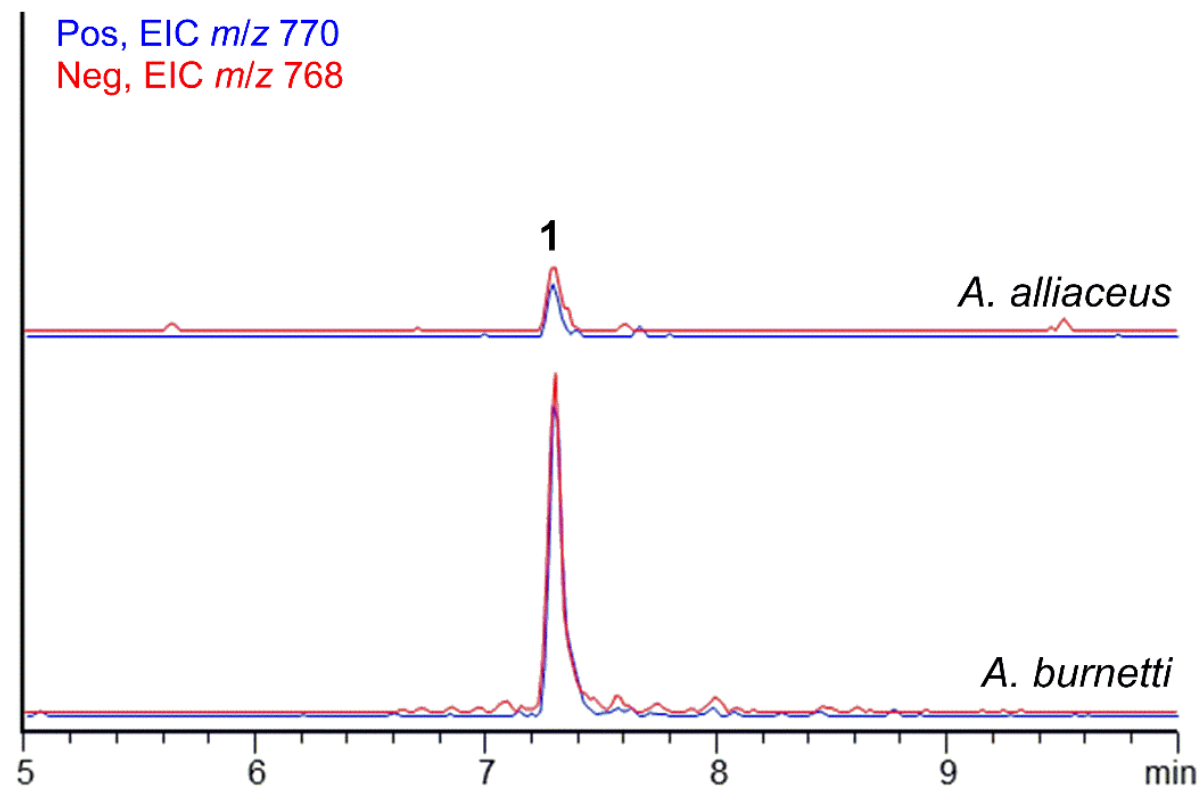

Figure S8. Comparison of the extracted ion chromatogram (EIC) of the metabolite profiles of Aspergillus alliaceus and Aspergillus burnetti indicating the presence of burnettramic acid A (1). The production of $\mathbf{1}$ in A. alliaceus is much lower than A. burnetti on Czapek-Dox agar extracted after 14 days of growth. 


\section{A}

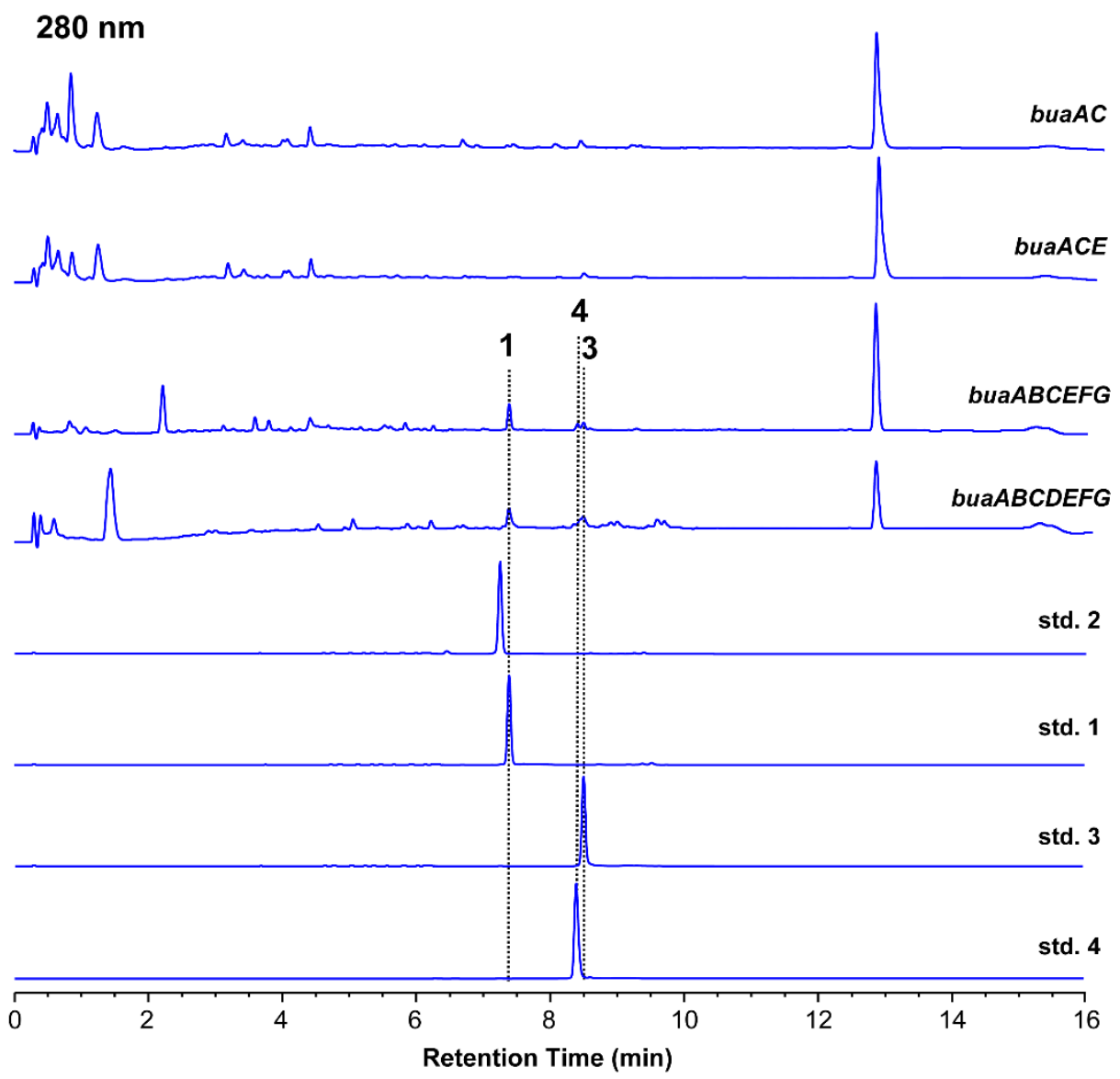

B

Pos, EIC $m / z 608,770$

buaAC

buaACE

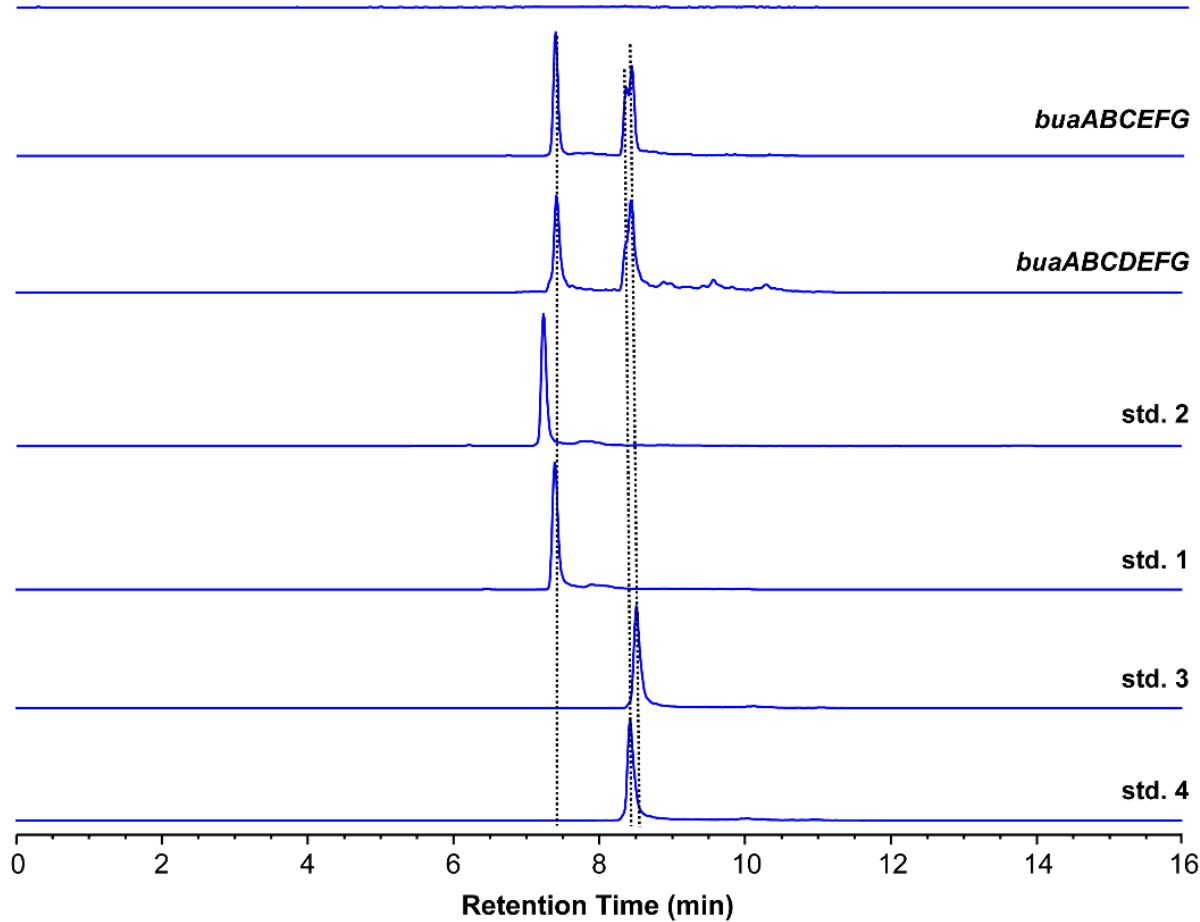

Figure S9. Chromatograms of $A$. nidulans expressing bua genes compared to standards. A) HPLC traces at $280 \mathrm{~nm}$. B) Extracted ion chromatograms (EIC) at $\mathrm{m} / \mathrm{z}, 608$ and 770. 


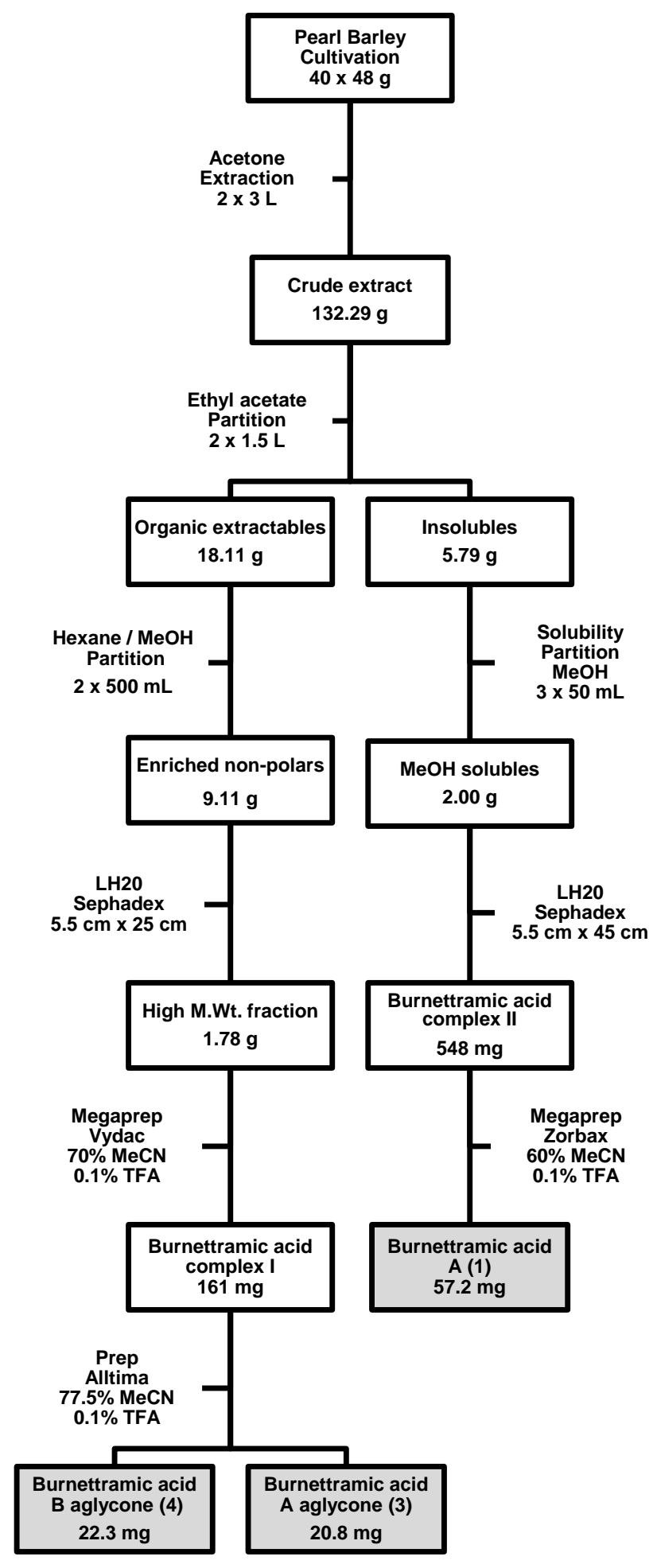

Figure S10. Flow chart of the isolation of burnettramic acids from A. burnettii 


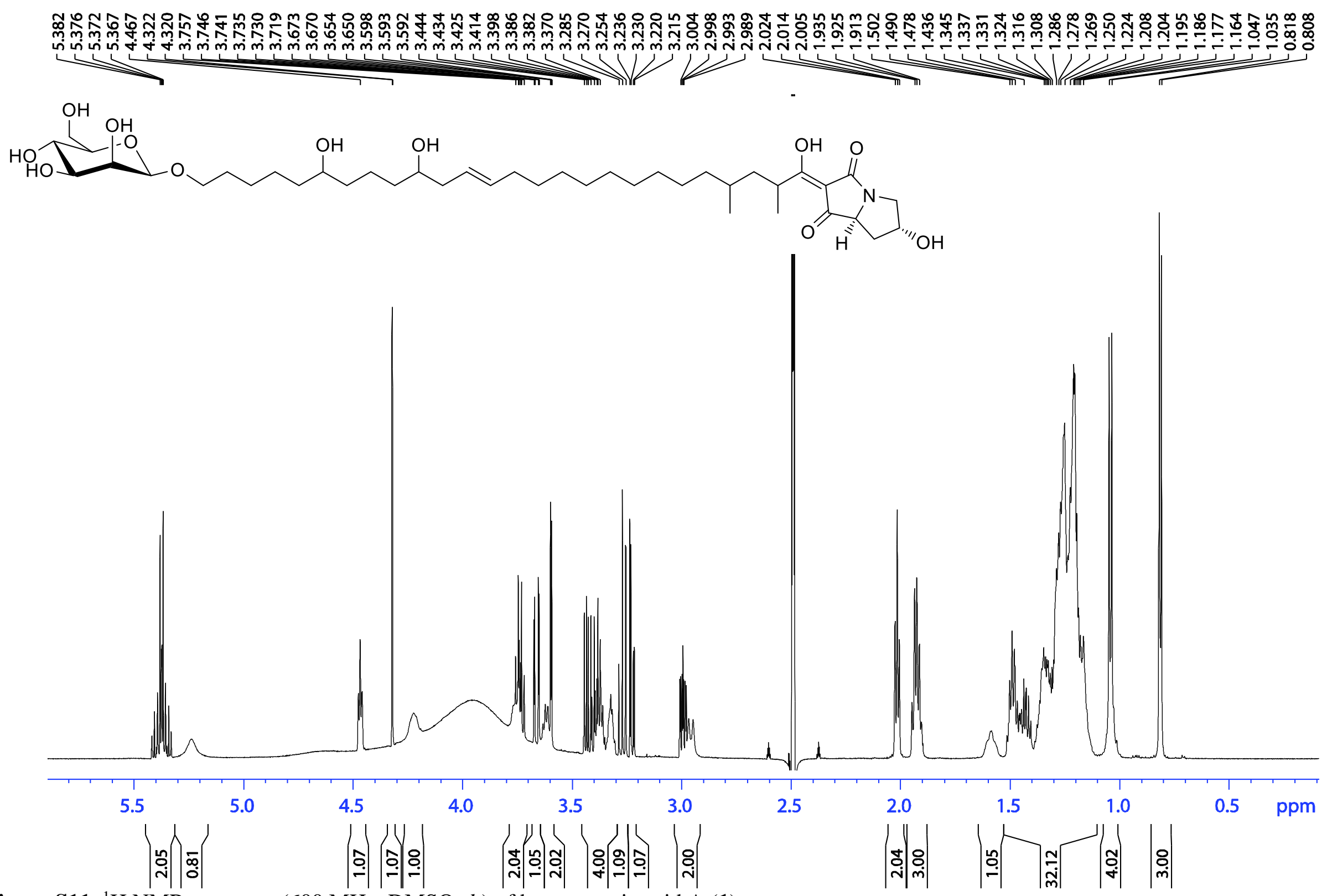

Figure S11. ${ }^{1} \mathrm{H}$ NMR spectrum $\left(600 \mathrm{MHz}, \mathrm{DMSO}-d_{6}\right)$ of burnettramic acid A (1) 


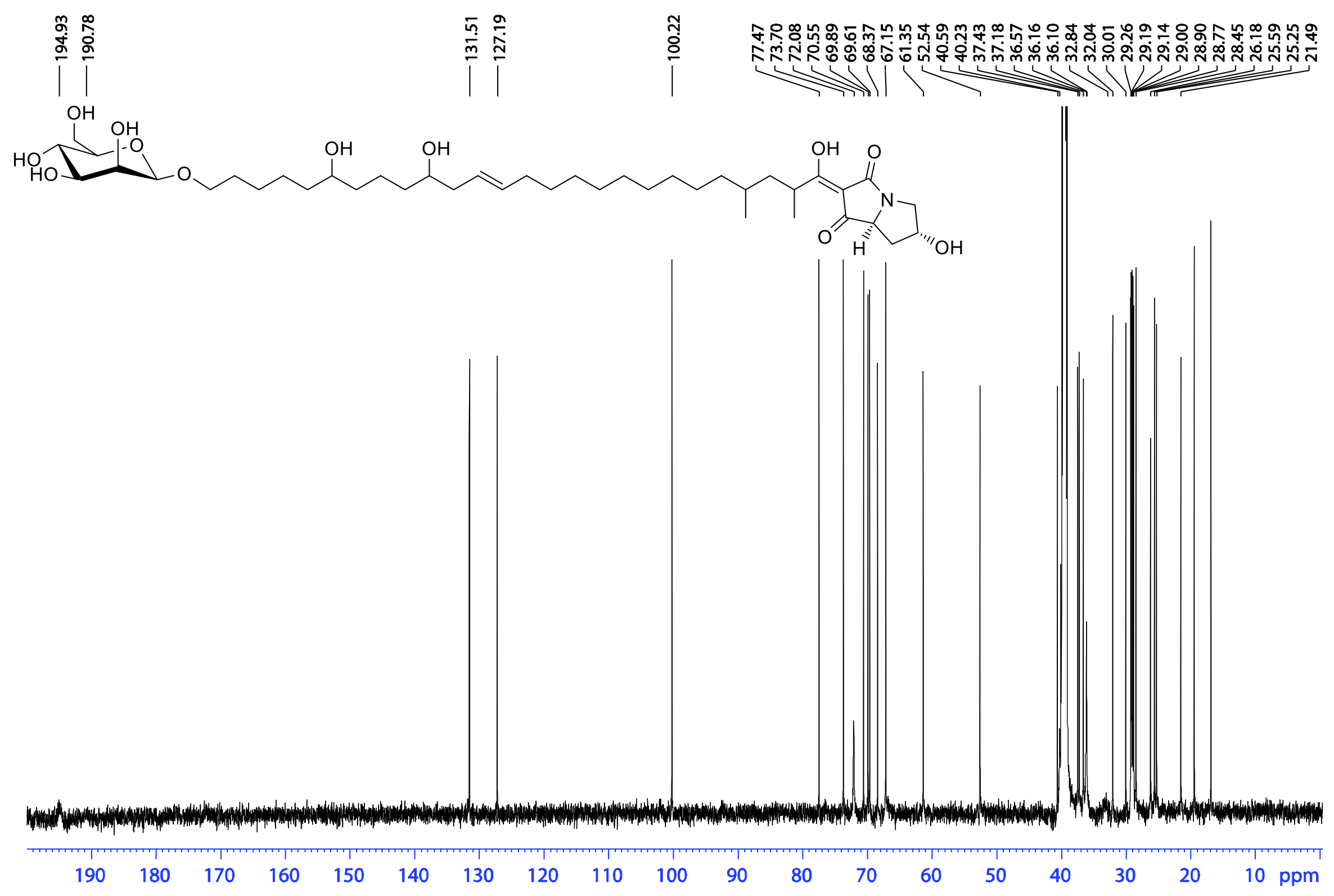

Figure S12. ${ }^{13} \mathrm{C}$ NMR spectrum $\left(150 \mathrm{MHz}, \mathrm{DMSO}-d_{6}\right)$ of burnettramic acid A (1) 


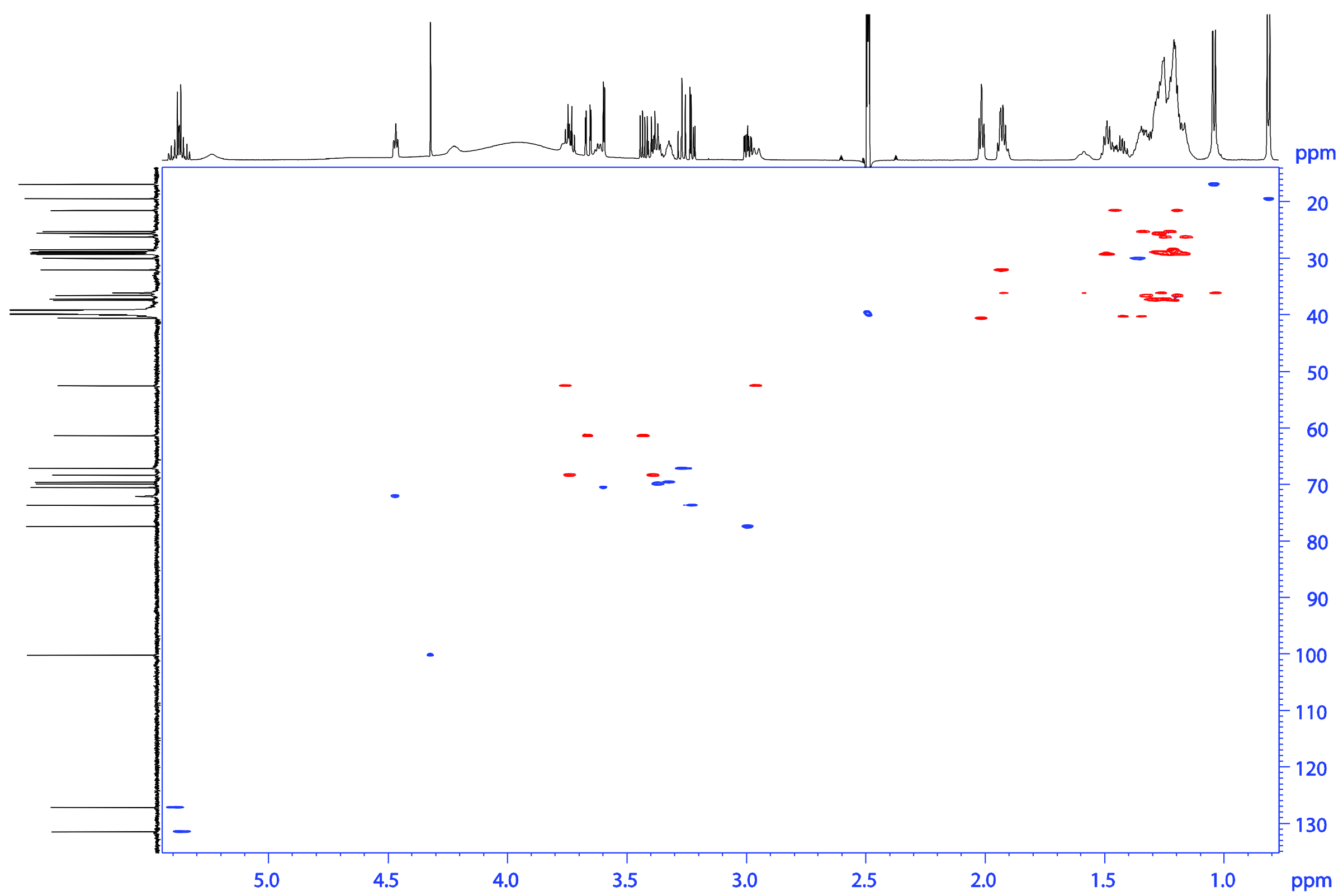

Figure S13. ${ }^{1} \mathrm{H}_{-}{ }^{13} \mathrm{C}$ HSQC NMR spectrum $\left(600 \mathrm{MHz}\right.$, DMSO- $\left.d_{6}\right)$ of burnettramic acid A (1) 


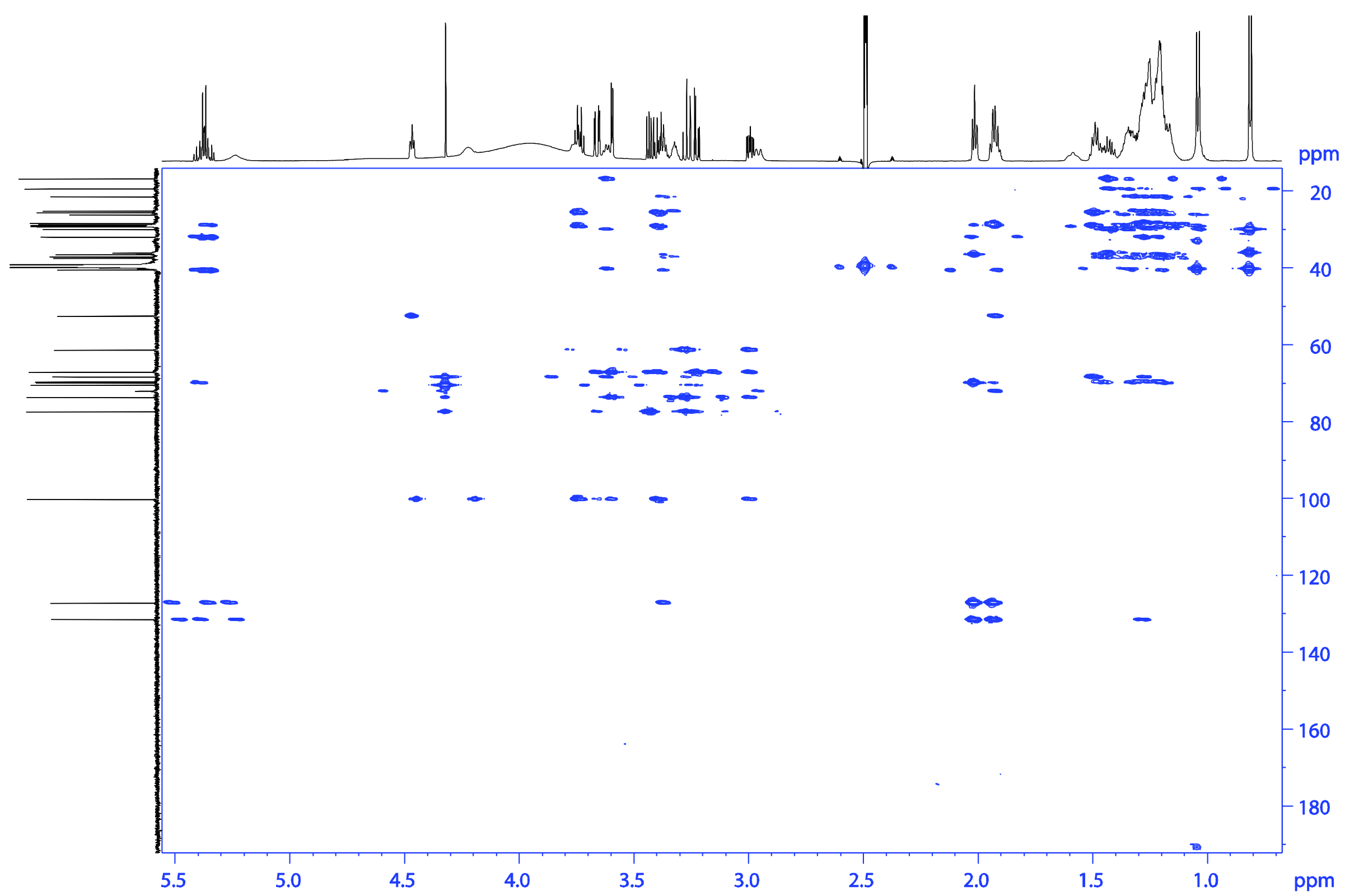

Figure S14. ${ }^{1} \mathrm{H}_{-}{ }^{13} \mathrm{C}$ HMBC NMR spectrum (600 MHz, DMSO- $d 6$ ) of burnettramic acid A (1) 


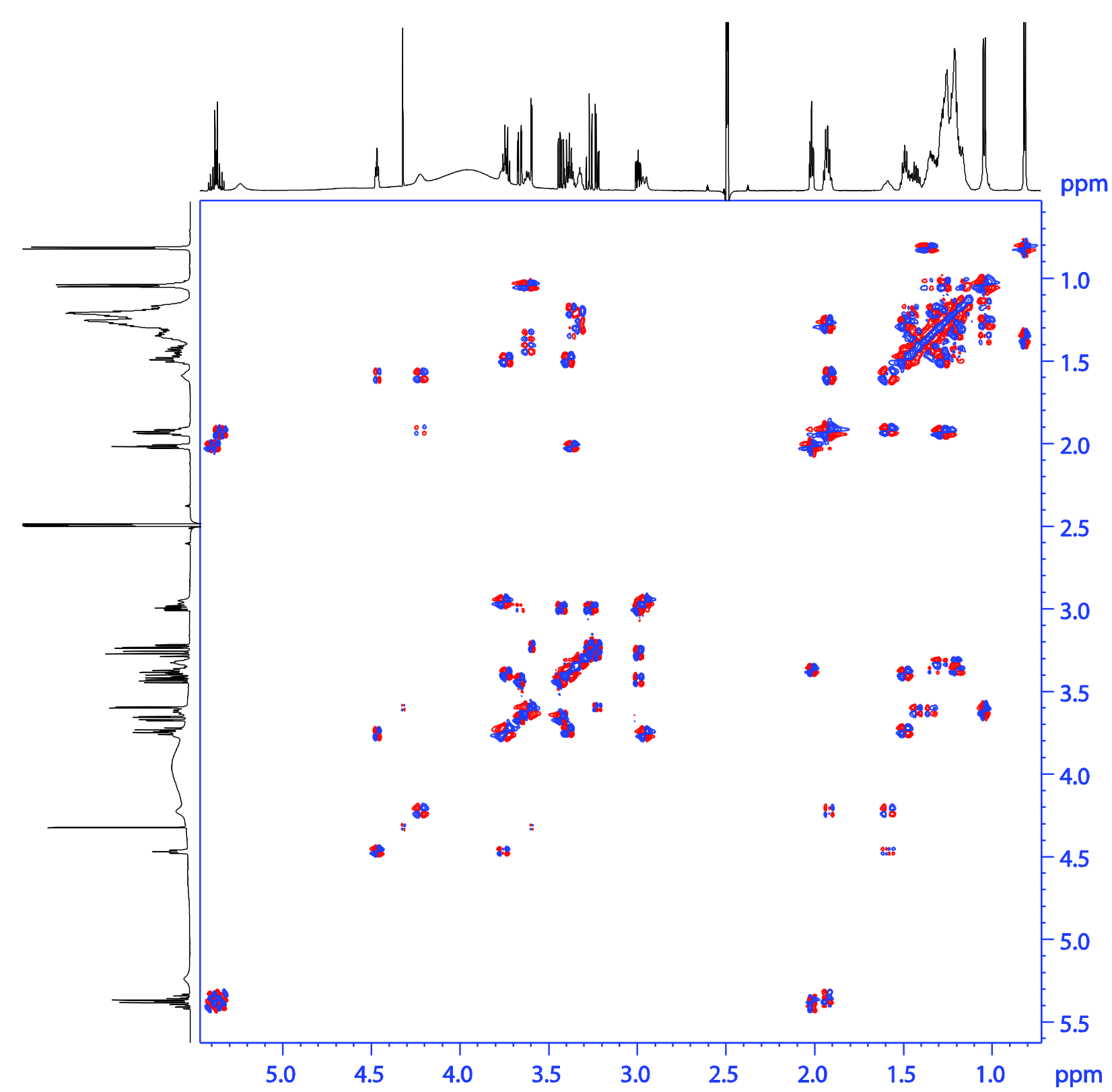

Figure S15. ${ }^{1} \mathrm{H}-{ }^{1} \mathrm{H}$ COSY NMR spectrum $\left(600 \mathrm{MHz}, \mathrm{DMSO}-d_{6}\right)$ of burnettramic acid A (1) 


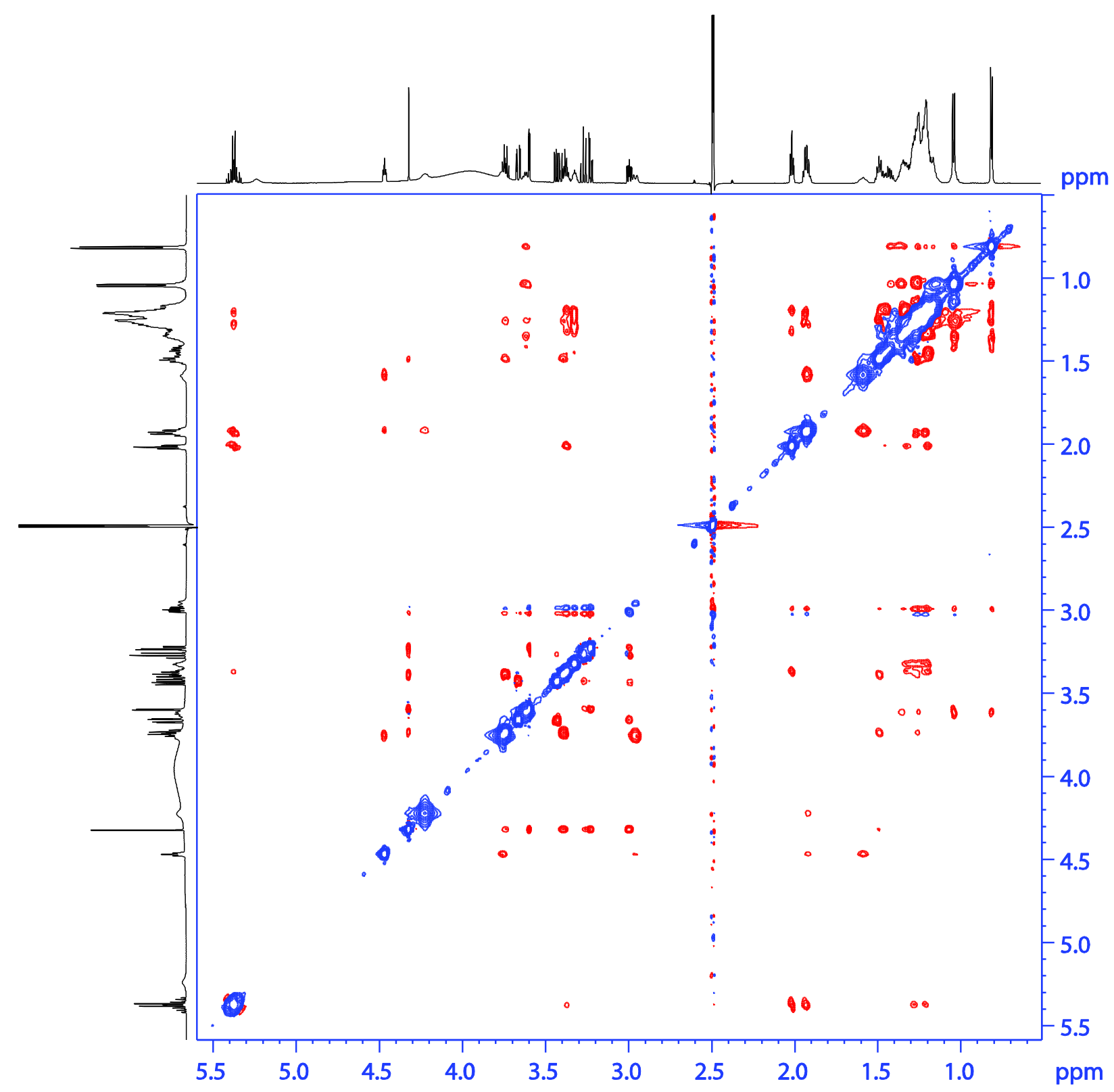

Figure S16. ${ }^{1} \mathrm{H}-{ }^{1} \mathrm{H}$ ROESY NMR spectrum (600 MHz, DMSO- $\left.d_{6}\right)$ of burnettramic acid A (1) 


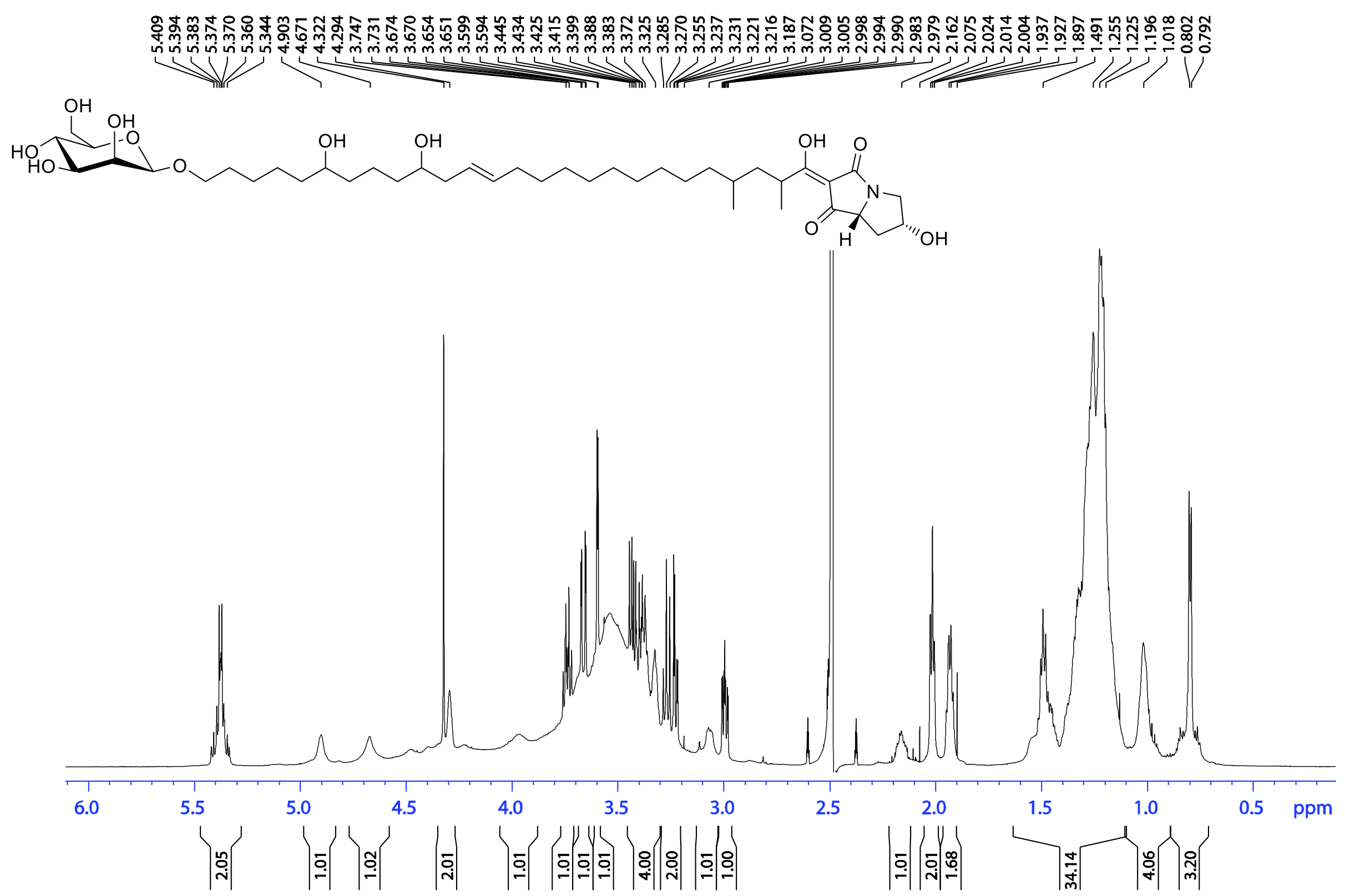

Figure S17. ${ }^{1} \mathrm{H}$ NMR spectrum (600 MHz, DMSO- $d 6$ ) of burnettramic acid B (2) 


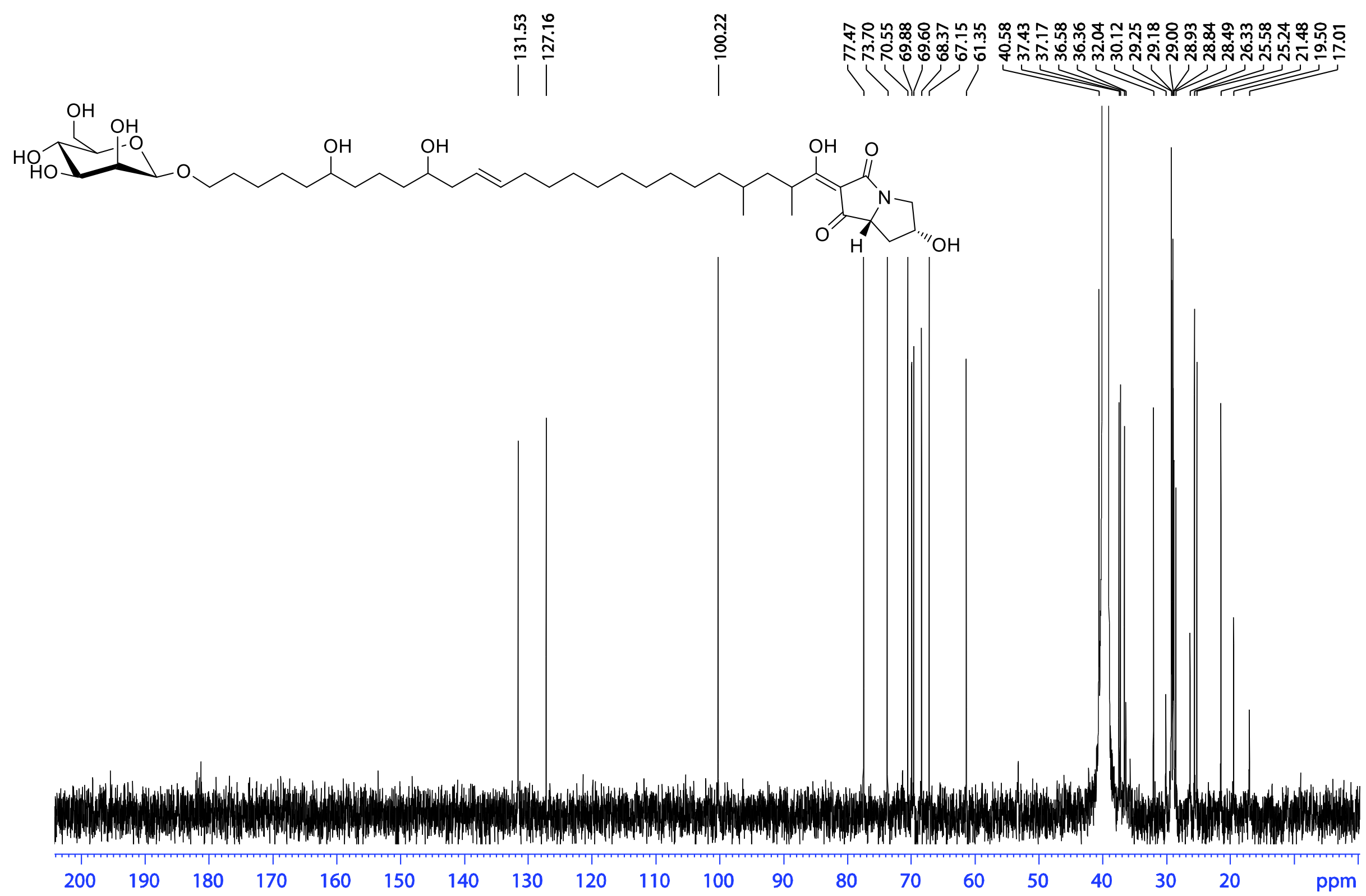

Figure S18. ${ }^{13} \mathrm{C}$ NMR spectrum $(150 \mathrm{MHz}, \mathrm{DMSO}-d 6)$ of burnettramic acid B (2) 


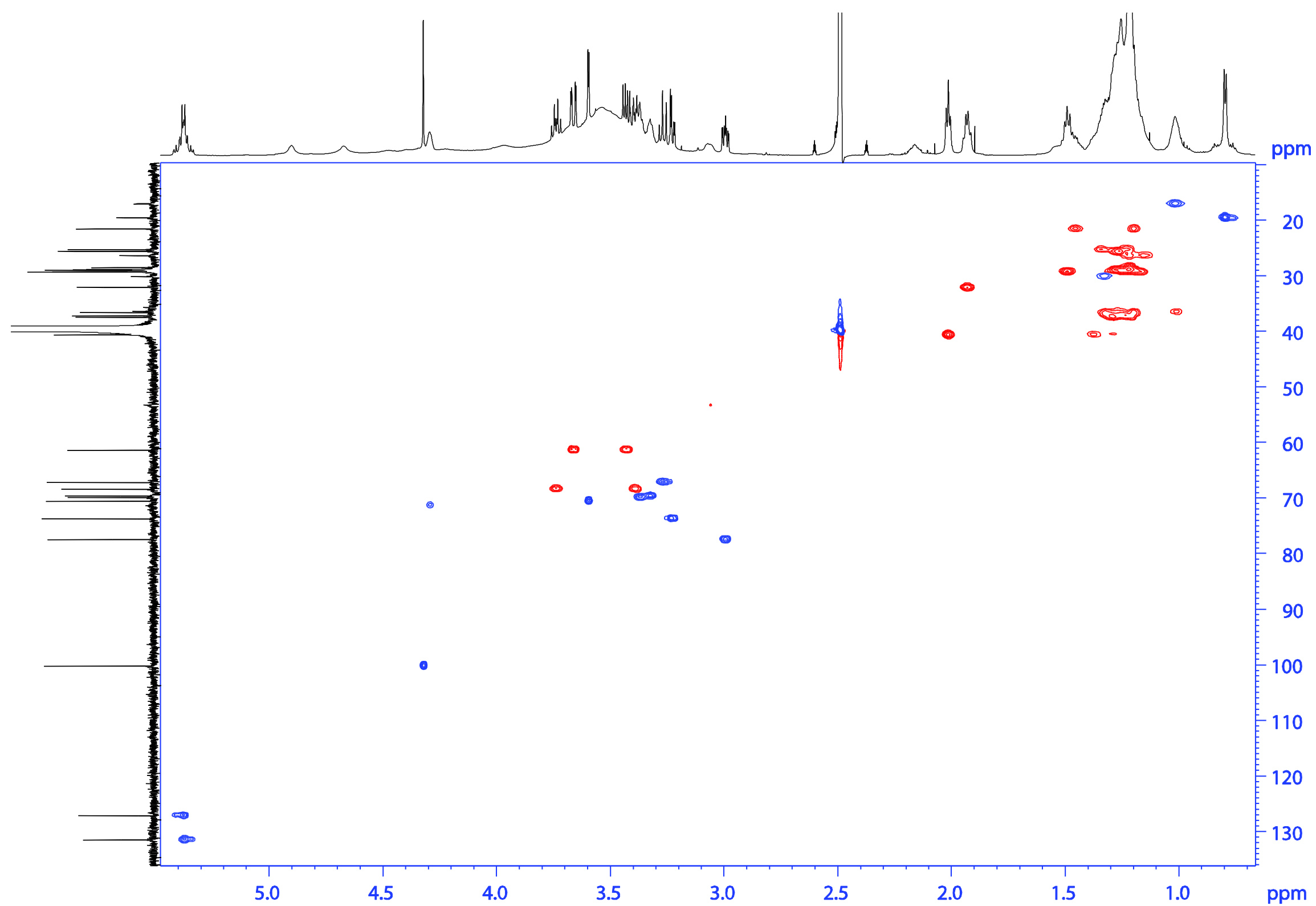

Figure S19. ${ }^{1} \mathrm{H}_{-}{ }^{13} \mathrm{C}$ HSQC NMR spectrum (600 MHz, DMSO- $d_{6}$ ) of burnettramic acid B (2) 


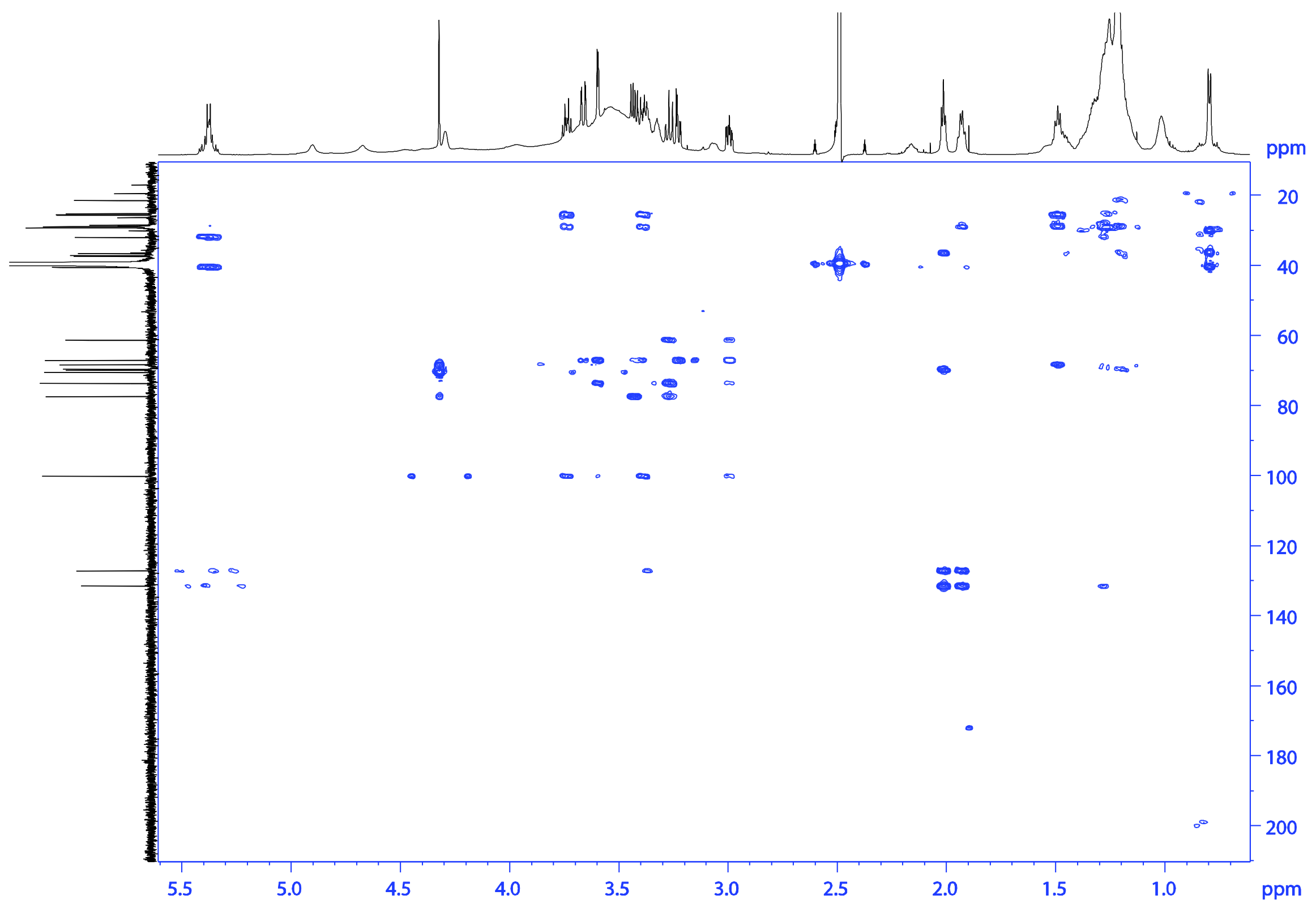

Figure S20. ${ }^{1} \mathrm{H}_{-}{ }^{13} \mathrm{C}$ HMBC NMR spectrum (600 MHz, DMSO- $d 6$ ) of burnettramic acid B (2) 


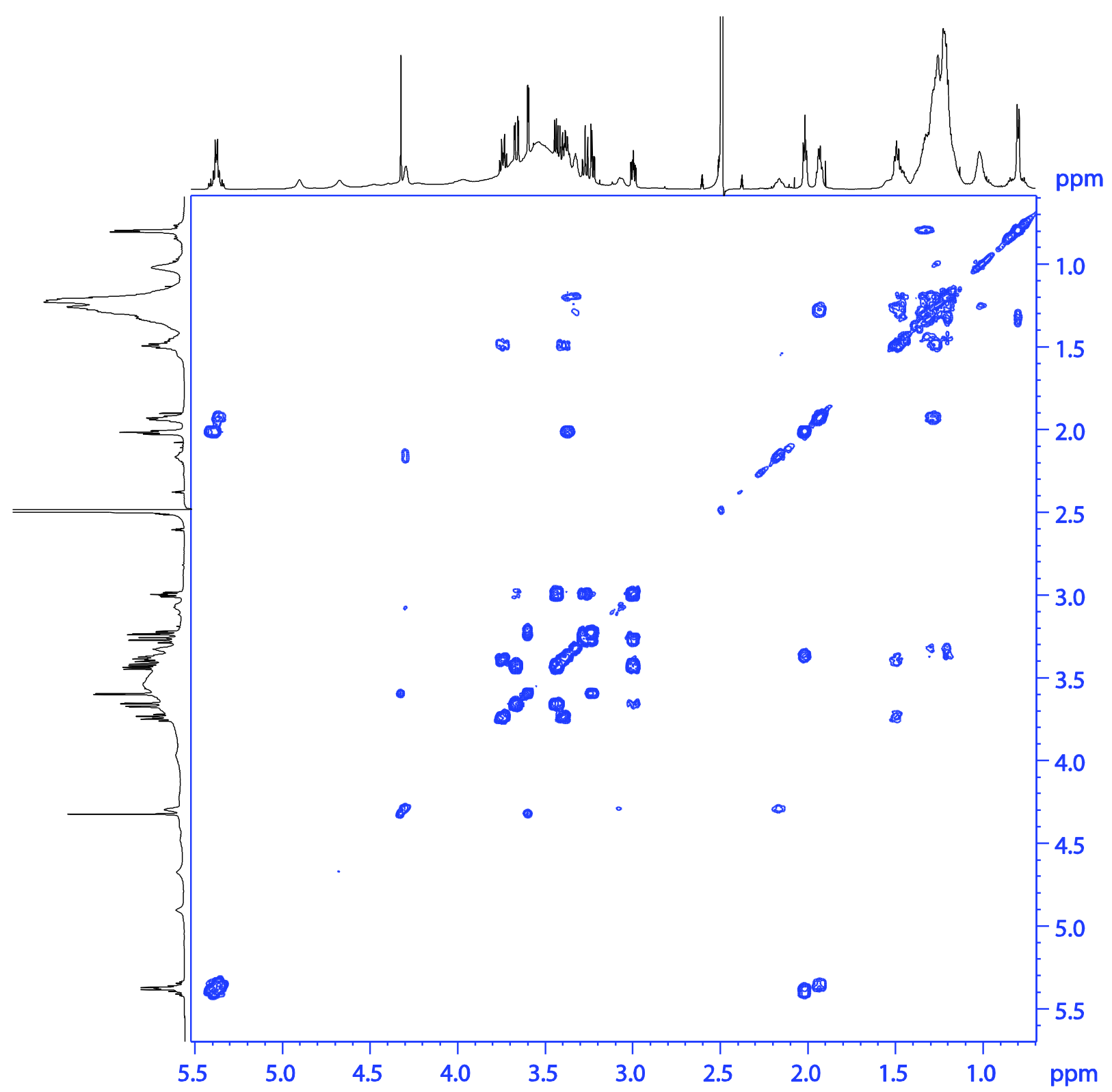

Figure S21. ${ }^{1} \mathrm{H}-{ }^{1} \mathrm{H}$ COSY NMR spectrum $\left(600 \mathrm{MHz}, \mathrm{DMSO}-d_{6}\right)$ of burnettramic acid B (2) 


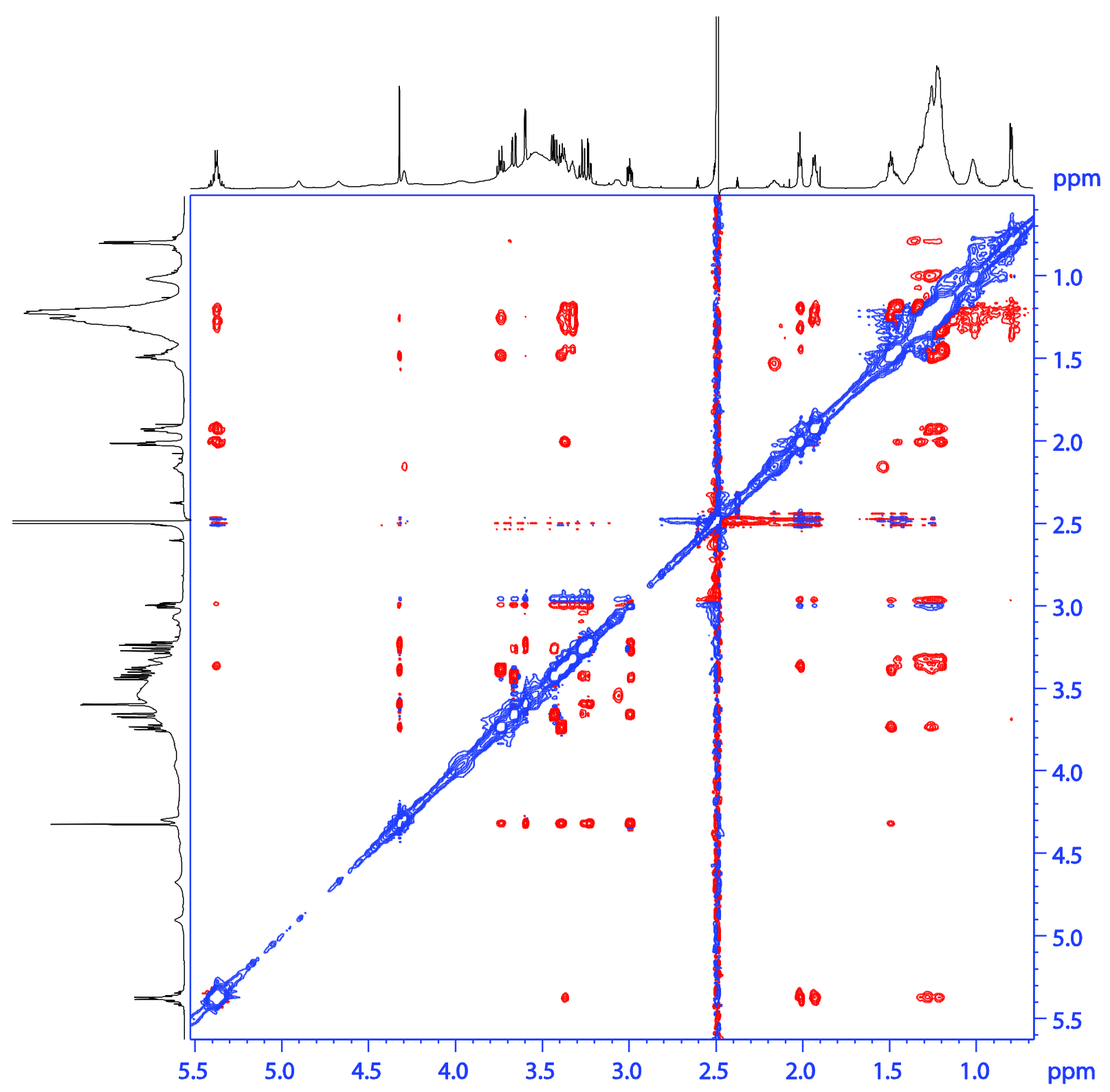

Figure S22. ${ }^{1} \mathrm{H}-{ }^{1} \mathrm{H}$ ROESY NMR spectrum (600 MHz, DMSO- $d 6$ ) of burnettramic acid B (2) 


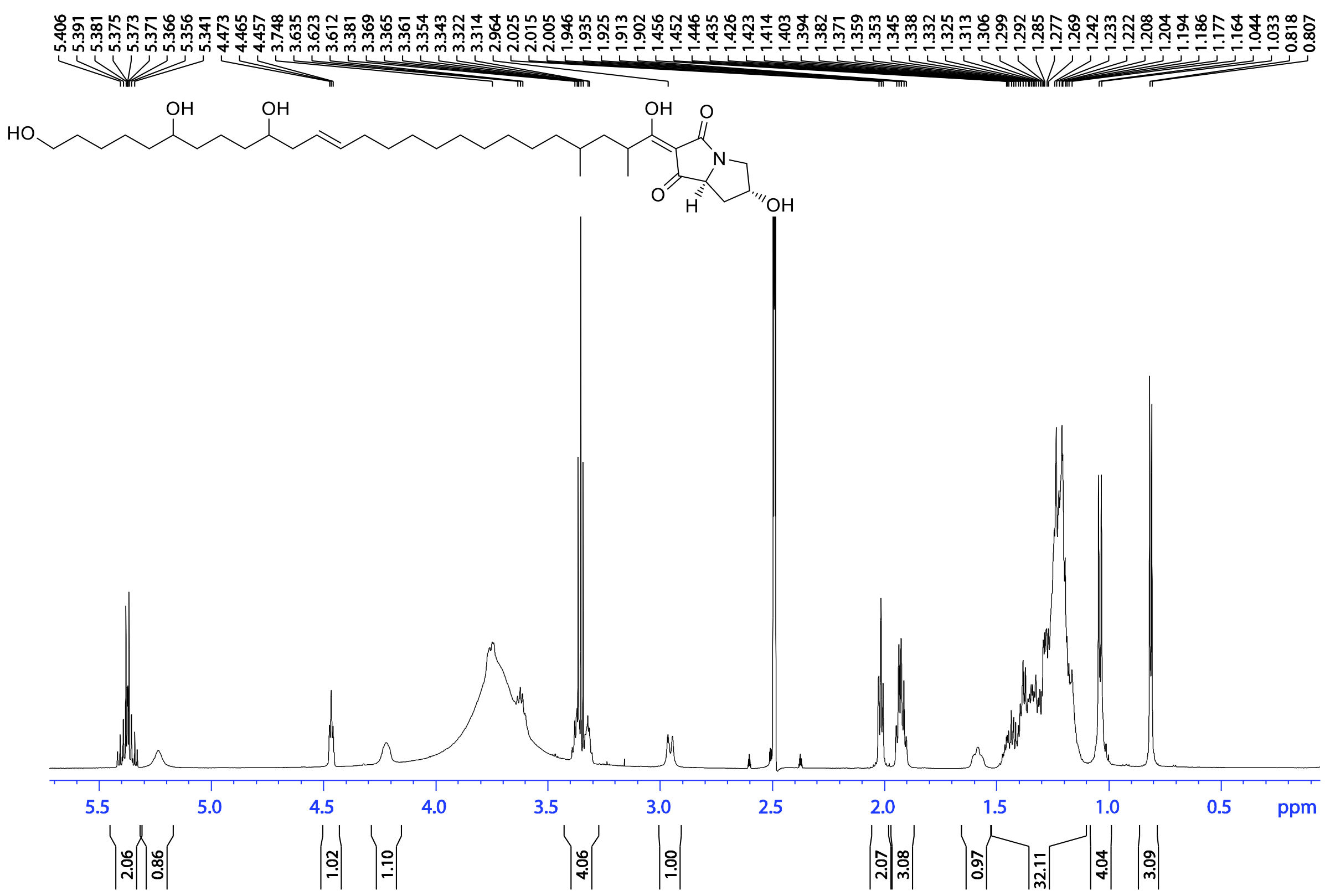

Figure S23. ${ }^{1} \mathrm{H}$ NMR spectrum (600 MHz, DMSO- $d_{6}$ ) of burnettramic acid A aglycone (3) 


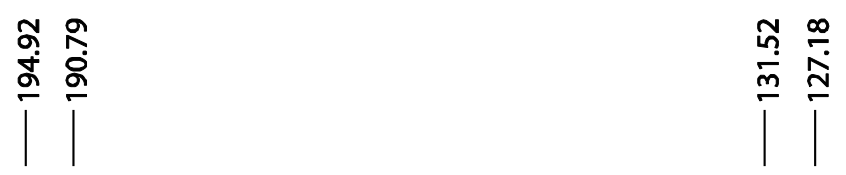

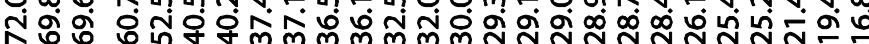<smiles>CC(CCCCCCCC/C=C/CCC(O)CCCC(O)CCCCCO)CC(C)C(O)=C1C(=O)N2C[C@H](O)C[C@H]1C2=O</smiles>

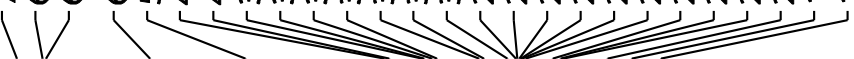

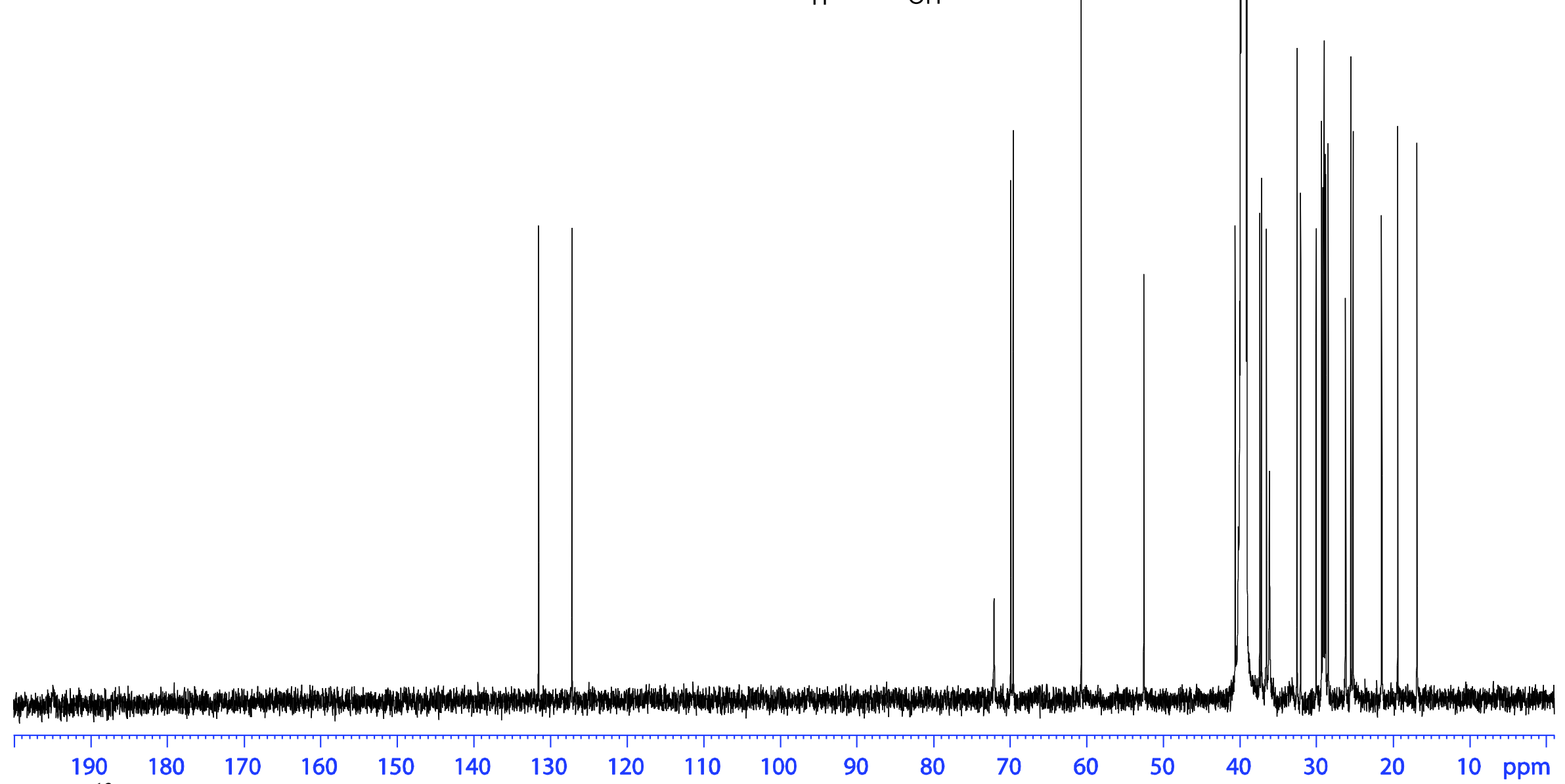

Figure S24. ${ }^{13} \mathrm{C}$ NMR spectrum $\left(150 \mathrm{MHz}, \mathrm{DMSO}-d_{6}\right)$ of burnettramic acid A aglycone (3) 


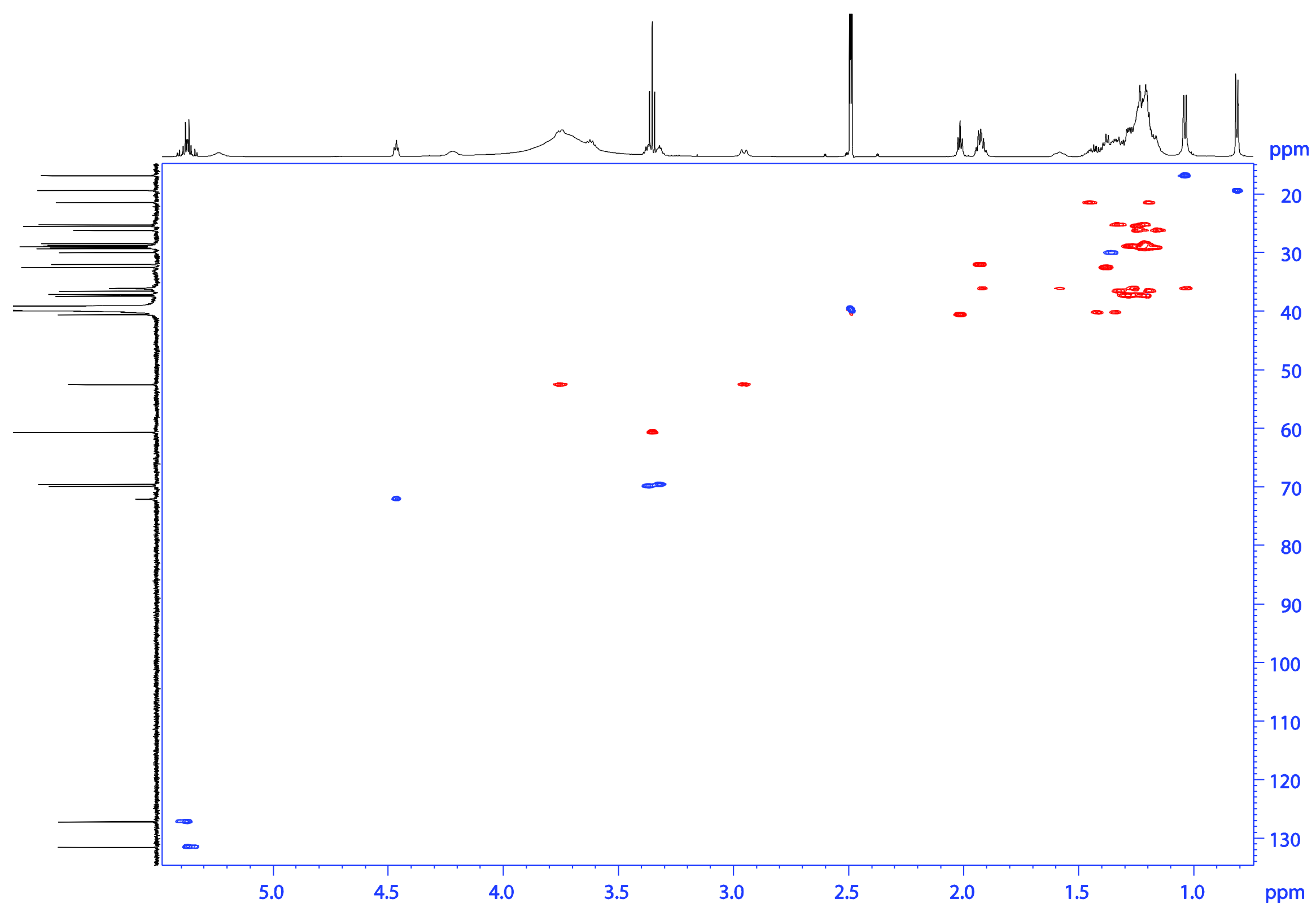

Figure S25. ${ }^{1} \mathrm{H}-{ }^{13} \mathrm{C}$ HSQC NMR spectrum (600 MHz, DMSO- $d_{6}$ ) of burnettramic acid A aglycone (3) S43 


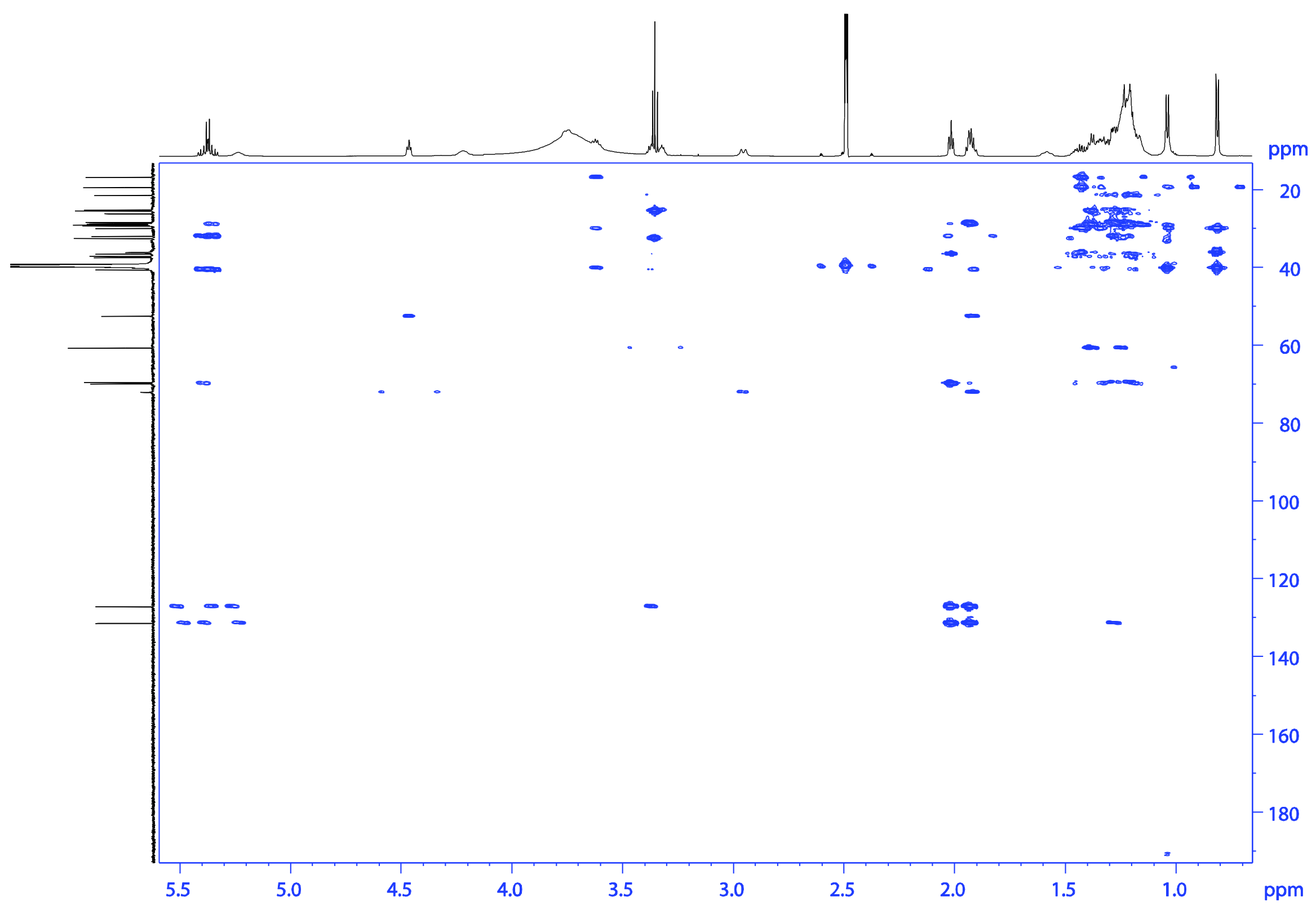

Figure S26. ${ }^{1} \mathrm{H}^{-13} \mathrm{C}$ HMBC NMR spectrum (600 MHz, DMSO- $\left.d_{6}\right)$ of burnettramic acid A aglycone (3) S44 


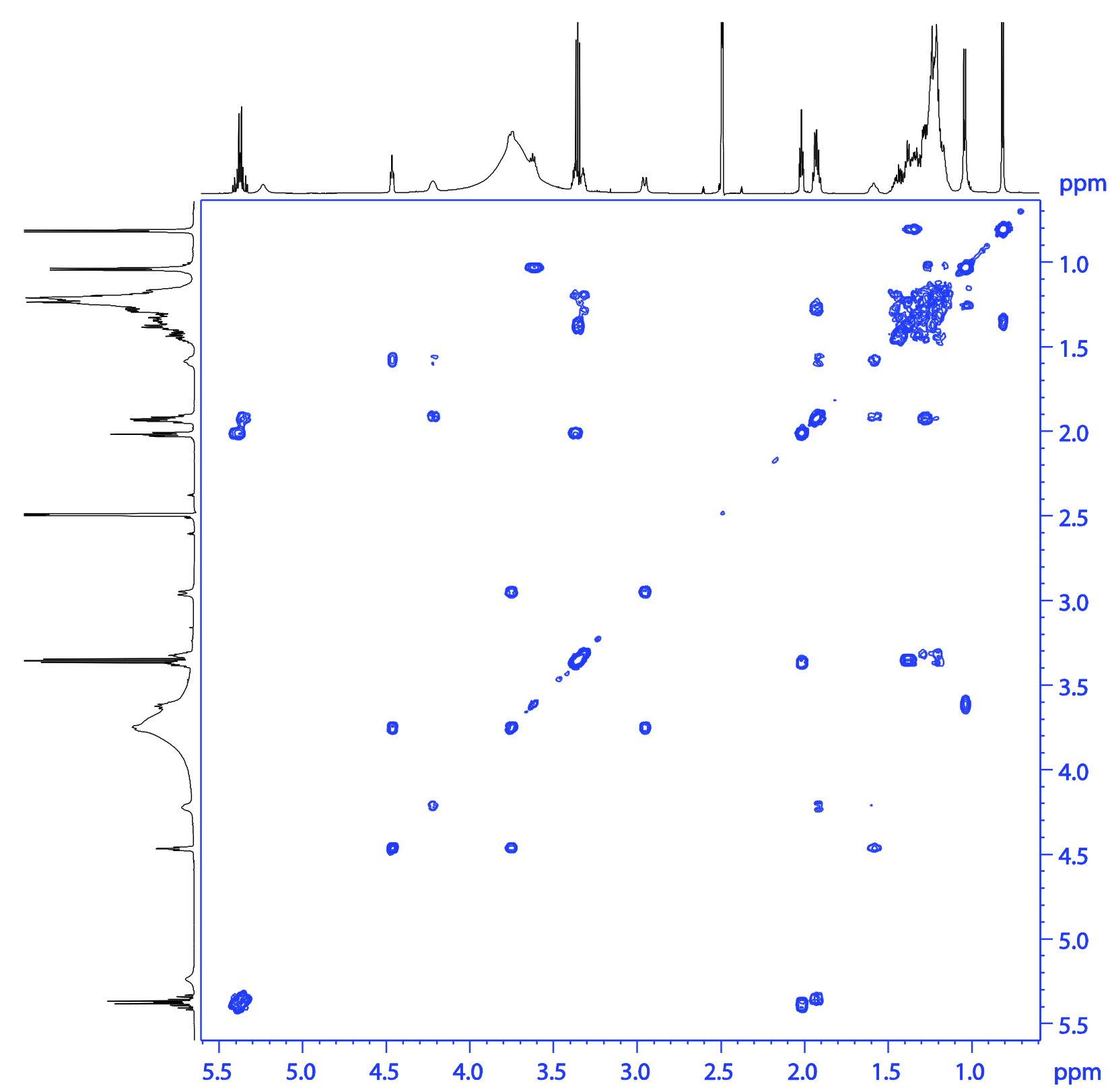

Figure S27. ${ }^{1} \mathrm{H}-{ }^{1} \mathrm{H}$ COSY NMR spectrum $(600 \mathrm{MHz}$, DMSO- $d 6$ ) of burnettramic acid A aglycone (3) 


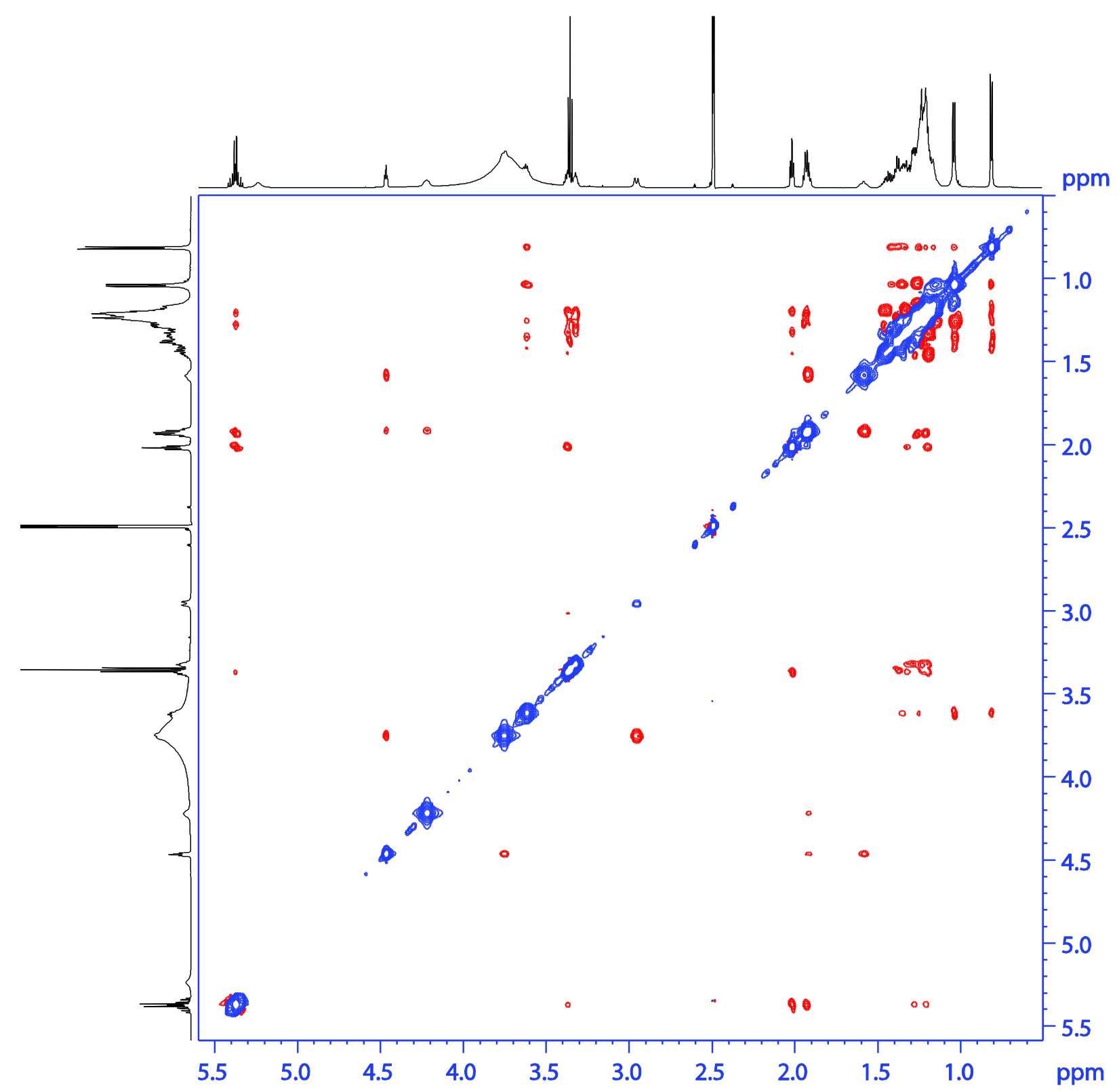

Figure S28. ${ }^{1} \mathrm{H}-{ }^{1} \mathrm{H}$ ROESY NMR spectrum $\left(600 \mathrm{MHz}\right.$, DMSO- $\left.d_{6}\right)$ of burnettramic acid A aglycone (3) 


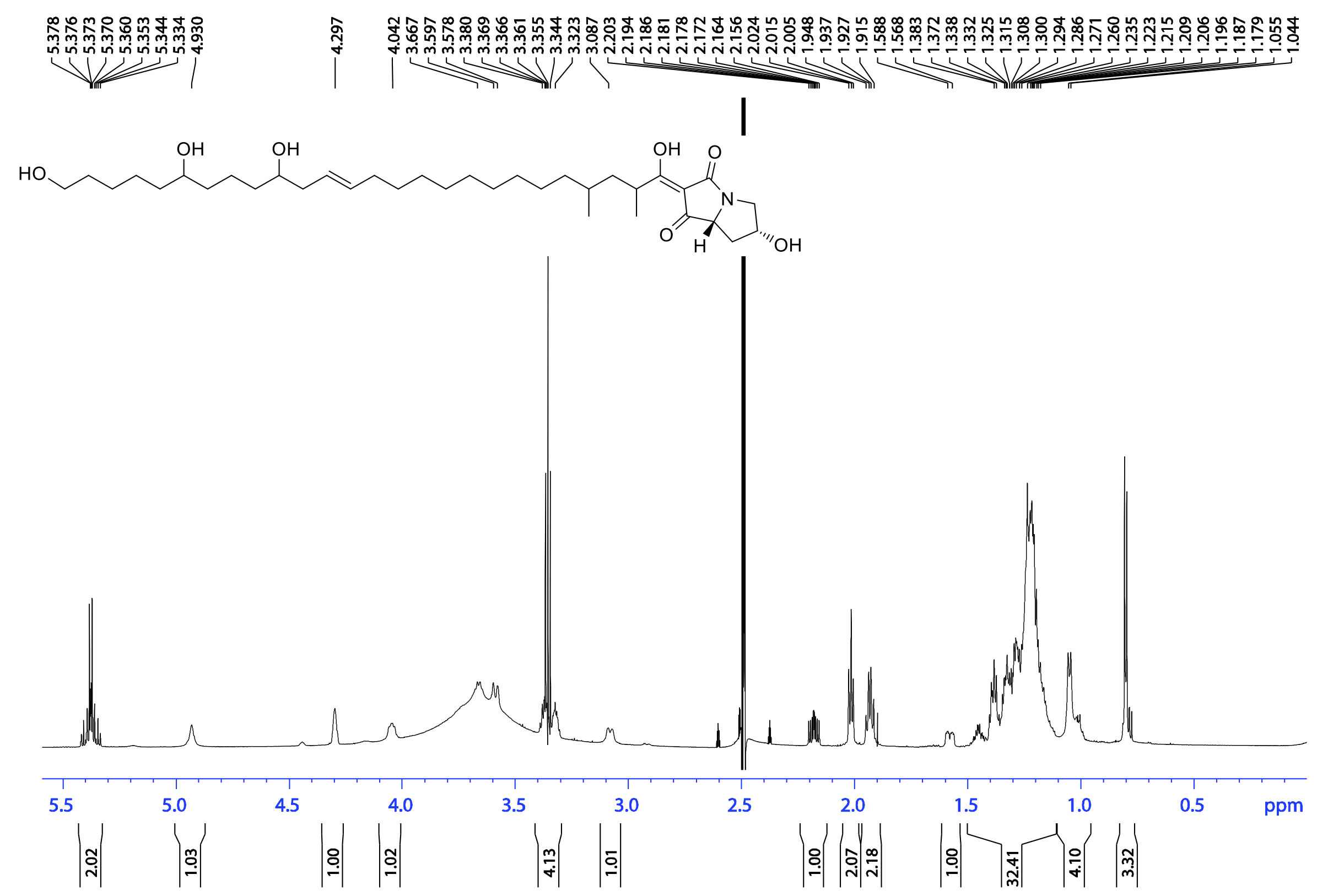

Figure S29. ${ }^{1} \mathrm{H}$ NMR spectrum (600 MHz, DMSO- $d_{6}$ ) of burnettramic acid B aglycone (4) 


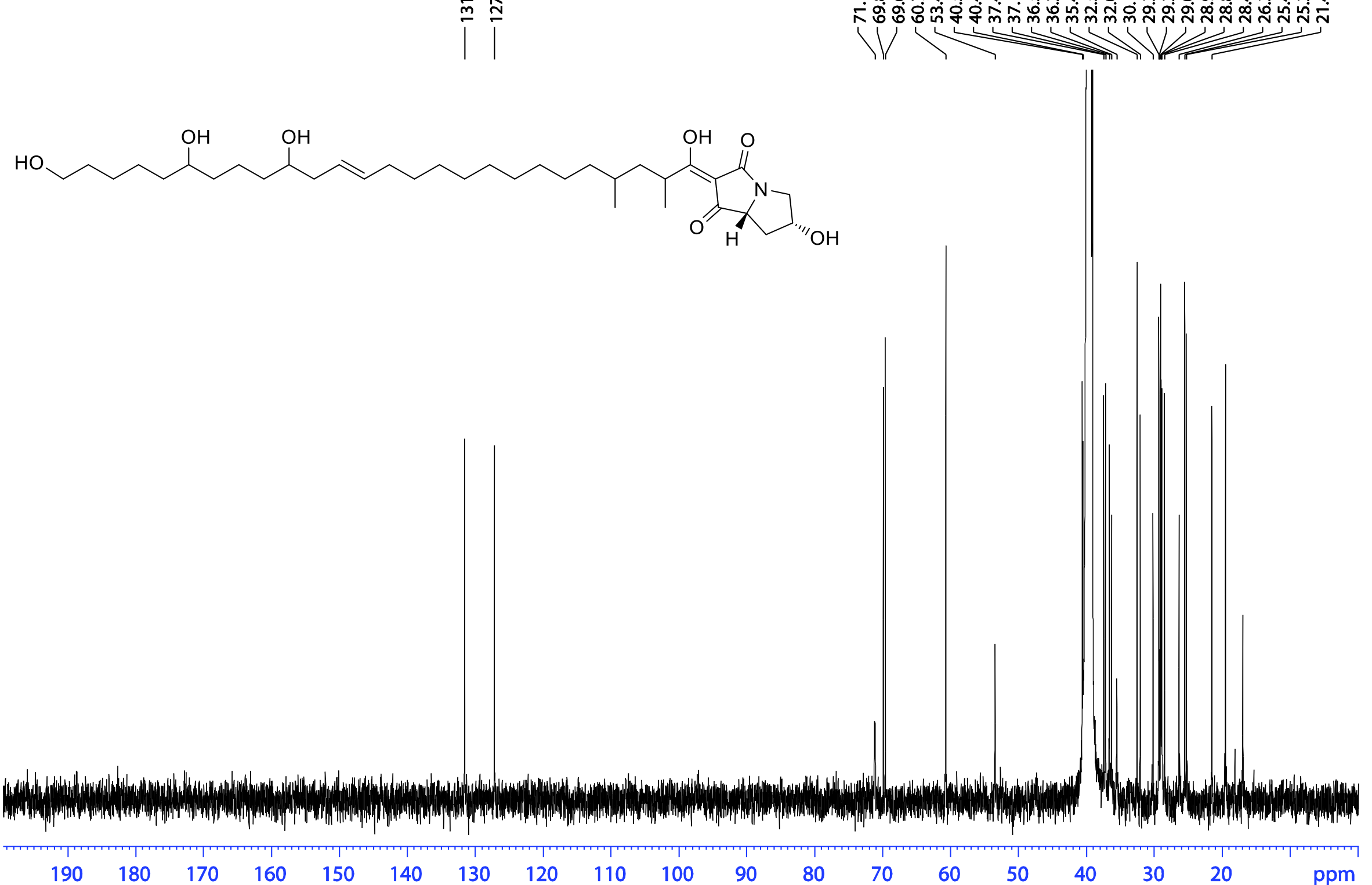

Figure S30. ${ }^{13} \mathrm{C}$ NMR spectrum (150 MHz, DMSO- $\left.d_{6}\right)$ of burnettramic acid B aglycone (4) 


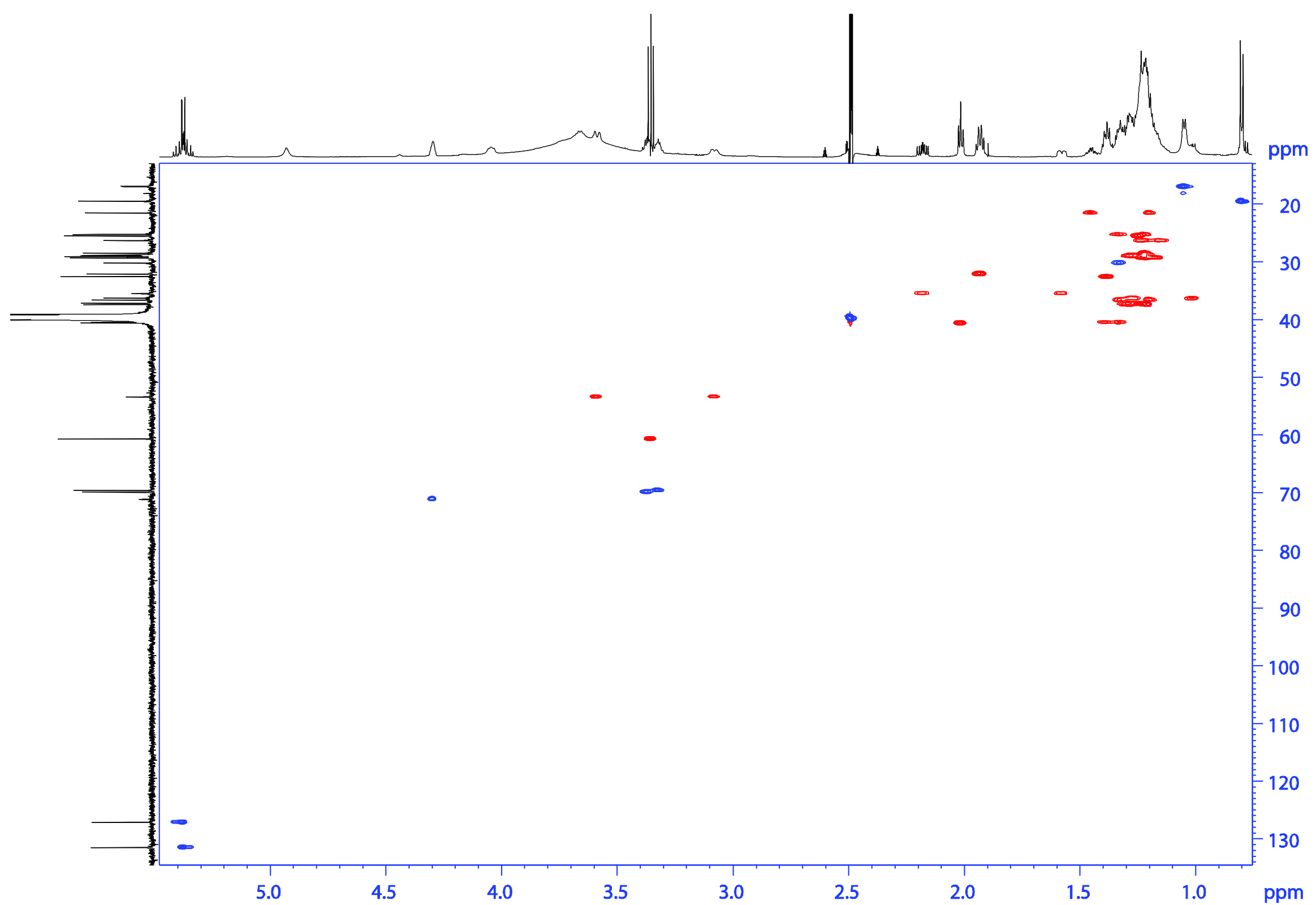

Figure S31. ${ }^{1} \mathrm{H}^{-13} \mathrm{C}$ HSQC NMR spectrum (600 MHz, DMSO- $d_{6}$ ) of burnettramic acid B aglycone (4) 


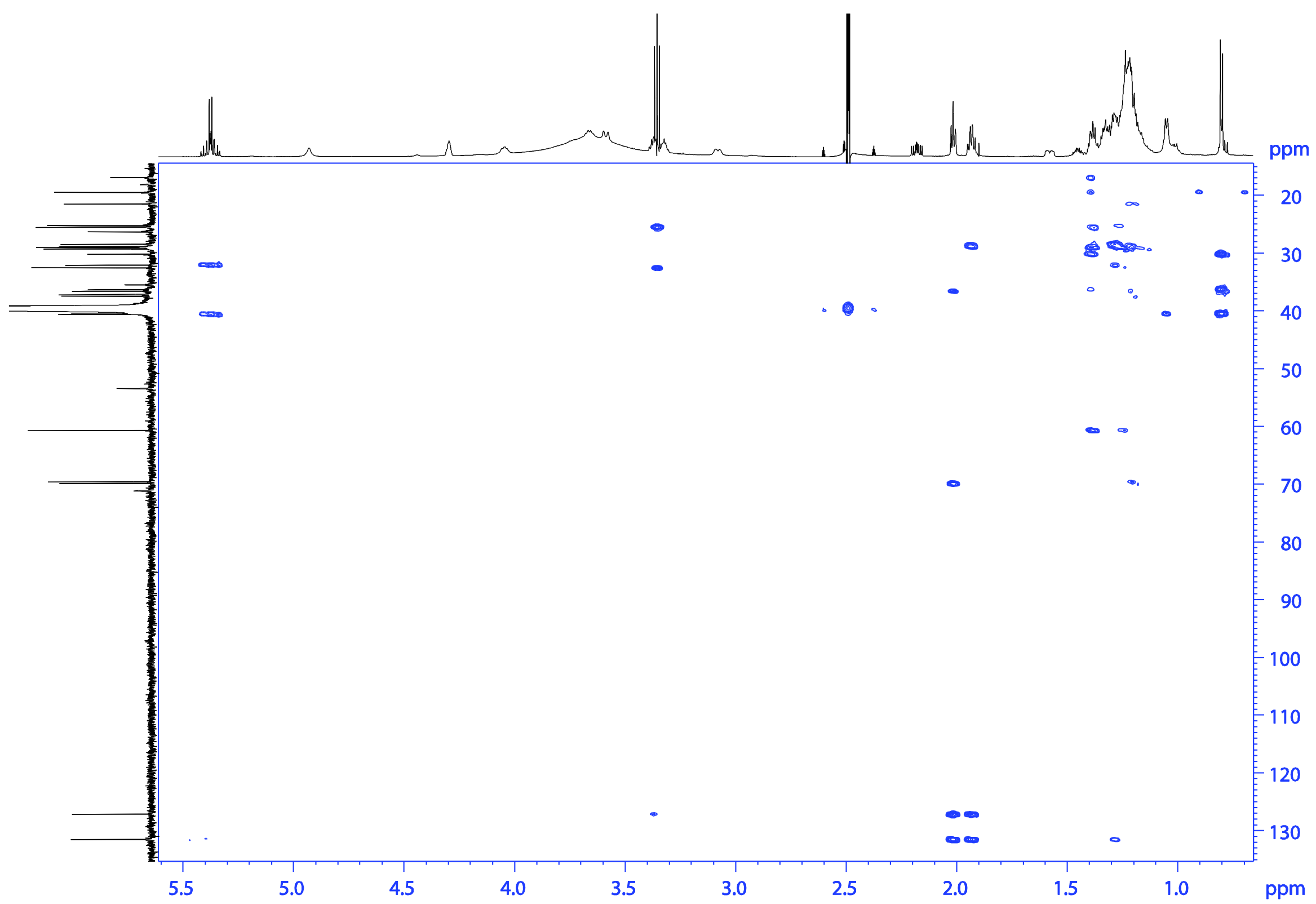

Figure S32. ${ }^{1} \mathrm{H}_{-}{ }^{13} \mathrm{C}$ HMBC NMR spectrum (600 MHz, DMSO- $d_{6}$ ) of burnettramic acid B aglycone (4) S50 


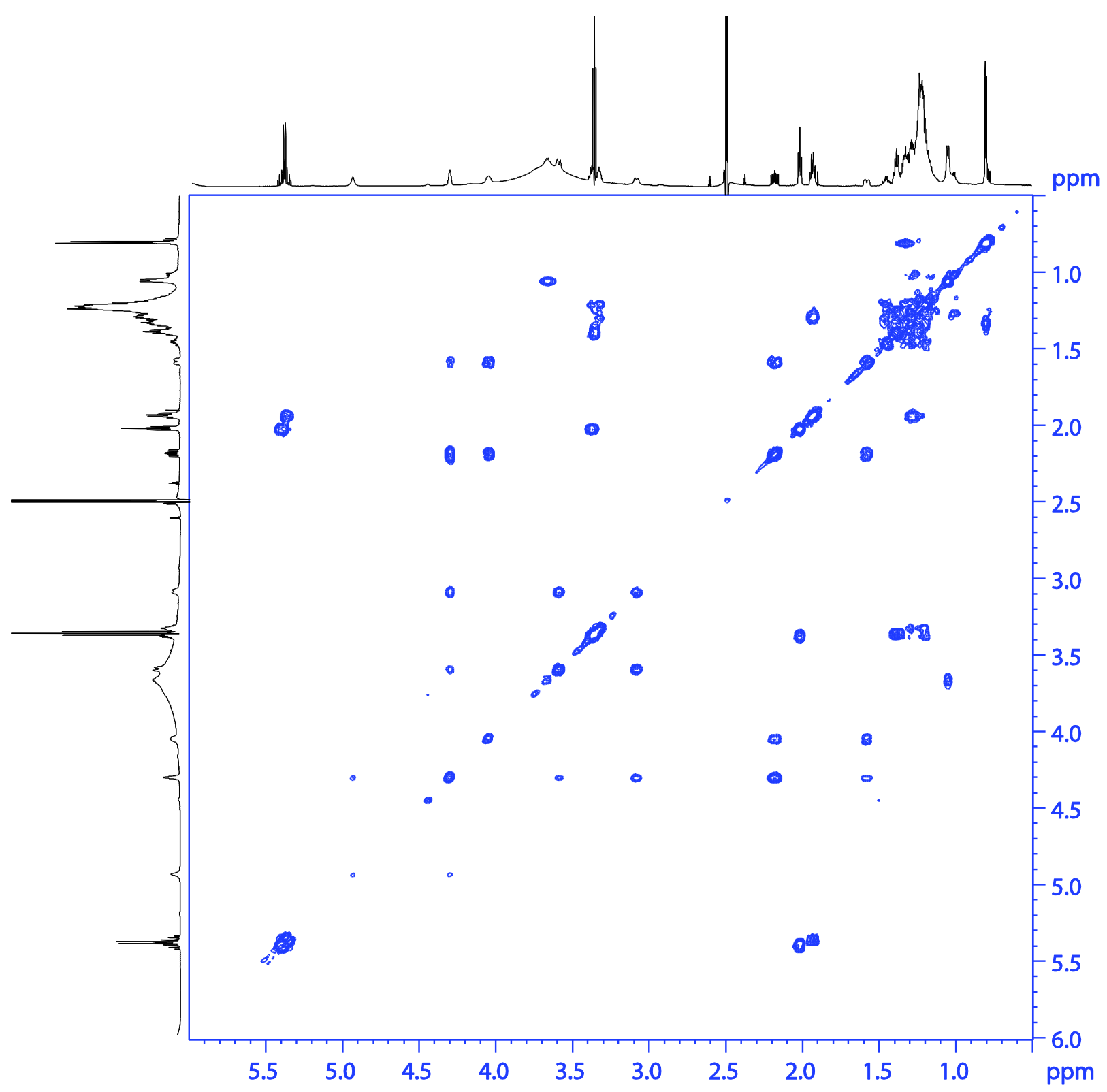

Figure S33. ${ }^{1} \mathrm{H}-{ }^{1} \mathrm{H}$ COSY NMR spectrum (600 MHz, DMSO- $\left.d_{6}\right)$ of burnettramic acid B aglycone (4) 


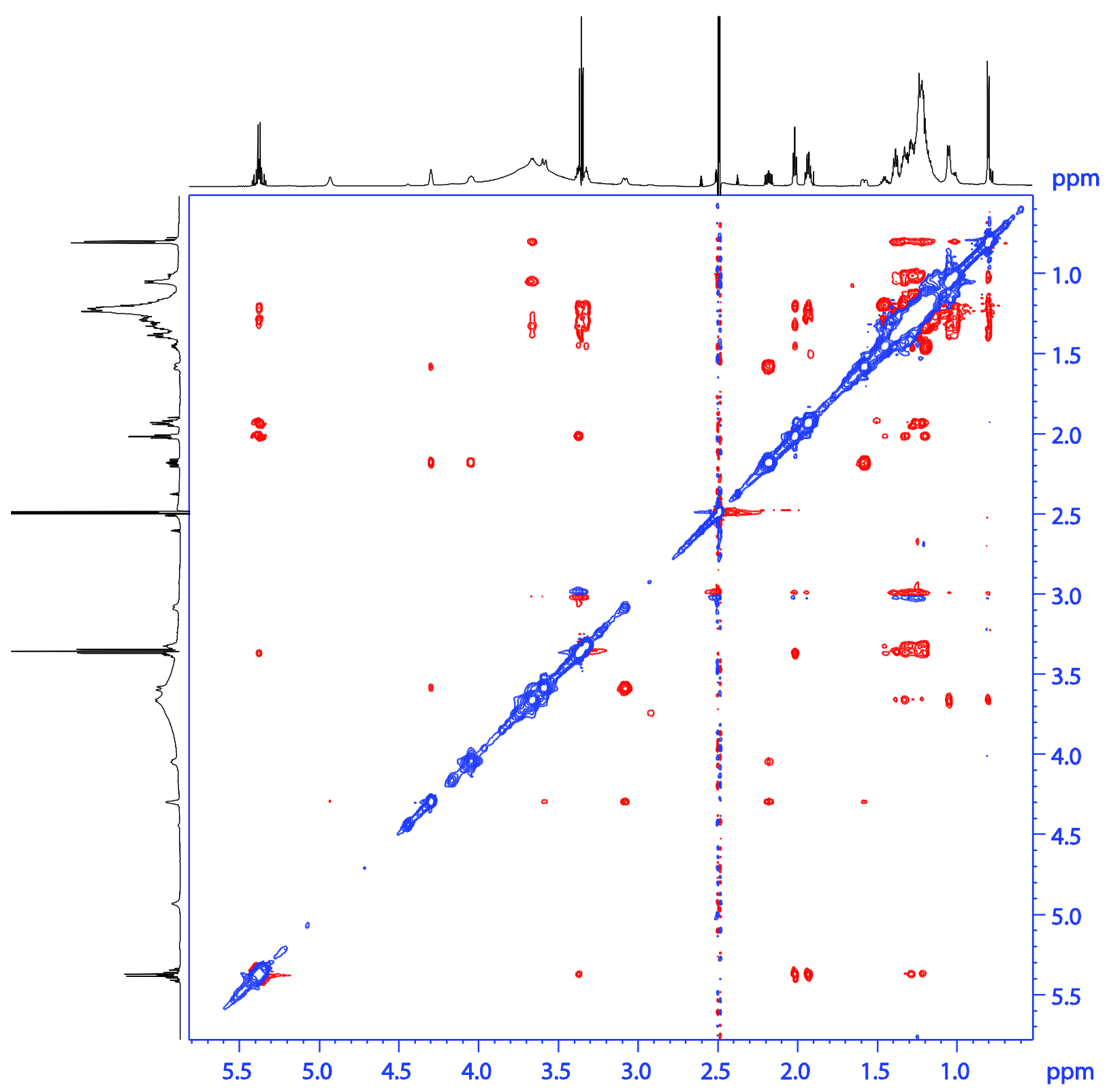

Figure S34. ${ }^{1} \mathrm{H}-{ }^{1} \mathrm{H}$ ROESY NMR spectrum (600 MHz, DMSO- $\left.d_{6}\right)$ of burnettramic acid B aglycone (4) 
180504_AP_6768_Neg_1 \#47 RT: 0.60 AV: 1 NL: $1.66 E 7$ T: FTMS - p ESI Fül ms [150.0000-1800.0000]

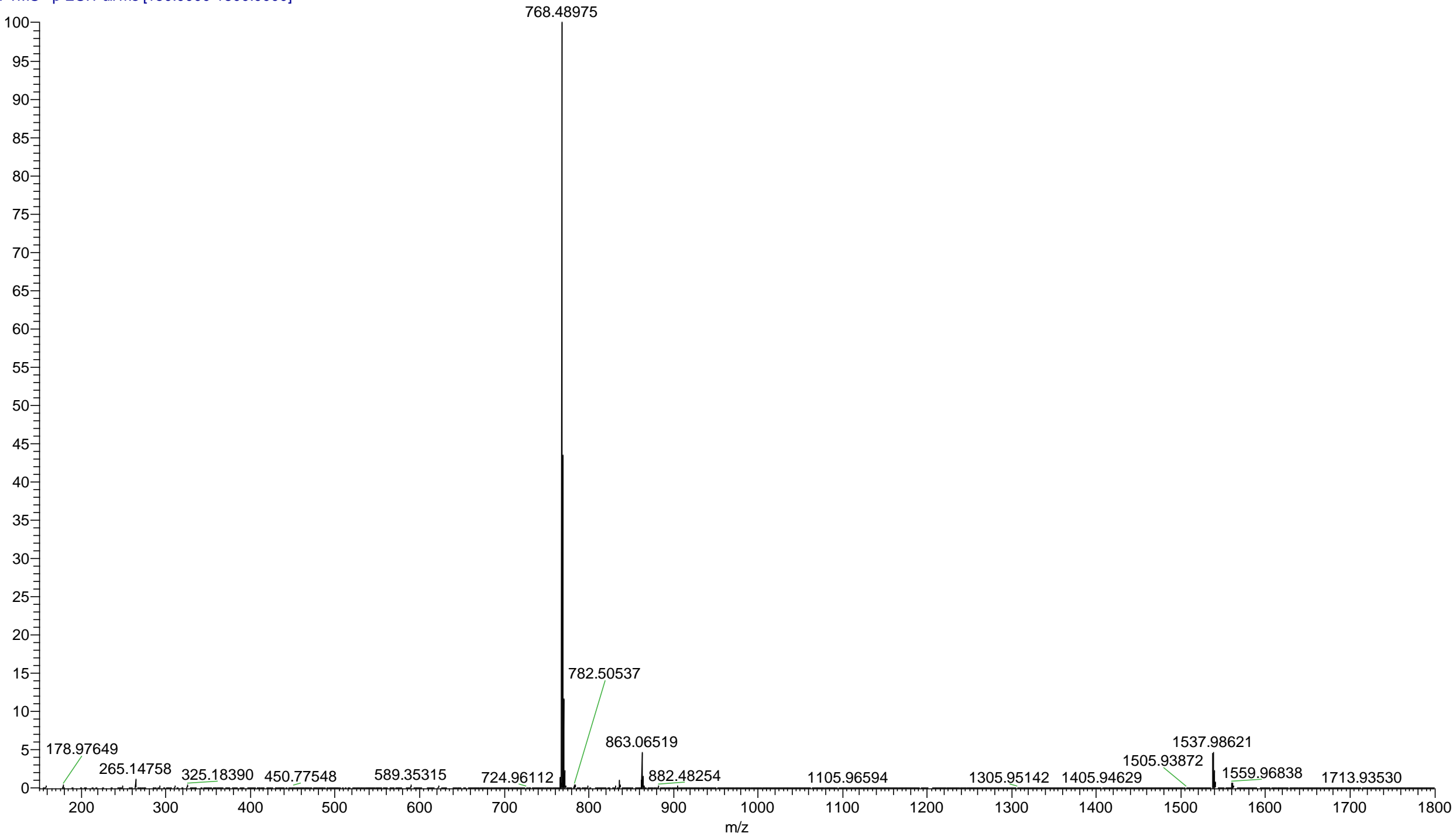

Figure S35. HRESI(-)MS spectrum of burnettramic acid A (1) 
180504_AP_5402_Neg_1 \#47 RT: 0.59 AV: 1 NL: 1.95E7

T: FTMS - p ESI Full ms [150.0000-1800.0000]

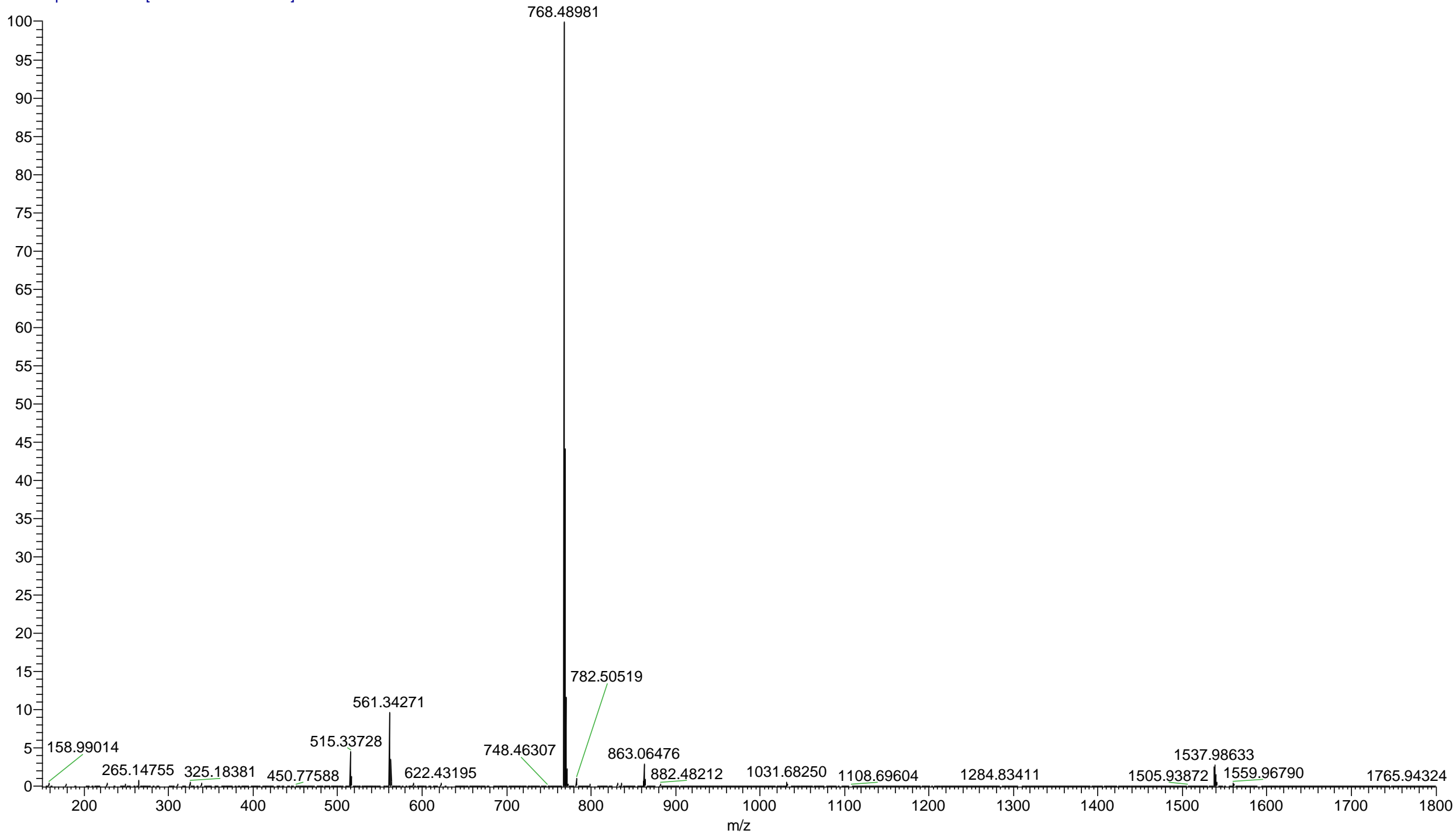

Figure S36. HRESI(-)MS spectrum of burnettramic acid B (2) 
180504_AP_5399_Neg_1 \#47 RT: 0.59 AV: 1 NL: 3.28E7

T: FTMS - $p$ ESI Full ms [150.0000-1800.0000]

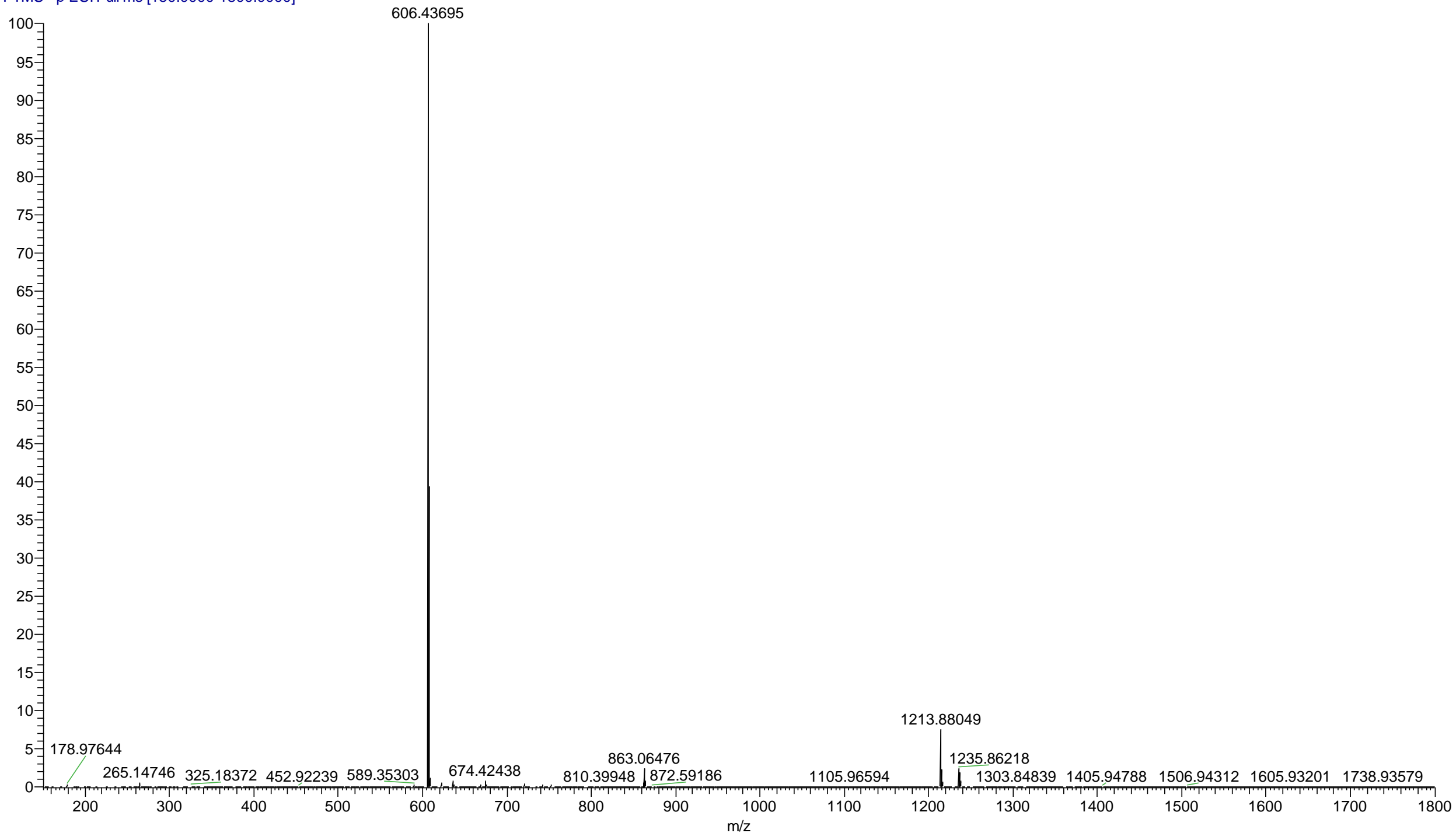

Figure S37. HRESI(-)MS spectrum of burnettramic acid A aglycone (3) 
180504_AP_5398_Neg_1 \#47 RT: 0.59 AV: 1 NL: 4.67E7

T: FTMS - $p$ ESI Full ms [150.0000-1800.0000]

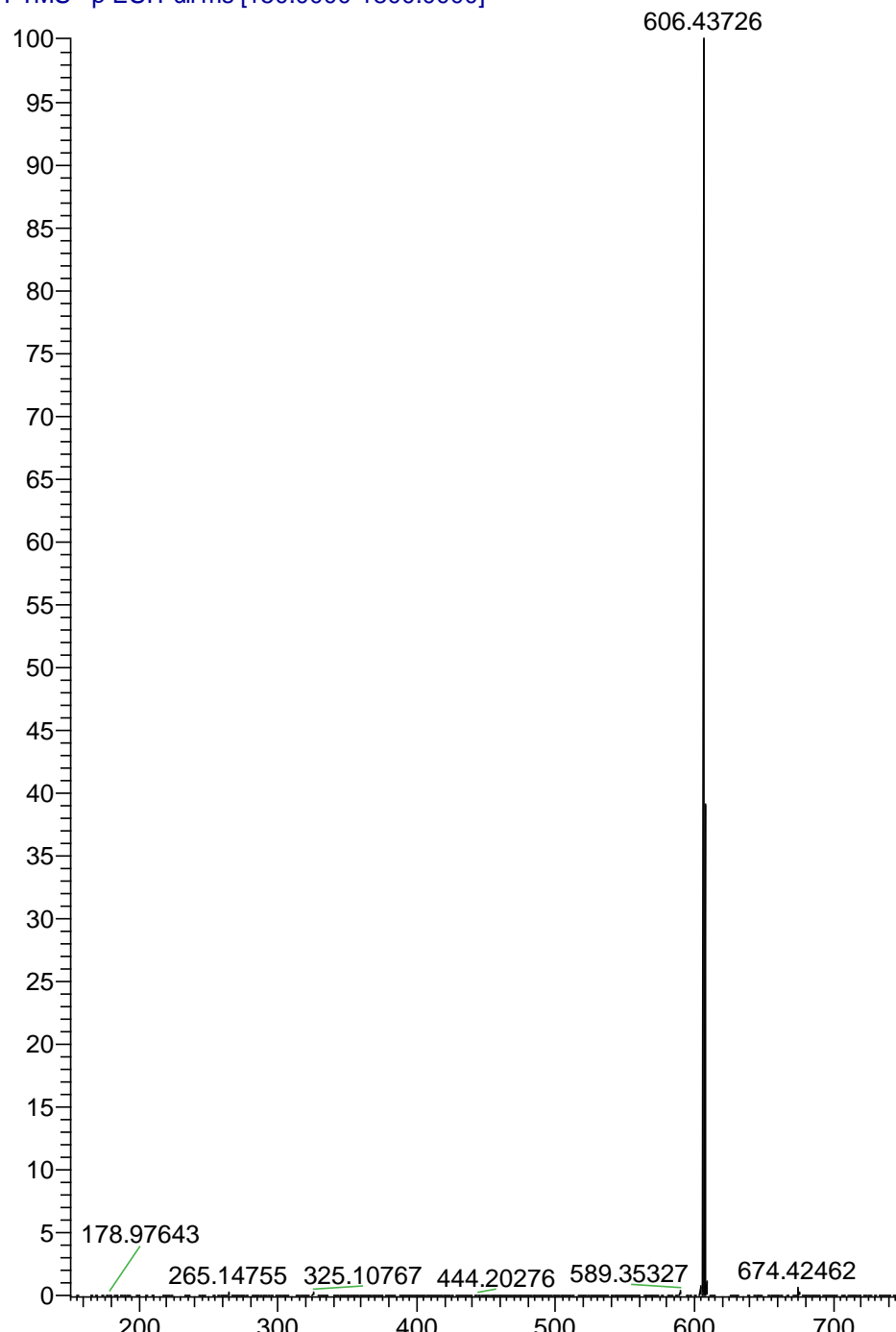

606.43726

1213.88123

863.06506

\begin{tabular}{l|l}
1192.93982 & 1235.86267
\end{tabular}

200

300

400

800

900

Figure S38. HRESI(-)MS spectrum of burnettramic acid B aglycone (4) 


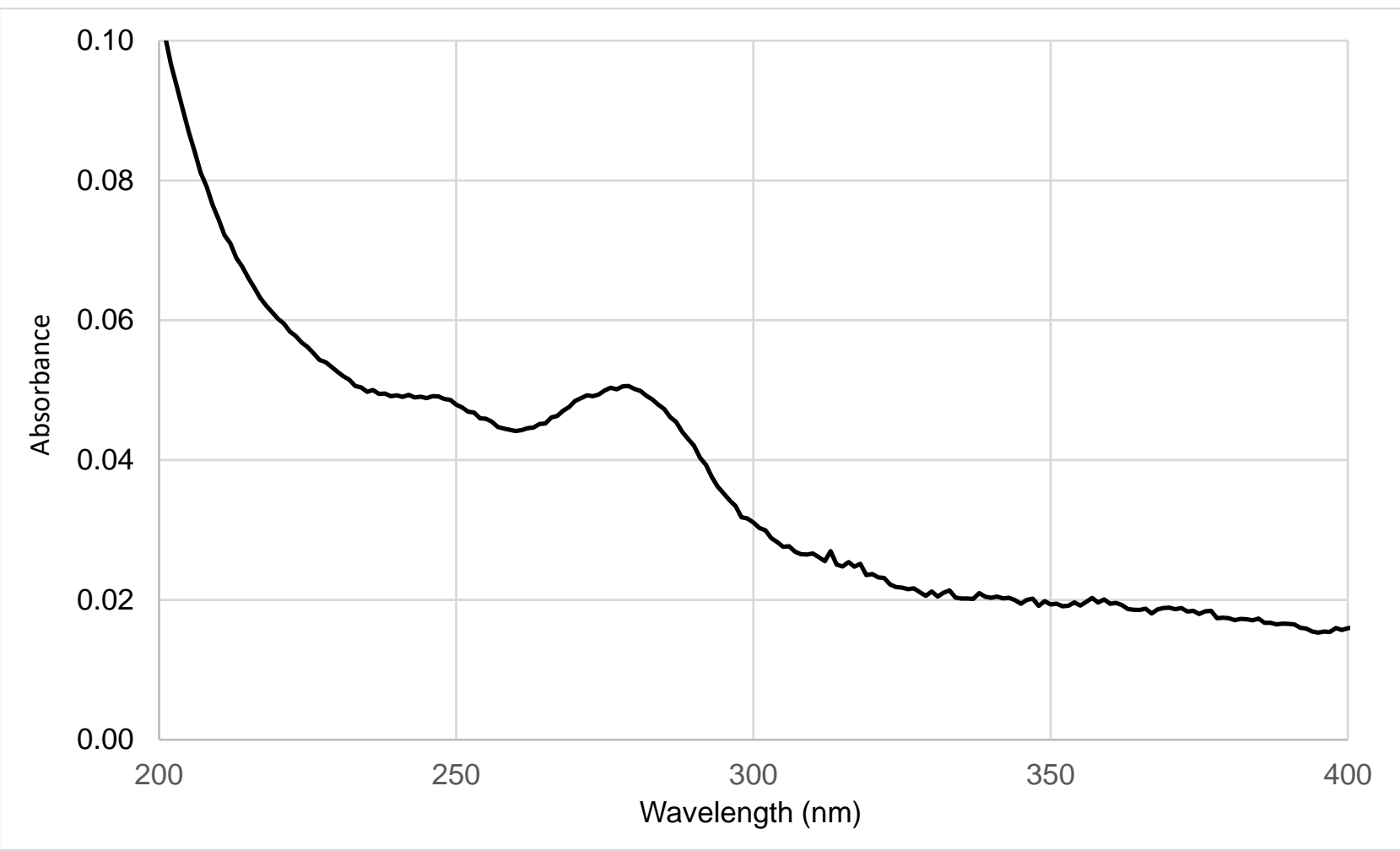

Figure S39. UV spectrum (MeCN) of burnettramic acid A (1)

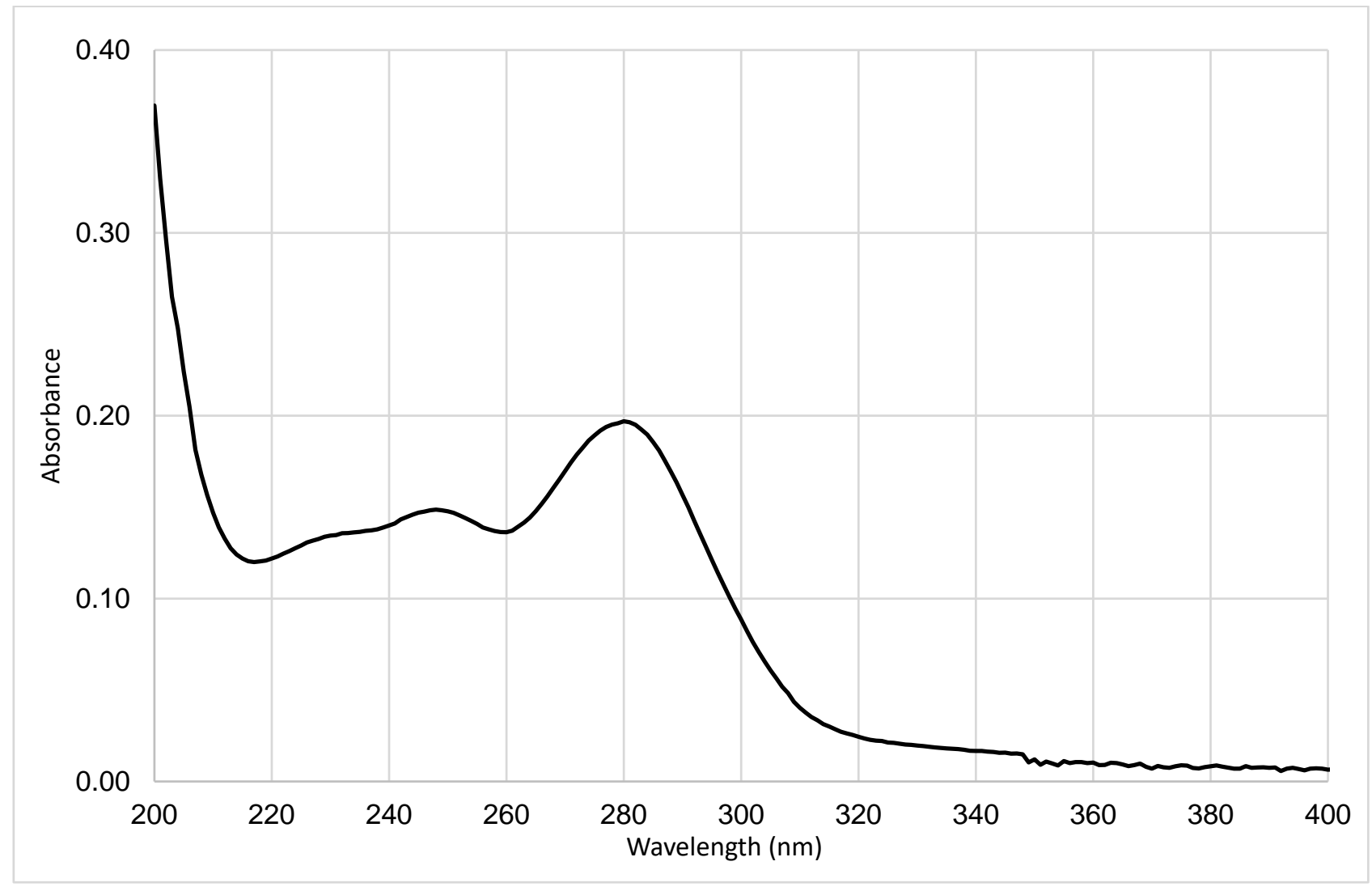

Figure S40. UV spectrum (MeCN) of burnettramic acid B (2) 


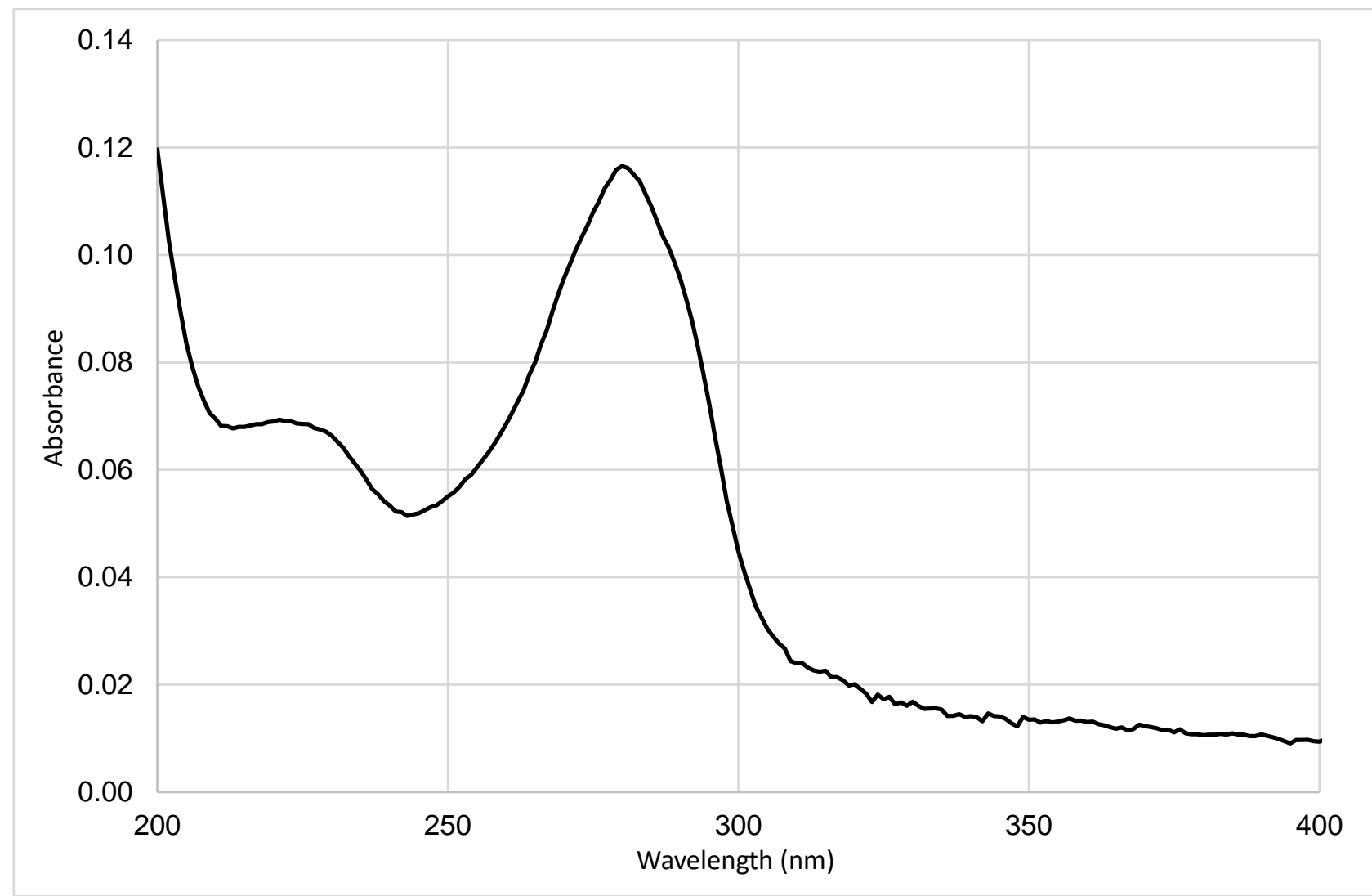

Figure S41. UV spectrum (MeCN) of burnettramic acid A aglycone (3)

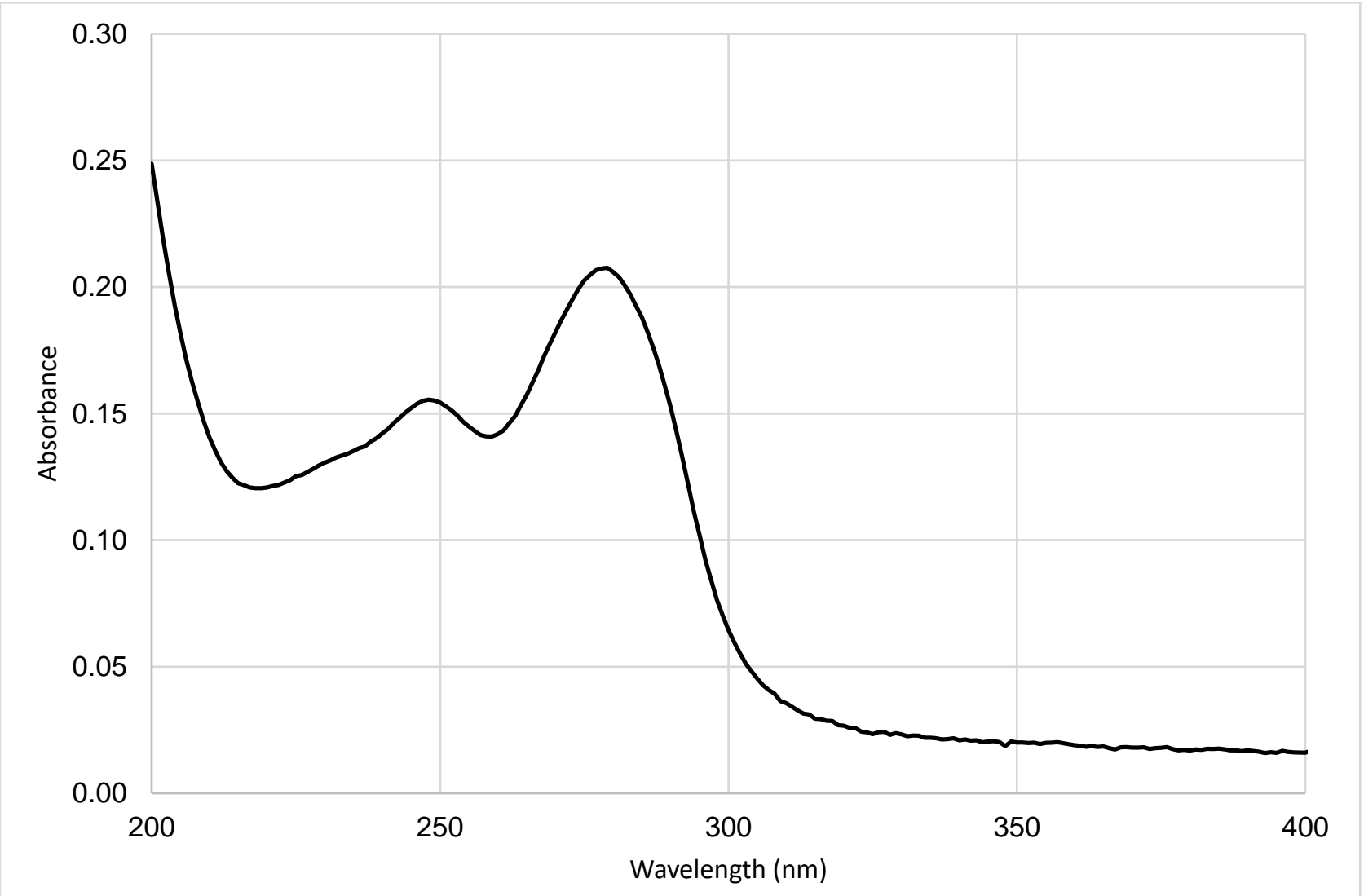

Figure S42. UV spectrum (MeCN) of burnettramic acid B aglycone (4) 


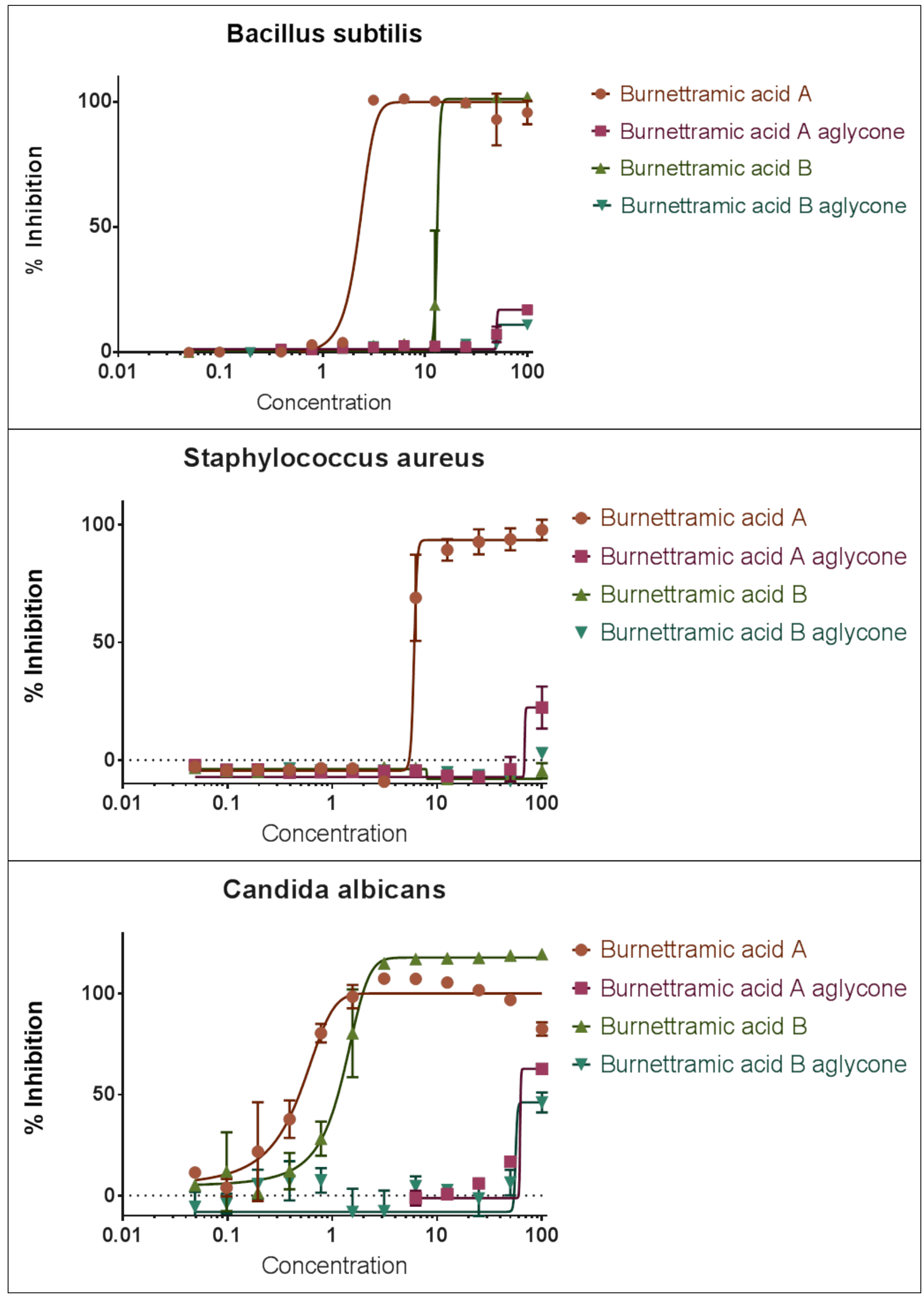




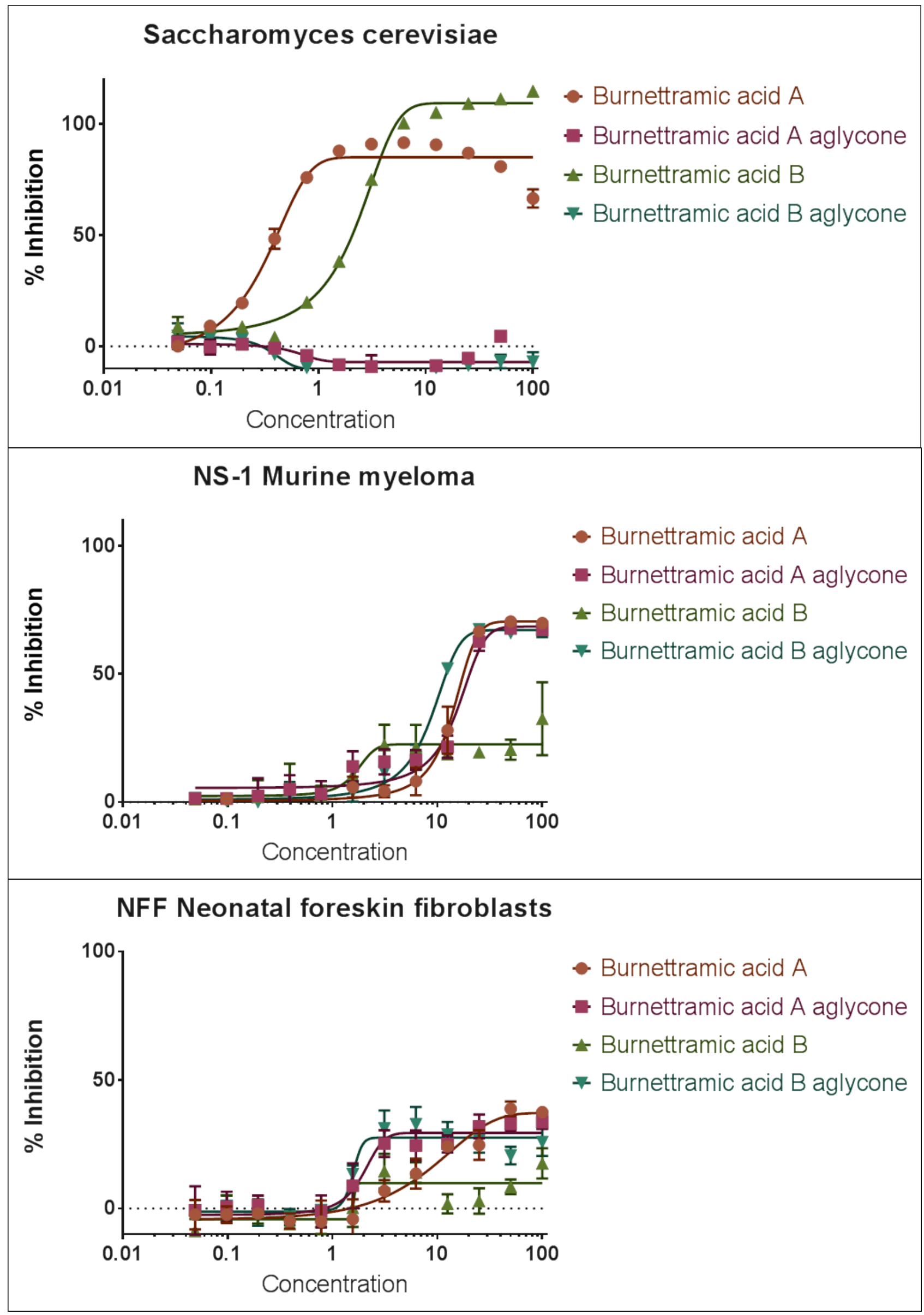




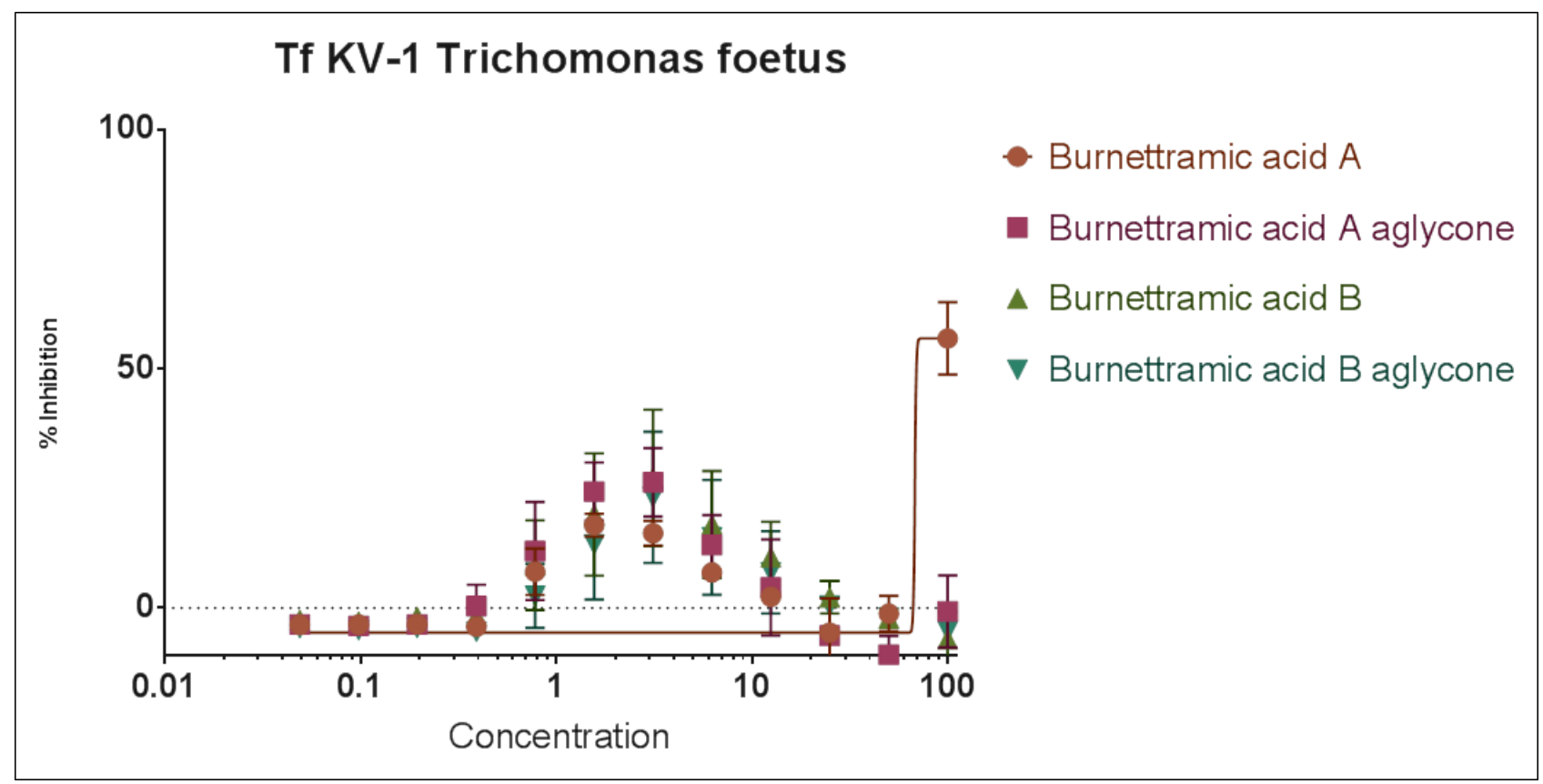

Figure S43. Fitted dose-response curves for the in vitro bioassays. 


\section{Supplementary references}

[1] a) J. H. Gill, E. Lacey, Int. J. Parasitol. 1993, 23, 375-381; b) J. H. Gill, J. M. Redwin, J. A. Van Wyk, E. Lacey, Int. J. Parasitol. 1995, 25, 463-470.

[2] W.-B. Yin, Y. H. Chooi, A. R. Smith, R. A. Cacho, Y. Hu, T. C. White, Y. Tang, ACS Syn. Biol. 2013, 2, 629-634.

[3] a) A. M. Bolger, M. Lohse, B. Usadel, Bioinformatics 2014, 30, 2114-2120; b) A. Bankevich, S. Nurk, D. Antipov, A. A. Gurevich, M. Dvorkin, A. S. Kulikov, V. M. Lesin, S. I. Nikolenko, S. Pham, A. D. Prjibelski, A. V. Pyshkin, A. V. Sirotkin, N. Vyahhi, G. Tesler, M. A. Alekseyev, P. A. Pevzner, J. Comput. Biol. 2012, 19, 455-477.

[4] R. C. Edgar, Nucleic Acids Res. 2004, 32, 1792-1797.

[5] a) M. Kearse, R. Moir, A. Wilson, S. Stones-Havas, M. Cheung, S. Sturrock, S. Buxton, A. Cooper, S. Markowitz, C. Duran, T. Thierer, B. Ashton, P. Meintjes, A. Drummond, Bioinformatics 2012, 28, 1647-1649; b) K. Katoh, D. M. Standley, Mol. Biol. Evol. 2013, 30, 772-780.

[6] a) A. Kozlov, D. Darriba, T. Flouri, B. Morel, A. Stamatakis, bioRxiv 2018; b) F. Ronquist, M. Teslenko, P. van der Mark, D. L. Ayres, A. Darling, S. Höhna, B. Larget, L. Liu, M. A. Suchard, J. P. Huelsenbeck, Syst. Biol. 2012, 61, 539-542; c) J. Huerta-Cepas, F. Serra, P. Bork, Mol. Biol. Evol. 2016, 33, 1635-1638.

[7] K. Blin, T. Wolf, M. G. Chevrette, X. Lu, C. J. Schwalen, S. A. Kautsar, H. G. Suarez Duran, Emmanuel L. C. de los Santos, H. U. Kim, M. Nave, J. S. Dickschat, D. A. Mitchell, E. Shelest, R. Breitling, E. Takano, S. Y. Lee, T. Weber, M. H. Medema, Nucleic Acids Res. 2017, 45, W36-W41.

[8] T. Stachelhaus, H. D. Mootz, M. A. Marahiel, Chem. Biol. 1999, 6, 493-505.

[9] D. Boettger, H. Bergmann, B. Kuehn, E. Shelest, C. Hertweck, ChemBioChem 2012, 13, 2363-2373.

[10] T. Weber, K. Blin, S. Duddela, D. Krug, H. U. Kim, R. Bruccoleri, S. Y. Lee, M. A. Fischbach, R. Müller, W. Wohlleben, R. Breitling, E. Takano, M. H. Medema, Nucleic Acids Res. 2015, 43, W237-W243.

[11] L. Li, M.-C. Tang, S. Tang, S. Gao, S. Soliman, L. Hang, W. Xu, T. Ye, K. Watanabe, Y. Tang, J. Am. Chem. Soc. 2018, 140, 2067-2071. 